\title{
The Life Cycle of Corporate Venture Capital
}

\author{
by
}

Song Ma

Department of Business Administration

Duke University

Date:

Approved:

John R. Graham, Co-Supervisor

David T. Robinson, Co-Supervisor

Manuel Adelino

Alon P. Brav

Manju Puri

Aaron K. Chatterji

Dissertation submitted in partial fulfillment of the requirements for the degree of

Doctor of Philosophy in the Department of Business Administration in the Graduate School of Duke University

2016 


\section{$\underline{\text { ABSTRACT }}$ \\ The Life Cycle of Corporate Venture Capital \\ by}

Song Ma

Department of Business Administration

Duke University

Date:

Approved:

John R. Graham, Co-Supervisor

David T. Robinson, Co-Supervisor

Manuel Adelino

Alon P. Brav

Manju Puri

Aaron K. Chatterji

An abstract of a dissertation submitted in partial fulfillment of the requirements for the degree of Doctor of Philosophy in the Department of Business Administration in the Graduate School of Duke University

2016 
Copyright (C) 2016 by Song Ma

All rights reserved except the rights granted by the Creative Commons Attribution-Noncommercial Licence 


\section{Abstract}

This paper establishes the life-cycle dynamics of Corporate Venture Capital (CVC) to explore the information acquisition role of CVC investment in the process of corporate innovation. I exploit an identification strategy that allows me to isolate exogenous shocks to a firm's ability to innovate. Using this strategy, I first find that the CVC life cycle typically begins following a period of deteriorated corporate innovation and increasingly valuable external information, lending support to the hypothesis that firms conduct CVC investment to acquire information and innovation knowledge from startups. Building on this analysis, I show that CVCs acquire information by investing in companies with similar technological focus but have a different knowledge base. Following CVC investment, parent firms internalize the newly acquired knowledge into internal R\&D and external acquisition decisions. Human capital renewal, such as hiring inventors who can integrate new innovation knowledge, is integral in this step. The CVC life cycle lasts about four years, terminating as innovation in the parent firm rebounds. These findings shed new light on discussions about firm boundaries, managing innovation, and corporate information choices. 
This is dedicated to my family. 


\section{Contents}

Abstract $\quad$ iv

List of Tables $\quad$ ix

List of Figures $\quad$ xi

Acknowledgements xii

1 Introduction 1

2 Discussion and Literature $\quad 8$

2.1 Reconciling Existing CVC Evidence . . . . . . . . . . . . 8

2.2 Entrepreneurs' Costs and Benefits . . . . . . . . . . . . . . . . . 10

2.3 CVC and the Innovation Process . . . . . . . . . . . . 10

2.4 Alternative CVC Rationales . . . . . . . . . . . . . . . . . . . 11

3 Sample and Data $\quad 12$

4 CVC Initiations: The Effect of Innovation Deterioration 18

4.1 Baseline Results . . . . . . . . . . . . . . . . . . . 20

4.1.1 Summary Statistics . . . . . . . . . . . . . . . 21

4.1 .2 Results . . . . . . . . . . . . . . . . . 24

4.2 Identification Strategy . . . . . . . . . . . . . . . . . . . 26

4.2.1 Instrumental Variable and Empirical Strategy . . . . . . . . . 26

$4.2 .2 \quad$ 2SLS Results . . . . . . . . . . . . . . . . . . . 28

4.3 Industry CVC Waves . . . . . . . . . . . . . . . . . 31 
4.4 Additional Economic Forces and Robustness . . . . . . . . . . . . . . 38

5 CVC Operations: Select, Acquire, and Integrate Information 41

5.1 CVC Portfolio Formation . . . . . . . . . . . . . . . . . . . . 41

5.1.1 Measurements . . . . . . . . . . . . . . . . 43

5.1 .2 Results....................... 44

5.2 Internalizing Acquired Information . . . . . . . . . . . . 46

5.2.1 Internal Research and Development . . . . . . . . . . . . . 47

5.2.2 Using Information through External Acquisitions . . . . . . . 51

5.3 Human Capital Renewal and Information Acquisition . . . . . . . . . 55

6 CVC Terminations: Staying Power and Investment Dynamics 62

6.1 The Staying Power of Corporate Venture Capital . . . . . . . . . . 63

6.2 Innovation Improvements and CVC Termination . . . . . . . . . . . 66

7 Conclusion and Literature Revisited $\quad 69$

A Background Reading on Corporate Venture Capital 71

A.1 What Is (not) Corporate Venture Capital? . . . . . . . . . . . . . 71

A.2 Economic Motivation and Operation: Survey Evidence . . . . . . . . 72

A.3 Acquiring Portfolio Companies . . . . . . . . . . . . . 73

A.4 Macromedia: An Illustrative Case . . . . . . . . . . . . . . . . . 74

$\begin{array}{ll}\text { B Instrument Obsolescence } & \mathbf{7 5}\end{array}$

B.1 The Conceptual Idea and Its Roots . . . . . . . . . . . . . . 75

B.2 Variable Construction . . . . . . . . . . . . . 76

B.3 A Simple Illustrative Example Using the Instrument . . . . . . . . . . 78

C Merging VentureXpert with Patent Databases $\quad 81$

C.1 Name Standardization . . . . . . . . . . . . . . . . 81

C.2 The Matching Procedure . . . . . . . . . . . . . . . . 82 
D Identifying Patent Transactions $\quad 84$

D.1 Data Sources . . . . . . . . . . . . . . . . . 84

D.2 Identifying Patent Transactions . . . . . . . . . . . . . . . . 86

$\begin{array}{ll}\text { E Supplementary Discussions and Results } & 88\end{array}$

E.1 Additional Analysis on the CVC Initiation Stage . . . . . . . . . . 88

E.2 Internal Innovation during CVC . . . . . . . . . . . . . . . . . . 89

$\begin{array}{ll}\text { Bibliography } & 102\end{array}$

$\begin{array}{ll}\text { Biography } & 110\end{array}$ 


\section{List of Tables}

3.1 Summary Statistics of the CVC Sample . . . . . . . . . . . . . . 13

4.1 Summary Statistics of the Regression Sample . . . . . . . . . . . 23

4.2 Innovation Deterioration and CVC Initiation . . . . . . . . . . . 25

4.3 Innovation Deterioration and CVC Initiation-Causality . . . . . . . 30

4.4 Industry CVC waves . . . . . . . . . . . . . . . . . . 35

5.1 The Selection of CVC Portfolio Companies . . . . . . . . . . . . 45

5.2 Direct Information Acquisition from Portfolio Companies . . . . . . . 49

5.3 Integration of CVC-Acquired Information through External Acquisitions 52

5.4 Inventor Adjustment and Information Acquisition . . . . . . . . . . 57

6.1 The Staying Power of Corporate Venture Capital . . . . . . . . . 65

6.2 Innovation Improvement and the Termination of CVC Life Cycle . . . 67

B.1 A Simple Illustrative Example Using the Instrument . . . . . . . . . . 79

E.1 Innovation Deterioration and CVC Initiation-The Role of Uncertainty 92

E.2 Success Rate of CVC Investment . . . . . . . . . . . . . . . . . . 94

E.3 Innovation Deterioration and CVC Initiation-Financially Constrained Firms . . . . . . . . . . . . . . . . . . 95

E.4 Innovation Deteriorations and CVC Initiations-4-year and 2-year Innovation Changes . . . . . . . . . . . . . . . 96

E.5 Innovation Deteriorations and CVC Initiations-Different Sampling Criterion . . . . . . . . . . . . . . . . . 97 
E.6 Firm Performance and CVC Initiations - Product Market Performance Change . . . . . . . . . . . . . . . . . . . . . . . 999

E.7 Characteristics of Internal Innovation around CVC Investment . . . . 100 


\section{List of Figures}

1.1 The Life Cycle of Corporate Venture Capital . . . . . . . . . . . 5

4.1 Corporate Innovation before CVC Initiations . . . . . . . . . . . . . 19

4.2 Time Series of CVC Investment . . . . . . . . . . . . . . . 33

4.3 Time Series of CVC Investment-By Industry . . . . . . . . . . . . . 34 


\section{Acknowledgements}

I would like to express my sincere gratitude to all those who helped me complete this dissertation. First, I am indebted to my dissertation committee: John Graham (co-chair), David Robinson (co-chair), Manuel Adelino, Alon Brav, Manju Puri, and Ronnie Chatterji. John is my role model as a researcher, teacher, and adviser, as well as an active contributor to the profession, and I thank him for always being there for me and shaping who I am as a scholar. Likewise, I am extremely grateful to David, not only for his guidance on exploring my research agenda, but also for the chance to learn under him as a co-author. Manju opened the door of entrepreneurial finance research to me and provided crucial feedbacks at each stage of my dissertation study. Alon taught me a great deal, through patient conversations as well as heated debates, on how to produce rigorous finance research and be a critical thinker. Manuel provides expert advice on my papers, my job market, and how to establish myself as a young scholar. I am also grateful to Ronnie for encouragements and his unique view of CVC research.

I would also like to thank a number of faculty who were not on my committee but who nonetheless were very gracious with their time and effort-Hengjie Ai, Ravi Bansal, Simon Gervais, Cam Harvey, Wei Jiang, Adriano Rampini, and many others. I also thank the participants of many workshops that I presented at for valuable feedback that has significantly improved this work. I also learned a great deal and immensely enjoyed the close friendship of many fellow students: Gabriel Bonilla, 
Sergio Correia, Shiming Fu, Donghee Jo, Ben McCartney, Tae-Rog Oh, Alexandru Rosoiu, Basil Williams, and Yichong Zhang,.

My family has made many sacrifices (beginning long before I enrolled at Duke University) and offered me a tremendous amount of support, and for that I am truly grateful. My parents, Suhui Yang and Frank Ma, taught me to follow my dream and have been extremely supportive of the path I chose. Their constant pride, if at times undeserved, has nevertheless been a source of inspiration to me. I owe a tremendous thanks to my parents-in-law, Hua Wei and Peng Zhao. Without their assistance over the past year, it would have been physically impossible for me to go on the job market and defend my dissertation.

All of this is second to the friendship, love, and support (and occasional prodding) of my wife, Yize Zhao. Ever since we fell in love in college, she has been my inspiration and motivation for continuing to improve my knowledge and move my career forward. She is my rock. I hope that over the course of my life I am able to repay the love and steadfast devotion she has shown me. I also want to express my thanks to my daughter, Carol, for always being such a good girl and cheering me up. 


\section{Introduction}

ONE IMPORTANT THEME IN ECONOMICS is to understand how to make investment, organizational, and financial decisions to achieve innovation and long-term growth. ${ }^{1}$ Financial economists seek to understand the economics of financing innovation by examining such activities as internal research and development, mergers and acquisitions, and strategic alliances. ${ }^{2}$ Yet the pathways to successful innovation and long-term growth remain far from clear (Lerner, 2012).

This paper contributes to this broad research agenda by studying financing innovation through the lens of Corporate Venture Capital (CVC), an emerging yet understudied piece in the innovation puzzle. As opposed to producing innovation internally through research and development $(\mathrm{R} \& \mathrm{D})$ or purchasing external innovation through mergers and acquisitions (M\&A), corporations create Corporate Venture

${ }^{1}$ See, e.g., Schumpeter (1942), Arrow (1962), Aghion and Tirole (1994), and Klette and Kortum (2002). This topic is crucial to understanding such broad economic questions as economic growth and productivity (Acemoglu, Akcigit, Bloom, and Kerr, 2013; Aghion, Akcigit, and Howitt, 2014; Bloom, Schankerman, and Van Reenen, 2013), finance (Brown, Fazzari, and Petersen, 2009; Hall and Lerner, 2010), entrepreneurship (Chemmanur, Loutskina, and Tian, 2014; Acemoglu and Cao, 2015), and organizational economics (Fulghieri and Sevilir, 2009; Hackbarth et al., 2014).

${ }^{2}$ See, e.g., Robinson (2008), Brown et al. (2009), Manso (2011), Bena and Li (2014), Seru (2014), among others. 
Capital (CVC) divisions to make systematic minority equity investments in early stage entrepreneurial ventures. Consider, for example, GM Ventures, the CVC unit initiated by General Motors in 2010. On behalf of General Motors, GM Ventures invested in dozens of auto-related technological startups, including automotive cleantech, advance materials, among other fields, through minority equity stakes. The case of GM Ventures is hardly an isolated occurrence. According to the National Venture Capital Association (NVCA), CVC investments accounted for about $20 \%$ of Venture Capital (VC) investment in $2015,{ }^{3}$ and are undertaken not only by technology firms in the media spotlight (such as Google Venture and Intel Capital) but also by moderate-size firms in a variety of industries.

Firms state that they conduct CVC investment to acquire information - that is, to gain exposure to new technologies and markets which in turn benefit their capacity for innovation and broader corporate decisions (Siegel et al., 1988; Macmillan et al., 2008). ${ }^{4}$ As GM Ventures states, its mission as a CVC is to "invest in growth-stage companies to enhance GM's ability to innovate." Theoretically, this information acquisition rationale echoes a long-held framework in the economics of managing and organizing innovation that dates back at least to Nelson (1982). ${ }^{5}$ The innovation process is typically framed as a two-stage sequential process, in which firms acquire information and generate ideas (first stage) before they invest in and produce those ideas (second stage). Including this information acquisition stage in studying innovation can reconcile many important patterns in economic growth and innovation dynamics

${ }^{3}$ In 1999 and 2000, CVC investment peaked at almost $\$ 20$ billion a year. Although the numbers throughout the VC industry fell in the 2000s, CVC growth has rebounded in recent years $(37 \%$ increase in 2015, 69\% increase in 2014, according to NVCA).

4 Startups are an important source of technological and market knowledge, as well as innovative ideas (Scherer, 1965; Acs and Audretsch, 1988; Kortum and Lerner, 2000; Zingales, 2000).

5 See also Nelson and Winter (1982); Dosi (1988); Fleming and Sorenson (2004); Frydman and Papanikolaou (2015), among others. 
(Jovanovic and Rob, 1989; Kortum, 1997). ${ }^{6}$ Despite the importance of acquiring information, little empirical work has studied how firms organize their investment to achieve this goal. Focusing on CVC therefore provides a unique empirical setting to understand how firms seek out and generate new ideas in the broad innovation process.

Motivated by the empirical significance and value of CVC for understanding the process of innovation, I develop empirical tests to assess its role in acquiring information. Those tests examine each stage of a CVC, from why it is initiated, to how it is operated, to when it is terminated. The results establish an investment pattern, labeled as the $C V C$ life cycle, that shows how CVC fits into the process of corporate innovation - deteriorating firms in need of information launch CVC; they actively invest in and use valuable information and knowledge gained through CVC; and they terminate CVC after having regained an edge in innovation therefore informational benefit shrinks - lending support to the information acquisition rationale. Using these findings, I further explore alternative forces that could determine CVC investment and the management of innovation in general, as well as the implication of CVC on corporate innovation at both the firm and industry levels. Figure 1.1 summarizes the CVC life cycle.

The CVC life cycle begins with the initiation stage, in which a firm launches CVC investment, typically following a deterioration in internal innovation. That is, when firms experience a decline in internal innovation, and therefore can benefit from

${ }^{6}$ Existing studies have overwhelmingly focused on the second stage of the innovation processinvesting and organizing innovation with an exogenous idea and predetermined informational structure. Aghion and Tirole (1994) model several cases in which, taking the research idea and informational environment as given, equity investment is optimal to provide incentive for R\&D projects; Mathews (2006) and Fulghieri and Sevilir (2009) study the problem of strategic equity investment from the industrial organization perspective, and theorize the benefits of coordinating market entry and obtaining competitive advantages; Hellmann (2002) emphasizes that asset complementarity and product market synergies lead firms to invest in synergistic entrepreneurial ventures, particularly when external financing is costly (Allen and Phillips, 2000). 
potential informational gains by connecting to highly innovative entrepreneurs, they are more likely to initiate CVC investment. Quantitatively, a two-standard-deviation decline in innovation quantity (quality) increases the probability that a firm will initiate CVC by about 52\% (67\%). Firms in the same industry cluster CVC activities when their sector experiences technological shocks, forming "industry CVC waves."

To mitigate the concern that innovation capability is endogenously determined, I identify plausibly exogenous shocks to firms' ability to generate ideas and produce innovation. The instrumental variable Knowledge Obsolescence captures the evolution of usefulness of a firm's knowledge base accumulated in the past, which results from exogenous technological evolution but is independent to such endogenous factors as corporate governance and product market status. In addition, several potential alternative interpretations of the result, such as the effects of financial constraints and excess cash, do not explain this finding. 


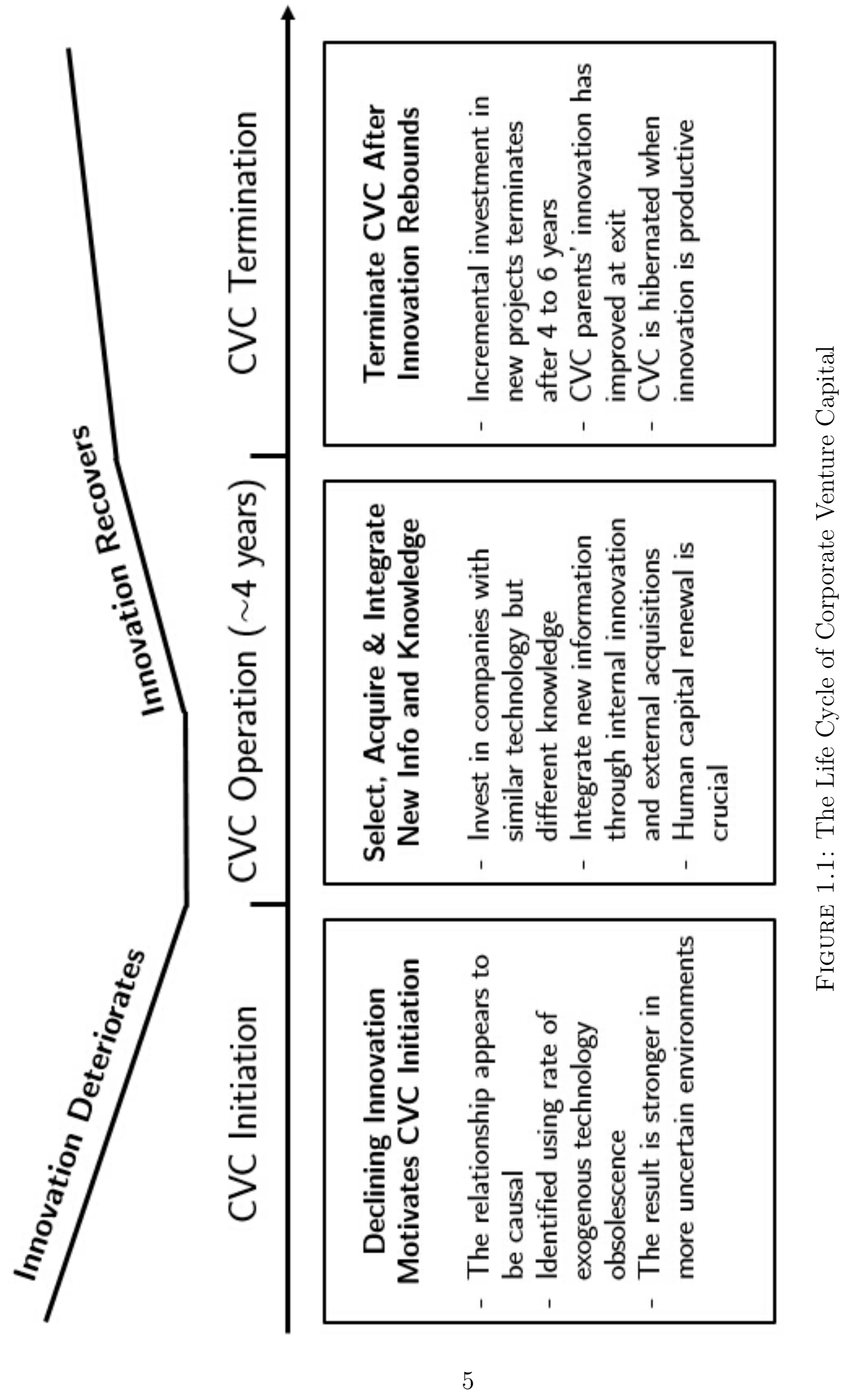


How do CVCs select and use information and innovative knowledge? At the operation stage of the CVC life cycle, I examine how CVC units strategically select which portfolio companies to acquire information from. I find that CVCs primarily invest in startups that are innovating in technological areas that are close to the CVC parent firm, suggesting that CVCs prefer to invest in companies whose technologies can be adapted to the parent firms' innovation. Moreover, the portfolio companies appear to possess incremental knowledge, measured using fewer overlaps of innovation profiles and patent citations, which suggests that CVC parents aim to acquire updated knowledge with higher informational gain. ${ }^{7}$ This means, for example, that an automobile CVC parent firm is likely to invest in an engine startup, particularly when this startup specializes in cutting-edge clean-tech that the outdated parent firm does not possess.

I perform two analyses to isolate how CVC-acquired information is incorporated into parent firms. First, CVC parent firms appear to internalize acquired knowledge through research incorporating the information acquired from their portfolio companies. Second, they capitalize on information by gaining efficiency when making information-sensitive decisions, such as external acquisitions of companies and innovations. Moreover, human capital renewal, such as hiring additional inventors who can use the newly acquired knowledge, is integral to this information acquisition and integration.

The CVC life cycle ends with the termination stage, when CVC parents stop making incremental investment in startups, typically when internal innovation begins to recover. The median duration of the life cycle is about four years. When CVC divisions last more than four years, firms typically hibernate CVC activities during

${ }^{7}$ Interestingly, CVC investment appears to have a "reverse home bias" — even though CVCs are less likely to invest in geographically distant companies, they are also less likely to invest in companies in their own geographic regions, from which they may acquire information through local innovation spillover (Peri, 2005; Matray, 2014). 
years when internal innovation remains productive. This evidence is consistent with the information acquisition rationale, which predicts decreased CVC activity when the marginal benefit shrinks after information is assimilated into parent firms. Interestingly, if innovation again deteriorates at the parent firm, the CVC life cycle begins anew.

All told, this paper presents the CVC life cycle in the course of examining CVC's role of acquiring information in the process of innovation. Essentially, CVC serves as a transitory information-acquiring step in regaining an upward innovation trajectory, typically after a firm experiences a deterioration in internal innovation. Centered around this overview, Section 2 discusses how to understand the information acquisition rationale of CVC from various aspects and its implications on corporate and entrepreneurial finance. Section 3 describes how the data are constructed. Section 4 through 6 cover each stage of the CVC life cycle. Section 7 concludes. 


\section{2}

\section{Discussion and Literature}

The life-cycle pattern lends support to the information acquisition view of Corporate Venture Capital. How does this rationale help us understand existing evidence on CVC activities? What trade-offs do entrepreneurs face when accepting CVC investment and sharing their knowledge? How does CVC and its role of acquiring information fit into the innovation process? What other forces might shape CVC behaviors? This section discusses the implications of CVC and its information acquisition rationale on corporate and entrepreneurial finance in light of these questions.

\subsection{Reconciling Existing CVC Evidence}

An emerging literature, at the intersection of economics, finance, and strategy, attempts to understand the function and influence of CVC (Dushnitsky, 2006; Maula, 2007; Lerner, 2012; Chemmanur et al., 2014; Chemmanur and Fulghieri, 2014). This paper adds to the literature in three ways. First, it asks an under-explored question on $\mathrm{CVC}$ and financing innovation. It deviates from the existing framework that takes 
CVC as given ${ }^{1}$ by seeking the economic rationale behind $\mathrm{CVC}$ investment and its role in the innovation process. The empirical analysis in this paper complements earlier work surveying corporate venture capitalists about their motivation.

Second, in the course of seeking the CVC rationale, this paper makes two empirical contributions to the literature. Unlike previous approaches, which typcally focus on a single phase in CVC activities, I characterize the full CVC life-cycle dynamics from initiation through operation to termination. In addition, by collecting a larger and longer sample of CVCs accompanied by detailed innovation, investment, and entrepreneurship records, I can better control for the influence of anecdotal superstar CVC cases (such as Google Venture and Intel Capital), specific industries, and specific time periods, thus offering many findings that could be masked.

Third, by studying the information acquisition step of corporate innovation through the lens of $\mathrm{CVC},{ }^{2}$ this paper helps to explain CVCs' active participation in the due diligence of startups (Henderson and Leleux, 2002), obtaining (sometimes non-voting) board seats (Maula et al., 2001; Bottazzi, Da Rin, and Hellmann, 2004), and creating communication platforms for inventors in both the parent firm and entrepreneurial ventures (Dushnitsky and Lenox, 2005b). This information acquisition rationale is also consistent with the flexibility and lower adjustment cost (Lerner, 2012) of CVC, which enables firms to respond quickly, to change course easily (abandon a project with lower sunk costs), and to leverage outside funding sources. ${ }^{3}$

\footnotetext{
1 See, e.g., Siegel, Siegel, and MacMillan (1988); Gompers and Lerner (2000); Bottazzi, Da Rin, and Hellmann (2004); Dushnitsky and Lenox (2006); Benson and Ziedonis (2010); Chemmanur, Loutskina, and Tian (2014); Dimitrova (2013); Ceccagnoli, Higgins, and Kang (2015); Wadhwa, Phelps, and Kotha (2015).

${ }^{2}$ Closer to this paper, Dushnitsky and Lenox (2005a) and Basu et al. (2011) indirectly support the information acquisition rationale of CVC by studying environmental variables affecting the efficiency of information acquisition with analyses tilted toward industry-level factors.

${ }^{3}$ Indeed, this learning process often does not involve later asset consolidation (Dimitrova, 2013).
} 


\subsection{Entrepreneurs' Costs and Benefits}

The life-cycle CVC investment pattern and the information acquisition rationale lean heavily on the willingness of entrepreneurs to channel their knowledge to CVC investors. But what do entrepreneurs gain from the relation with CVC? Early research finds that $\mathrm{CVC}$ investors can better nurture innovative entrepreneurs by providing technical support and by tolerating riskier projects. Consistent with this argument, Gompers and Lerner (2000) and Chemmanur, Loutskina, and Tian (2014) show that entrepreneurial companies backed up by CVCs have a higher possibility of making a successful exit and become more innovative after the investment. Second, building relations with established corporations through CVC investment increases the potential for future business. Ceccagnoli et al. (2015) show that an ex ante CVC relation increases the possibility of ex post technology licensing. Last but not least, the acceptance of CVC equity investment aligns the interests of the startup with the CVC investor, working as insurance against competitive behavior from incumbent CVC parent firms (Mathews, 2006).

Admittedly, the efficiency of information acquisition factors in how entrepreneurs trade off the costs and benefits of receiving CVC investment. Hellmann (2002) and Hellmann (1998) discuss this problem and analyze why entrepreneurs might prefer CVC over alternative entrepreneurial investment - a more formal test of the model will rely on detailed startup financing data, which is beyond the scope of this paper.

\subsection{CVC and the Innovation Process}

This paper highlights the information acquisition step in the innovation process (Nelson, 1982), complementing existing studies that typically assume that the information structure is predetermined (Aghion and Tirole, 1994; Robinson, 2008; Bena and Li, 2014; Seru, 2014). This is in the same spirit as the recent endeavor of incorporating 
information acquisition in financial economics, which studies how economic agents search, process, and use information to guide information-sensitive decisions. ${ }^{4}$

The framework also creates the ability not only to study CVC alone but also to explicitly identify the process of integrating CVC-acquired knowledge into R\&D and acquisition decisions. Ideally, these analyses can be viewed as stepping stones toward understanding the whole system of financing and organizing innovation, in which different organizational structures interact with each other in the dynamic innovation process.

\subsection{Alternative CVC Rationales}

A nice feature of this life-cycle finding is that we can analyze several alternative CVC rationales by extending the framework. Early research on CVC and strategic investment proposed many economic forces that could shape CVC activities (Allen and Phillips, 2000; Hellmann, 2002; Mathews, 2006; Fee et al., 2006; Fulghieri and Sevilir, 2009). Results suggest that such factors as corporate governance, financial constraint, and purely outsourcing innovation seem to be secondary to the intention to acquire valuable technological knowledge from startups. Exhausting all potential economic forces that could affect CVC, though definitely of interest, is beyond the scope of this paper. However, the extensions provided give an overview of those forces surrounding the central theme of information acquisition.

\footnotetext{
${ }^{4}$ See Dow and Gorton (1997); Chen, Goldstein, and Jiang (2007); Van Nieuwerburgh and Veldkamp (2010); Bond, Edmans, and Goldstein (2012); Yang (2013).
} 
I exploit a hand-collected sample of Corporate Venture Capital units affiliated with US-based public firms. I start with a list of CVCs identified by the VentureXpert Venture Capital Firms database (accessed through Thomson Reuters SDC Platinum), which is standard in VC studies (Chemmanur, Loutskina, and Tian, 2014). Each CVC on the list is manually matched to its unique corporate parent in Compustat by checking multiple sources (Factiva, Google, etc.). I remove VC divisions operated by financial firms, which differ from CVC arms of industrial firms (Hellmann, Lindsey, and Puri, 2008). From VentureXpert I obtain the investment history of each CVC, including basic information about the startup companies it invests in and the timing and features of each CVC deal. 


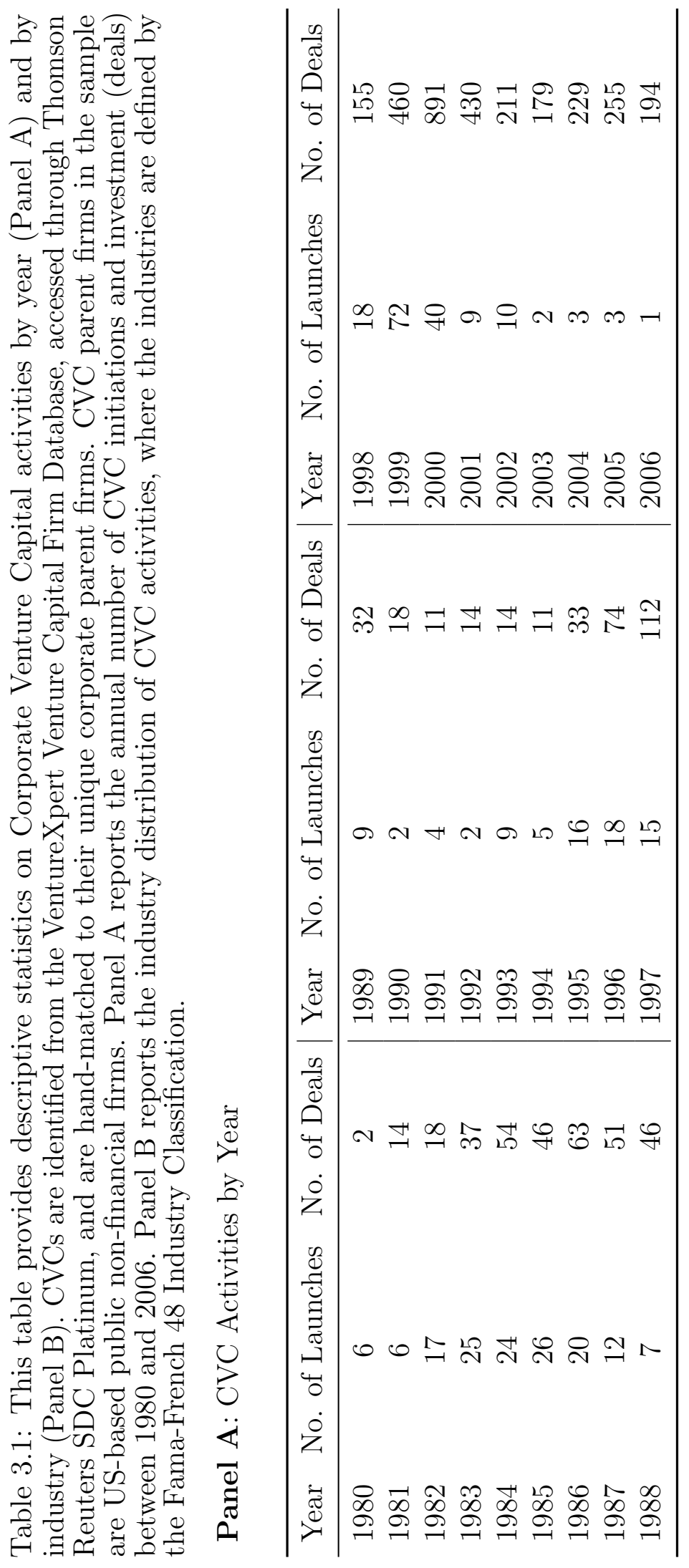




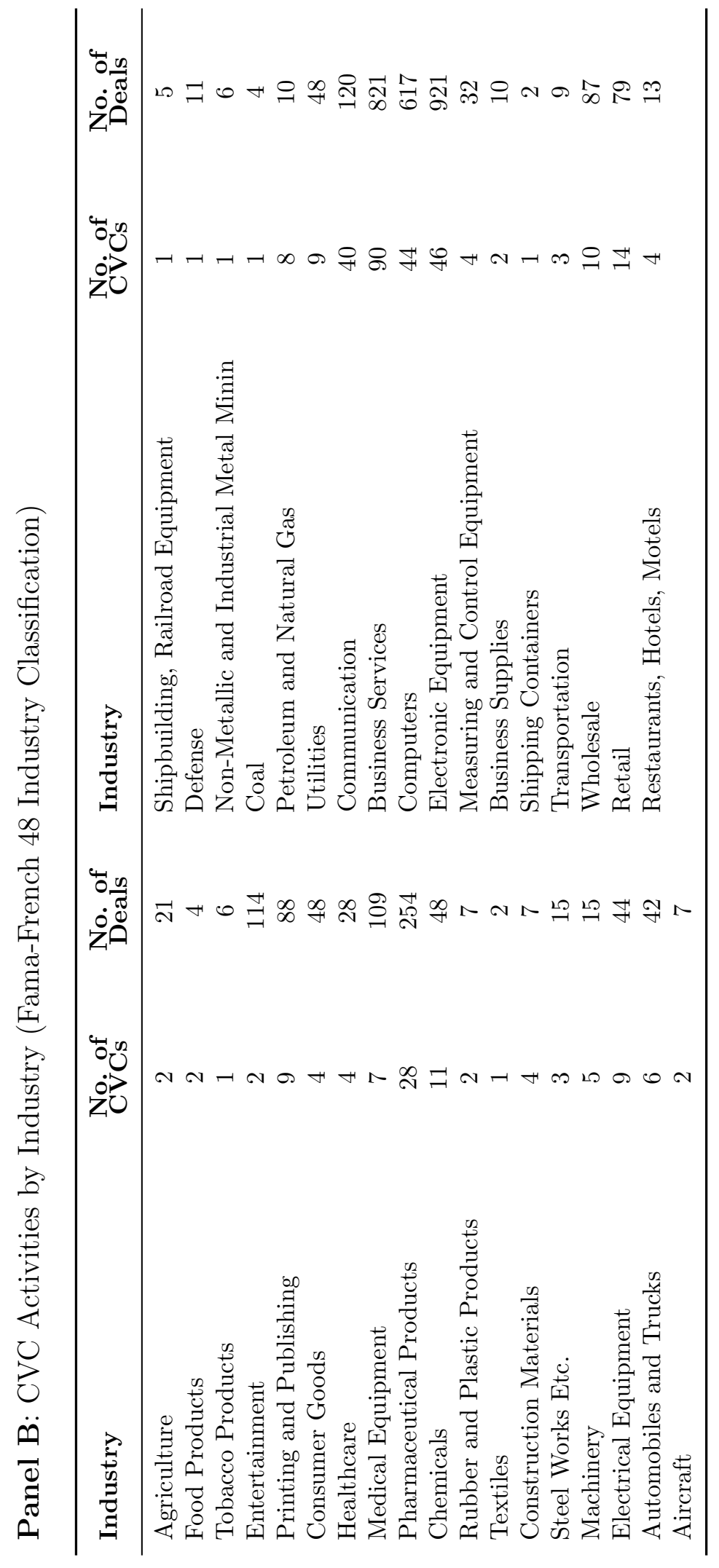


The main sample consists of 381 CVC firms initiated between 1980 and $2006 .^{1}$ Table 3.1 summarizes this CVC sample by tabulating the time-series dynamic and the industry composition. Panel A presents the number of CVC division initiations and investment deals by year. CVC activities are heavily concentrated in the first half of the 1980s and the second half of the 1990s. This is consistent with existing studies on "CVC waves" (Gompers and Lerner, 2000; Dushnitsky, 2006) and is revisited and refined in Section 4.3. Panel B summarizes the industry distribution of CVC parent firms, where industries are defined by the Fama-French 48 Industry Classification. The Business Services industry (including IT) was the most active sector in CVC investment, with 90 firms investing in 821 venture companies. Electronic Equipment firms initiated $46 \mathrm{CVC}$ divisions that invested in 921 companies. Pharmaceutical firms launched 28 CVCs and invested in 254 deals. Other active sectors include Computers and Communications.

The CVC sample is augmented with Compustat for financial statement data and with CRSP for stock market performance. Variable constructions are described in the Appendix. All data items are pre-winsorized at the $1 \%$ and $99 \%$ levels. SDC Platinum provides organizational information on M\&As and strategic alliances. For corporate governance data, I extract institutional shareholding information from the WRDS Thomson Reuters 13(f) data and obtain G-index data from Andrew Metrick's data library. ${ }^{2}$

Innovation is a crucial data component of this paper for three reasons. First, because innovation knowledge generated in the entrepreneurial sector has the potential to create great value for CVC parent firms (Scherer, 1965; Acs and Audretsch, 1988; Kortum and Lerner, 2000; Macmillan et al., 2008), it is an important part of the

${ }^{1}$ I focus on CVCs initiated no later than 2006 to allow for investment behaviors to realize (after 2006) and to ensure the quality of the innovation database.

2 Accessed using http://faculty.som.yale.edu/andrewmetrick/data.html. 
information set that CVC units intend to acquire. Second, comprehensive innovation data create a valuable setting to measure informational relationships (Bena and Li, 2014) and knowledge flows (Gomes-Casseres et al., 2006; Gonzalez-Uribe, 2013). Third, the quality of detailed innovation data maintained and updated by the United States Patent and Trademark Office (USPTO) is superior to most alternative data sources on corporate activities.

I obtain basic innovation data from the NBER Patent Data Project and from Bhaven Sampat's patent and citation data. ${ }^{3}$ The combined database provides detailed patent-level records on more than 3 million patents granted by USPTO between 1976 and 2012. I link this database to Compustat using the bridge file provided by NBER. Beyond the standard database, I also introduce several data sets and cleaning procedures that are relatively new to the literature (detailed in related sections and the Appendix): I link the USPTO database to entrepreneurial companies in VentureXpert using a fuzzy matching method based on company name, basic identity information, and innovation profiles, similar to Gonzalez-Uribe (2013) and Bernstein, Giroud, and Townsend (2014); I also introduce the Harvard Business School inventor-level database in order to examine how firms adjust their innovative human capital as a specific channel to facilitate information acquisition and integration; and last, I introduce the Google Patent Assignment and Reassignment database, which tracks all transactions of each patent.

The combined innovation data provide three layers of innovation information that are helpful for the analysis. First, I employ two main variables to measure basic corporate innovation performance. I measure innovation quantity by calculating the number of patent applications, which are eventually granted, filed by a firm in

${ }^{3}$ For more information on the NBER Patent Data Project, please refer to Hall, Jaffe, and Trajtenberg (2001). The data used in this paper were downloaded from https://sites.google. com/site/patentdataproject/. Sampat's data can be accessed using http://thedata.harvard. edu/dvn/dv/boffindata. 
each year. I use the patent's year of application instead of the year it is granted because that better captures the actual timing of innovation. I use the logarithm of one plus this variable, that is, $\ln (1+$ NewPatent) (denoted as $\ln ($ NewPatent $))$, to fix the skewness problem for better empirical properties. I measure the quality of innovation, based on the average lifetime citations of all new patents produced by a firm in each year. Similar to the logarithm transformation performed on quantity, I use $\ln (1+$ Pat.Quality) (denoted as $\ln ($ Pat.Quality $))$.

The second layer of innovation data is citations firms make in their own patents. By tracking the citations a firm makes, we can measure the technological areas in which the firm works and the specific underlying technologies. Moreover, examining the citation network among firms (including both established firms and startups) allows us to construct variables capturing the technological relation between CVCs and startups and to measure dynamic information flows between firm pairs.

The third layer of innovation data concerns the micro-level information beyond patents - the inventors (engineers, scientists, etc.) who contributed to a firm's patents and their mobility. As shown in Gonzalez-Uribe (2013), Bernstein, Giroud, and Townsend (2014), and Brav et al. (2016), inventor-level information can help us infer the motivation behind corporate activities from the perspective of labor adjustment. Second, I construct a full set of patent transactions from the Google Patent database, and this panel of patent life cycles allows me to examine how information acquisition improves the efficiency in the market for technologies. 
4

\section{CVC Initiations: The Effect of Innovation Deterioration}

Why do firms initiate CVC programs? Under the information acquisition view of Corporate Venture Capital, capacity-constrained firms trade off between acquiring information for new ideas and producing existing ideas (Nelson, 1982; Jovanovic and Rob, 1989). The allocation of capacity to information acquisition is determined by the quantity and quality of existing ideas available to the firm - the fewer (lower) the quantity (quality) of existing innovation ideas become, the more likely it is the firm that implement information acquisition strategies, such as CVC, in search of better innovation paths.

Figure 4.1 visualizes CVC parent firms' innovation dynamics before initiating their CVC divisions. Innovation performance, measured by patenting quantity (Panel (a)) and quality (Panel (b)), is tracked for five years from $t-4$ to $t$ ( $t$ is the year of CVC initiation). Firm-year measures are adjusted by the averages of all peer firms in the same 3-digit SIC industry in the same year to exclude the influence of industry-specific time trends.

Panel (a) tracks innovation quantity of CVC parent firms, measured by the 

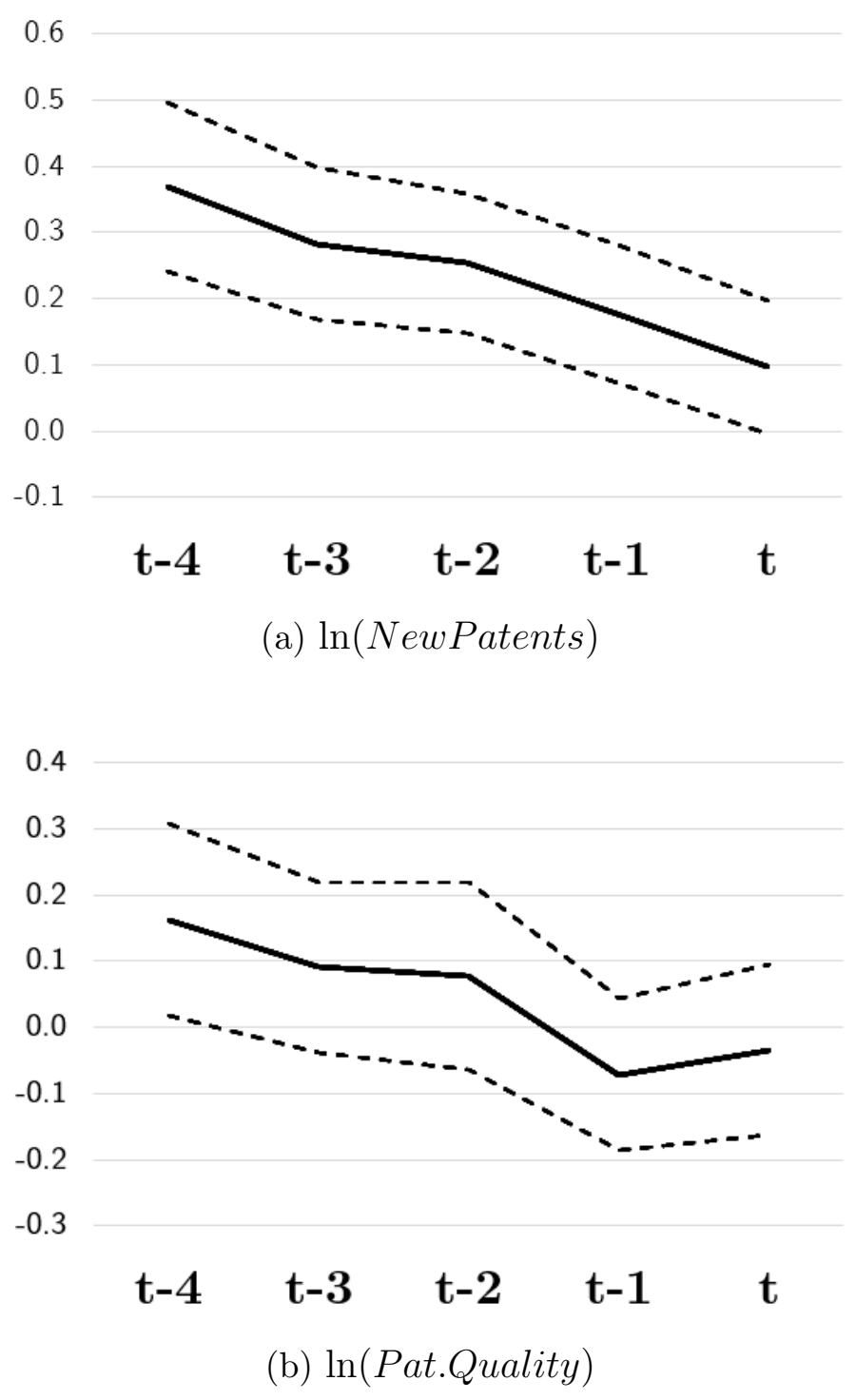

-Industry-Year Adjusted Value ---95\% Confidence Interval

FIGURE 4.1: This figure tracks corporate innovation performance of CVC parents before the initiation of their CVC units. $\ln ($ NewPatent $)$ is the logarithm of the number of new patents applied by a firm in each year. $\ln$ (Pat.Quality) is the logarithm of average citations of new patents. Each measure is adjusted by the mean of firms in the same year and industry (3-digit SIC level). The graph starts from four years before a firm launches its CVC unit $(t-4)$ and ends in the year of launching $(t) .95 \%$ confidence intervals are plotted in dotted lines. 
logarithm of the number of new patent applications. Four years before initiating their CVC units, CVC parents were significantly more innovative than their peers and on average doubled their peers' patent production. This advantage shrinks continuously by about $25 \%$ until year $t$. In Panel (b), CVC parent firms' innovation enjoys $15 \%$ higher average citations compared to their industry peers in $t-4$, and this number decreases to well below 0 at the time of CVC initiation. In untabulated results, I find that the performance deterioration pattern is robust to measures of product market performance, that is, ROA and sales growth. Overall, Figure 4.1 presents a clear pattern at the start of the CVC life cycle - that is, CVC initiations typically follow deteriorations in parent firms' internal innovation, which is consistent with the information acquisition view of CVC.

Building on Figure 4.1, I first confirm the relation between innovation deterioration and CVC initiation using a simple empirical setting. I then explore an identification strategy that controls for several endogeneity concerns and sharpens the role of the information acquisition motive by analyzing several alternative explanations of the pattern. Firm-level CVC initiation decisions are aggregated to an industrylevel pattern, which presents how the information acquisition function fits into the technological evolution in each industry.

\subsection{Baseline Results}

To statistically identify the effect of innovation performance on CVC initiations, I estimate the following specification using a panel data of firm-year observations:

$$
I(C V C)_{i, t}=\alpha_{\text {industry } \times t}+\beta \times \Delta_{\tau} \text { Innovation }_{i, t-1}+\gamma \times X_{i, t-1}+\varepsilon_{i, t},
$$

where $I(C V C)_{i, t}$ is equal to one if firm $i$ launches a CVC unit in year $t$, and zero otherwise. ${ }^{1} \Delta_{\tau}$ Innovation $_{i, t-1}$ is the change of innovation over the past $\tau$ years

${ }^{1}$ Dummy variable $I(C V C)_{i, t}$, instead of the size of CVC investment each year, is more appropriate to capture the corporate decision on CVC investment for two reasons: (1) the decision to start a 
ending in $t-1$. I use a three-year $(\tau=3)$ innovation shock throughout the main analysis and report robustness checks using other horizons in the Appendix. Firmlevel controls $X_{i, t-1}$ include ROA, size (logarithm of total assets), leverage, and R\&D ratio ( $R \& D$ expenditures scaled by total assets). Industry-by-year fixed effects are included to absorb industry-specific time trends in CVC activities and innovation. A negative $\beta$ indicates that the probability of starting a CVC increases with innovation deterioration.

\subsubsection{Summary Statistics}

Table 4.1 presents descriptive statistics based on whether a CVC division is initiated in the firm-year. Only observations with valid ROA, size, leverage, R\&D ratio, and at least $\$ 10$ million in book assets are kept in the sample. Only "innovative firms," defined as those that filed at least one patent application that was eventually granted by the USPTO, are included. Industries (3-digit SIC level) with no CVC activities during the sample period are removed.

Table 4.1 provides a benchmark to position CVC parent firms in the Compustat universe of publicly traded corporations. First, CVC parents are typically large firms. On average, a CVC parent has $\$ 10.1$ billion in book assets in 2007 USD (median is $\$ 2.4$ billion) just before launching its CVC unit, whereas non-CVC parent firms have less than $\$ 3$ billion in book assets (median is $\$ 0.2$ billion). Second, CVC parent firms are innovation intensive in terms of patenting quantity, echoing the size effect. Third, corporate governance variables are comparable between the two subsamples. Overall, the basic characteristics are consistent with existing stylized facts that CVC parent firms tend to be larger corporations with more business resources (Dushnitsky and

CVC unit is at the executive level, whereas the size of investment in subsequent years is plausibly determined by the CVC team; and (2) the data on investment size in VentureXpert have potential sample selection issues such as CVCs strategically hiding good deals they invested in (to avoid competition from other CVCs). I report the analysis on annual CVC investment size as an important result in Section 6. 
Lenox, 2005a; Basu, Phelps, and Kotha, 2011).

Consistent with Figure 4.1, CVC parent firms on average experience more negative innovation shocks before starting their CVC divisions. CVC parents on average experience a $-7 \%(-10 \%)$ change in patenting quantity (quality) three years before launching their CVC units, compared to the control firms, which experience a $12 \%$ $(8 \%)$ shock. Similar to the deterioration in innovation, CVC parents appear to underperform in terms of ROA and market-to-book ratio before CVC initiations. 


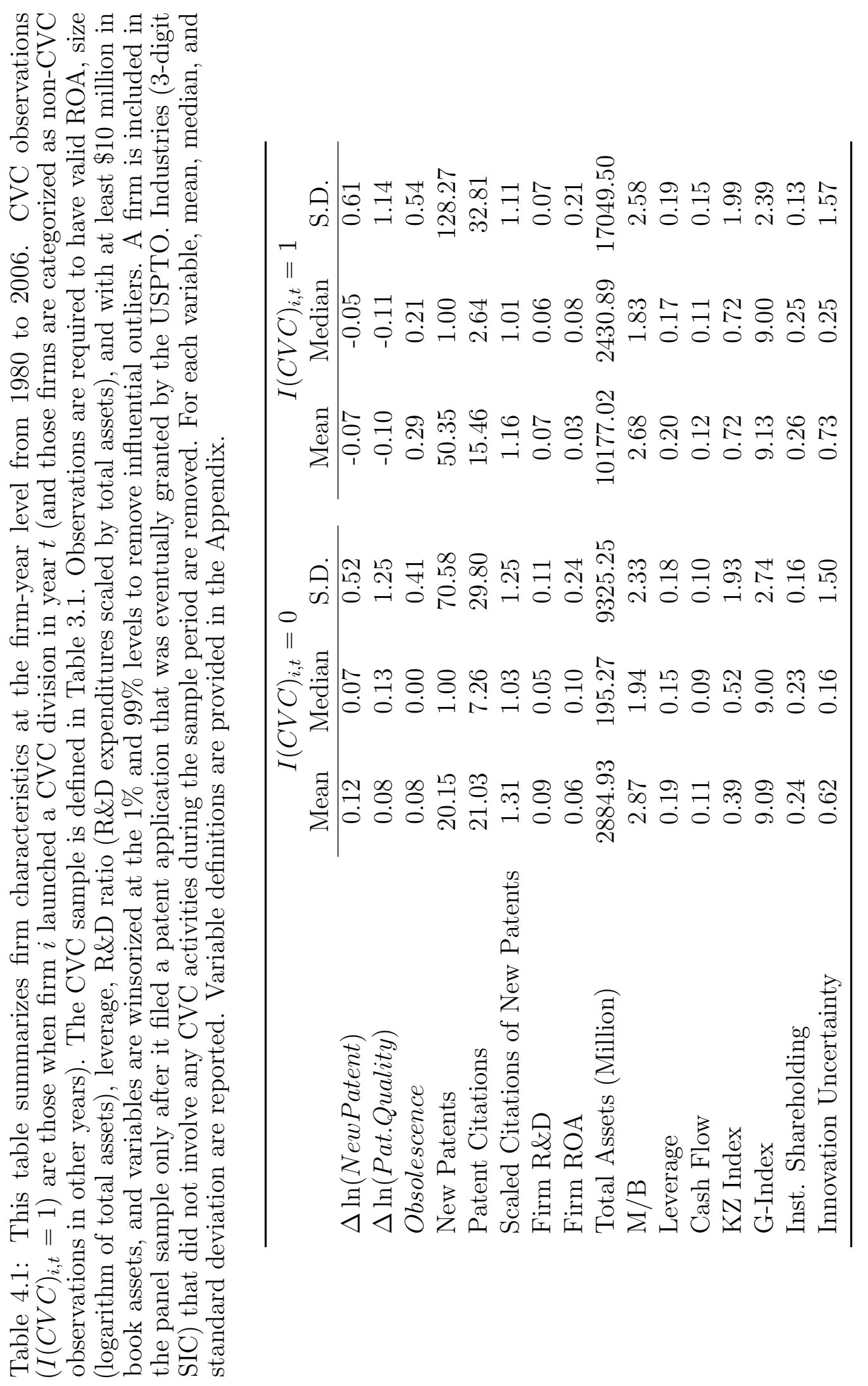




\subsubsection{Results}

Table 4.2 presents the estimation results of model (4.1). Columns (1) and (2) focus on the effect of changes in innovation quantity. In column (1), the model is estimated using Ordinary Least Squares (OLS). The coefficient of -0.007 is negative and significant, meaning that a more severe decline in innovation quantity in the past three years is associated with a higher probability of initiating CVC investment. This estimate translates a two-standard-deviation decrease (2 $\sigma$-change) in $\Delta \ln ($ NewPatent $)$ into a $51.54 \%$ increase from the unconditional probability of launching CVC unites. Column (2) reports the model estimation from a Logit regression, and I report the marginal effect evaluated at sample mean. Column (2) delivers an almost identical message as column (1).

Columns (3) and (4) study the effect of deterioration in innovation quality and use OLS and Logit, respectively. In column (3), the coefficient of -0.004 means that a two-standard-deviation decrease in $\Delta \ln ($ Pat.Quality) increases the probability of CVC initiation by $67.09 \%$, and this is economically comparable to that in column (1). Column (4) delivers a consistent message.

It is worth stressing the importance of incorporating industry-by-year fixed effects in the estimation. Previous studies on technological evolution and restructuring waves highlight the possibility that certain industry-specific technology shocks could be driving innovation changes and organizational activities at the same time (Mitchell and Mulherin, 1996; Harford, 2005; Rhodes-Kropf, Robinson, and Viswanathan, 2005). However, after absorbing this variation using industry-by-year fixed effects, the results in Table 4.2 are identified using the cross-sectional variation within an industry-by-year cell. This issue is revisited and studied in Section 4.3.

Overall, Table 4.2 confirms the pattern in Figure 4.1 that CVC initiations typically follow a deterioration in innovation, lending support to the information acquisition 
Table 4.2: This table documents the relation between innovation deterioration and the initiation of Corporate Venture Capital. The analysis is performed using the following specification: $I(C V C)_{i, t}=\alpha_{\text {industry } \times t}+\beta \times \Delta$ Innovation $_{i, t-1}+\gamma \times X_{i, t-1}+\varepsilon_{i, t}$, The panel sample is described in Table 4.1. $I(C V C)_{i, t}$ is equal to one if firm $i$ launches a Corporate Venture Capital unit in year $t$, and zero otherwise. $\Delta$ Innovation $_{i, t-1}$ is the innovation change over the past three years (i.e., the innovation change from $t-4$ to $t-1$ ). Innovation is measured using innovation quantity (the natural logarithm of the number of new patents in each firm-year plus one), shown in columns (1) and (2) and innovation quality (the natural logarithm of average citations per new patent in each firm-year plus one), shown in columns (3) and (4). Firm-level controls $X_{i, t-1}$ include ROA, size (logarithm of total assets), leverage, and $R \& D$ ratio ( $R \& D$ expenditures scaled by total assets). The model is estimated using Ordinary Least Squares (OLS) and Logit, respectively. Industry-by-year dummies are included in the model to absorb industry-specific time trends in CVC activities and innovation. T-statistics are shown in parentheses and standard errors are clustered by firm. ${ }^{*}, * *, * * *$ denote statistical significance at the $10 \%, 5 \%$, and $1 \%$ levels, respectively. Economic significance is calculated by changing two standard deviations of the $\Delta$ Innovation and is reported below the estimation results.

\begin{tabular}{|c|c|c|c|c|}
\hline & $\begin{array}{c}(1) \\
\text { OLS }\end{array}$ & $\begin{array}{c}(2) \\
\text { Logit }\end{array}$ & $\begin{array}{c}(3) \\
\text { OLS }\end{array}$ & $\begin{array}{c}(4) \\
\text { Logit }\end{array}$ \\
\hline$\Delta \ln ($ NewPatent $)$ & $\begin{array}{c}-0.007^{* * *} \\
(-6.227)\end{array}$ & $\begin{array}{c}-0.004^{* * *} \\
(-3.057)\end{array}$ & & \\
\hline$\Delta \ln ($ Pat.Quality $)$ & & & $\begin{array}{c}-0.004^{* * *} \\
(-4.459)\end{array}$ & $\begin{array}{c}-0.003^{* *} \\
(-2.263)\end{array}$ \\
\hline Firm ROA & $\begin{array}{l}-0.003 \\
(-1.275)\end{array}$ & $\begin{array}{c}0.000 \\
(0.703)\end{array}$ & $\begin{array}{l}-0.003 \\
(-1.567)\end{array}$ & $\begin{array}{c}0.000 \\
(0.935)\end{array}$ \\
\hline Size (Log of Assets) & $\begin{array}{l}0.003^{* * *} \\
(11.090)\end{array}$ & $\begin{array}{c}0.001^{* * *} \\
(10.584)\end{array}$ & $\begin{array}{l}0.003^{* * *} \\
(11.034)\end{array}$ & $\begin{array}{c}0.001^{* * *} \\
(8.832)\end{array}$ \\
\hline Leverage & $\begin{array}{l}-0.005^{* *} \\
(-2.371)\end{array}$ & $\begin{array}{c}-0.003^{* * *} \\
(-3.006)\end{array}$ & $\begin{array}{l}-0.004^{* *} \\
(-2.051)\end{array}$ & $\begin{array}{c}-0.003^{* * *} \\
(-2.908)\end{array}$ \\
\hline Firm R\&D & $\begin{array}{c}0.015^{* * * *} \\
(3.439)\end{array}$ & $\begin{array}{c}0.005 \\
(1.637)\end{array}$ & $\begin{array}{c}0.011^{* * *} \\
(3.093)\end{array}$ & $\begin{array}{c}0.004 \\
(1.356)\end{array}$ \\
\hline $\begin{array}{l}\text { Observations } \\
\text { Pseudo R-squared } \\
\text { Industry } \times \text { Year FE }\end{array}$ & $\begin{array}{c}25,976 \\
0.126 \\
\text { Yes }\end{array}$ & $\begin{array}{c}25,976 \\
0.261 \\
\text { Yes }\end{array}$ & $\begin{array}{c}25,976 \\
0.125 \\
\text { Yes }\end{array}$ & $\begin{array}{c}25,976 \\
0.268 \\
\text { Yes }\end{array}$ \\
\hline & \multicolumn{4}{|c|}{ Economic Significance $-2 \sigma$-change } \\
\hline $\begin{array}{l}\Delta \ln (\text { NewPatent }) \\
\Delta \ln (\text { Pat.Quality })\end{array}$ & $51.54 \%$ & $29.45 \%$ & $67.09 \%$ & $50.32 \%$ \\
\hline
\end{tabular}


view of CVC. However, what if the results are due to some endogenous common factor that drives both innovation dynamics and CVC activities (for example, poor management)? Moreover, what alternative economic forces, other than informational motives, could drive deteriorating firms to launch CVC? The analyses that follow adapt the framework in Table 4.2 to discuss these issues.

\subsection{Identification Strategy}

Potential endogeneity problems arise from unobservables that are hard to control for in model (4.1). For instance, agency problems (such as empire-building managers) could hinder innovation and lead simultaneously to the initiation of CVC as a pet project, biasing the estimation in favor of finding a negative relation between innovation and CVC investment. On the other hand, CEOs who are more risk tolerant could improve corporate innovation (Sunder, Sunder, and Zhang, 2014) as well as encourage interactions with entrepreneurs using CVC, biasing the estimation against finding the result.

\subsubsection{Instrumental Variable and Empirical Strategy}

To address endogeneity concerns and rule out competing interpretations, I construct a new instrumental variable by exploiting the influence of exogenous technological evolution on firm-specific innovation. The idea that technological evolution affects corporate innovation is intuitive - a firm specializing in manufacturing 14-inch hard disk drives (HHD) was less likely to produce valuable innovation when 8-inch HHD technology emerged, and this happened repeatedly along the development path of HHDs (5.25-inch, 3.5-inch, 2.5-inch, Solid State Drives). Indeed, "new technologies come and go, taking generations of companies with them" (Igami, 2014).

Earlier studies formalize this intuition and identify several mechanisms through which technological evolution affects firms' ability to innovate. A negative shock to 
the value of a firm's accumulated knowledge space implies a longer distance to the knowledge frontier and a higher knowledge burden to identify valuable ideas and produce radical innovation (Jones, 2009). Firms working in a fading area benefit less from knowledge spillover (Bloom, Schankerman, and Van Reenen, 2013), which in turn dampens growth in innovation and productivity. ${ }^{2}$

To implement the idea and measure the influence of exogenous technological evolution on each firm's capability to innovate, I build on the literature of bibliometrics and scientometrics, which measure the obsolescence and aging of a discipline or technology using the dynamics of citations that refer to the discipline or technology. The instrument, termed as Knowledge Obsolescence (Obsolescence hereafter), attempts to capture the $\tau$-year (between $t-\tau$ and $t$ ) rate of obsolescence of the knowledge possessed by a firm. For each firm $i$ in year $t$, this instrument is constructed in three steps (formally defined in formula (4.2)). First, firm $i$ 's predetermined knowledge space in year $t-\tau$ is defined as all the patents cited by firm $i$ (but not belonging to $i$ ) up to year $t-\tau$. I then calculate the number of citations received by this $K_{\text {nowledgeSpace }}{ }_{i, t-\tau}$ in $t-\tau$ and in $t$, respectively. Last, Obsolescence $e_{i, t}^{\tau}$ is defined as the change between the two, and a larger Obsolescence means a greater decline of the value and utility of a firm's knowledge,

Obsolescence $_{i, t}^{\tau}=-\left[\ln \left(\right.\right.$ Cit $_{t}\left(\right.$ KnowledgeSpace $\left.\left._{i, t-\tau}\right)\right)-\ln \left(\right.$ Cit $_{t-\tau}\left(\right.$ KnowledgeSpace $\left.\left.\left._{i, t-\tau}\right)\right)\right]$.

The validity of the exclusion restriction rests on the assumption that, controlling for industry-specific technological trends and firm-specific characteristics, the technological evolution regarding a firm's knowledge space, which is predetermined and

\footnotetext{
${ }^{2}$ One concern is that when a firm's knowledge space becomes hotter, product market competition grows more severe, which in turn could disincentivize innovation and imply that emerging knowledge value could lead to lower innovation performance. This concern, however, is shown to be secondary by Bloom, Schankerman, and Van Reenen (2013) and is resolved by the first-stage regression in Table 4.3.
} 
accumulated along its path, is orthogonal to its current decision on CVC other than through affecting innovation performance. One might worry that a firm's knowledge space could be affected by the type and capability of its managers, but this concern should be minimized by using a predetermined knowledge space formed along the corporate history rather than the concurrent one. One might also worry that the firm itself could be the main driver of the technological evolution. This concern is addressed first by excluding patents owned by the firm from its own knowledge space and then by excluding all citations made by the firm itself in the variable construction. It is mitigated further by a robustness check on a subsample of medium and small firms, which are less likely to endogenize technological evolution.

In Table 4.1, I report summary statistics for Obsolescence. The number of citations received by a firm's predetermined knowledge space decays by $8 \%$ in the control group, which can be interpreted as a mild three-year natural decay of knowledge. The knowledge space on average decays by $29 \%$ in the three years before a parent firm initiates its CVC arm, which demonstrate a much more severe hit by the technological evolution.

I exploit the instrument in a standard 2SLS framework. In the first stage, I instrument the change in innovation with Obsolescence ${ }_{i, t}^{\tau}$ using the following form:

$$
\Delta_{\tau} \text { Innovation }_{i, t-1}=\pi_{0, \text { industry } \times t}^{\prime}+\pi_{1}^{\prime} \times \text { Obsolescence }_{i, t-1}^{\tau}+\pi_{2}^{\prime} \times X_{i, t-1}+\eta_{i, t-1} .
$$

The predicted change in innovation is then used in the second stage to deliver a consistent estimator, that is,

$$
I(C V C)_{i, t}=\alpha_{\text {industry } \times t}+\beta \times \Delta_{\tau} \text { Innovation }_{i, t-1}+\gamma \times{X_{i, t-1}}+\varepsilon_{i, t} .
$$

\subsubsection{SLS Results}

Table 4.3 presents the estimation results of models (4.3) and (4.4). Column (1) reports a reduced-form regression in which Obsolescence is used to explain the decision to 
launch a CVC program. The positive coefficient 0.001 indicates that firms experiencing larger technological decays are more likely to initiate CVC activities.

Columns (2) and (4) report first-stage regressions where $\Delta$ Innovation (Innovation measured by the quantity and quality of new patents) is predicted using Obsolescence and a larger Obsolescence (faster rate of technological decaying) is associated with poorer innovation performance. The estimate of -0.114 in column (2) translates a $10 \%$ increase in the rate of obsolescence of a firm's knowledge space into a $1.14 \%$ decrease in its patent applications; this same change is associated with a $1.28 \%$ decrease of its patent quality as measured by lifetime citations. The $F$-statistics of these first-stage regressions are both well above the conventional threshold for weak instruments (Stock and Yogo, 2005).

Columns (3) and (5) show the second-stage estimation results. The key explanatory variables are now fitted innovation changes predicted from the first stage. The causal effect of innovation shocks on starting a CVC unit is both economically and statistically significant. The coefficient of -0.007 in column (2) translates a $2 \sigma$-change in $\Delta \ln ($ New Patent $)$ to a $52 \%$ change in the probability of launching CVC investment.

The gaps between the OLS estimates (in Table 4.2) and the 2SLS estimates are small. This comparison suggests that endogeneity issues are not biasing the OLS estimation in any clear direction on net. This does not mean, however, that no endogeneity issues are involved - as discussed above, competing endogenous forces could drive the OLS bias in either direction, mitigating the net effect. The Appendix shows that the result is robust to several sampling criteria, such as excluding the IT and Pharmaceutical sectors, excluding California-based firms, and excluding very big or very small firms. 
Table 4.3: This table documents the causal relationship between innovation deterioration and the initiation of Corporate Venture Capital. The analysis is performed using the following Two-Stage Least Squares (2SLS) specification: $\Delta$ Innovation $_{i, t-1}=$ $\pi_{0, \text { industry } \times t}^{\prime}+\pi_{1}^{\prime} \times$ Obsolescence $_{i, t-1}+\pi_{2}^{\prime} \times X_{i, t-1}+\eta_{i, t-1}, I(C V C)_{i, t}=\alpha_{\text {industry } \times t}+$ $\beta \times \Delta$ Innovation $_{i, t-1}+\gamma \times X_{i, t-1}+\varepsilon_{i, t}$. The panel sample is described in Table 4.1. Column (1) reports the reduced-form regression, which predicts the decision to initiate CVC using Obsolescence as defined in (4.2) in the paper. Columns (2) and (4) report the first-stage regression, which regress the three-year change in innovation quantity (the natural logarithm of the number of new patents in each firm-year plus one) and innovation quality (the natural logarithm of average citations per new patent in each firm-year plus one) on the three-year Obsolescence. Columns (3) and (5) report the second-stage regression, where $I(C V C)_{i, t}$ is equal to one if firm $i$ launches a Corporate Venture Capital unit in year $t$, and zero otherwise. $\Delta$ Innovation $_{i, t-1}$ is the fitted innovation change over the past three years (i.e., the innovation change from $t-4$ to $t-1)$. In the 2SLS framework, firm-level controls $X_{i, t-1}$ include the ROA, size (logarithm of total assets), leverage, and $R \& D$ ratio ( $R \& D$ expenditures scaled by total assets). Industry-by-year dummies are included in the model to absorb industry-specific time trends in CVC activities and innovation. T-statistics are shown in parentheses and standard errors are clustered by firm. ****,*** denote statistical significance at the $10 \%, 5 \%$, and $1 \%$ levels, respectively.

\begin{tabular}{lccccc}
\hline & $(1)$ & $(2)$ & $(3)$ & $(4)$ & $(5)$ \\
& Reduced Form & First Stage & 2SLS & First Stage & 2SLS \\
\cline { 2 - 6 } Obsolescence & & & & \\
& $0.001^{* *}$ & $-0.114^{* * *}$ & & $-0.128^{* * *}$ & \\
$\Delta \ln ($ NewPatent $)$ & $(2.171)$ & $(-12.165)$ & & $(-17.064)$ & \\
& & & $-0.007^{* * *}$ & & \\
$\Delta \ln$ (Pat.Quality) & & & $(-3.597)$ & & $-0.004^{* * *}$ \\
& & & & & $(-2.577)$ \\
Firm ROA & -0.000 & $0.090^{* * *}$ & -0.003 & $0.070^{* * *}$ & -0.003 \\
& $(-0.071)$ & $(4.711)$ & $(-1.289)$ & $(4.170)$ & $(-1.600)$ \\
Size (Log of Assets) & $0.003^{* * *}$ & $0.028^{* * *}$ & $0.003^{* * *}$ & $0.031^{* * *}$ & $0.003^{* * *}$ \\
& $(6.353)$ & $(12.664)$ & $(11.401)$ & $(16.106)$ & $(11.238)$ \\
Leverage & 0.002 & $-0.103^{* * *}$ & $-0.005^{* *}$ & $-0.091^{* * *}$ & $-0.004^{* *}$ \\
& $(0.921)$ & $(-5.155)$ & $(-2.484)$ & $(-5.179)$ & $(-2.095)$ \\
Firm R\&D & $0.006^{*}$ & $0.489^{* * *}$ & $0.015^{* * *}$ & $0.420^{* * *}$ & $0.011^{* * *}$ \\
& $(1.794)$ & $(11.931)$ & $(3.476)$ & $(11.423)$ & $(3.157)$ \\
F-Statistic & & & & & \\
Observations & & 147.99 & & 291.18 & \\
R-squared & 25,976 & 25,976 & 25,976 & 25,976 & 25,976 \\
Industry $\times$ Year FE & 0.315 & 0.398 & 0.122 & 0.370 & 0.117 \\
\hline
\end{tabular}




\subsection{Industry CVC Waves}

In previous analyses that focus on firm-level evidence, I control for industry-by-year fixed effects to absorb potential confounding factors. In this section, I look into this part of the variation that was controlled for by fixed effects in order to examine the industry-by-year pattern of CVC investment and how it speaks to the information acquisition view of CVC.

Existing CVC research documents that CVC investment clusters as waves and shows strong cyclicality (Gompers, 2002; Lerner, 2012). Figure 4.2 plots the time series of the instances of 381 CVCs studied in the sample. Both the number of launches of new CVC units and the number of deals invested are plotted. Similar to Gompers (2002) and Dushnitsky (2006), the graph highlights two waves - most CVC units were launched in either the early to mid-1980s or the later 1990s. More than 20 firms began CVC investments in each year from 1983 to 1986, and 71 firms started CVC units in 1999. CVC deals occurred in two similar waves: in the first wave, from 1983 to 1986, CVC units invested in about 60 deals each year; this number was reached again 10 years later, in 1996, at the beginning of the second CVC wave.

Existing explanations for these waves emphasize macro-level factors (tax change, market condition, etc.) that do not directly speak to one important aspect that attracts less attention - CVC waves do not happen uniformly in each industry. That is, some industries waved in only one of the two periods, with little activity in the other. In Figure 4.3, the sample is broken down to produce a by-industry CVC investment graph. Four industries are presented-machinery, printing and publishing, business services (including IT), and pharmaceuticals. Two observations can be gleaned from these figures. First, CVC investments cluster not only at the aggregate level (as in Figure 4.2) but also at the industry level, and this industry-level clustering is what can be termed an "industry CVC wave." Second, and more important, 
different industries waved at different times. Specifically, most CVC investments in the machinery industry were made in the 1980s, but the industry was not heavily involved in the second aggregate CVC wave in the 1990s. In contrast, printing and publishing firms were relatively silent during the 1980s CVC wave but rode the second wave in the later 1990s. Even IT firms, the overall most active group in the CVC field, were relatively uninvolved in the first aggregate wave but invested aggressively in the second wave. The pharmaceutical industry, another highly active industry in CVC investments, was almost equally active during the two aggregate waves, and this industry continued investing even outsider the waves (in contrast to most other industries). 


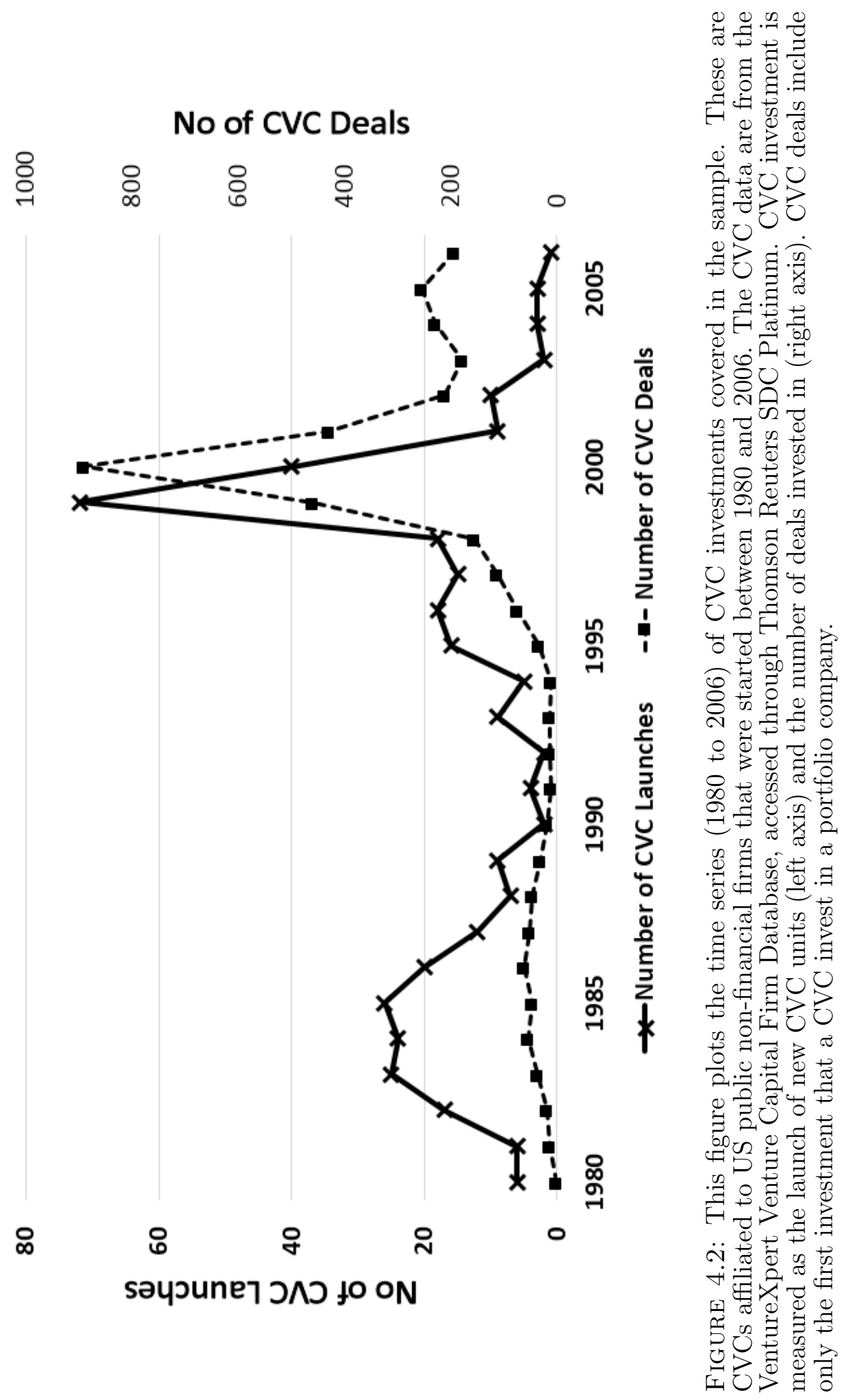



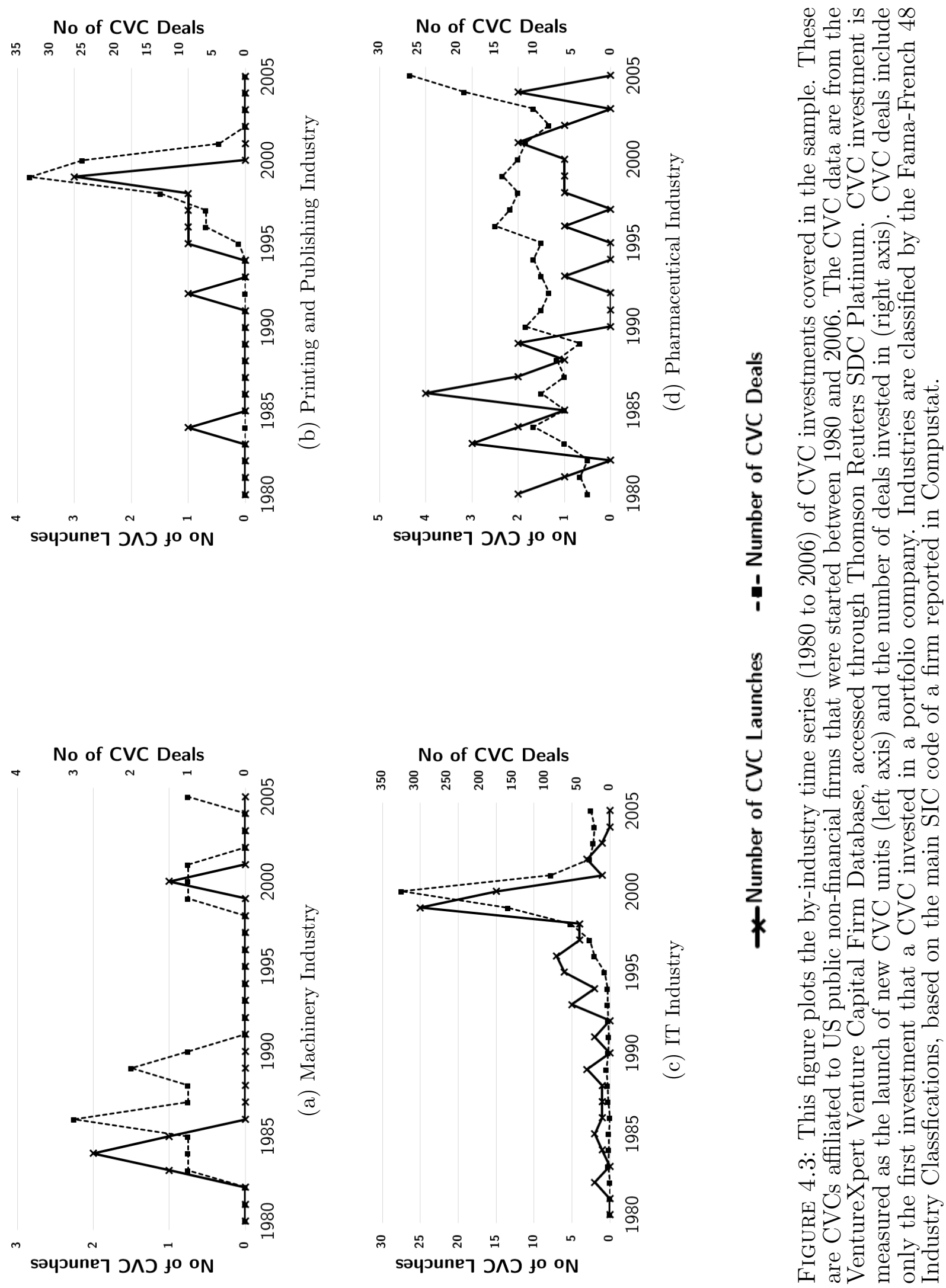
Table 4.4: This table studies the industry clustering in CVC investment on the sample of Corporate Venture Capital (CVC) which are affiliated to US public nonfinancial firms between 1980 and 2006. The CVC data are from VentureXpert Venture Capital Firm Database, accessed through Thomson Reuters SDC Platinum. Panel A compiles all of the industry CVC wave periods, jointly defined using the clustering of launches of CVC units and investment deals made by CVCs. Each wave period is limited to at most four years. Industry is defined using the Fama-French 48 Industry Classification. Panel B lists potential economic and technological changes affecting CVC investment for the important industry CVC wave periods, as discovered in Panel A. The explaining events column is partially motivated by Table 2 in Harford (2005). 


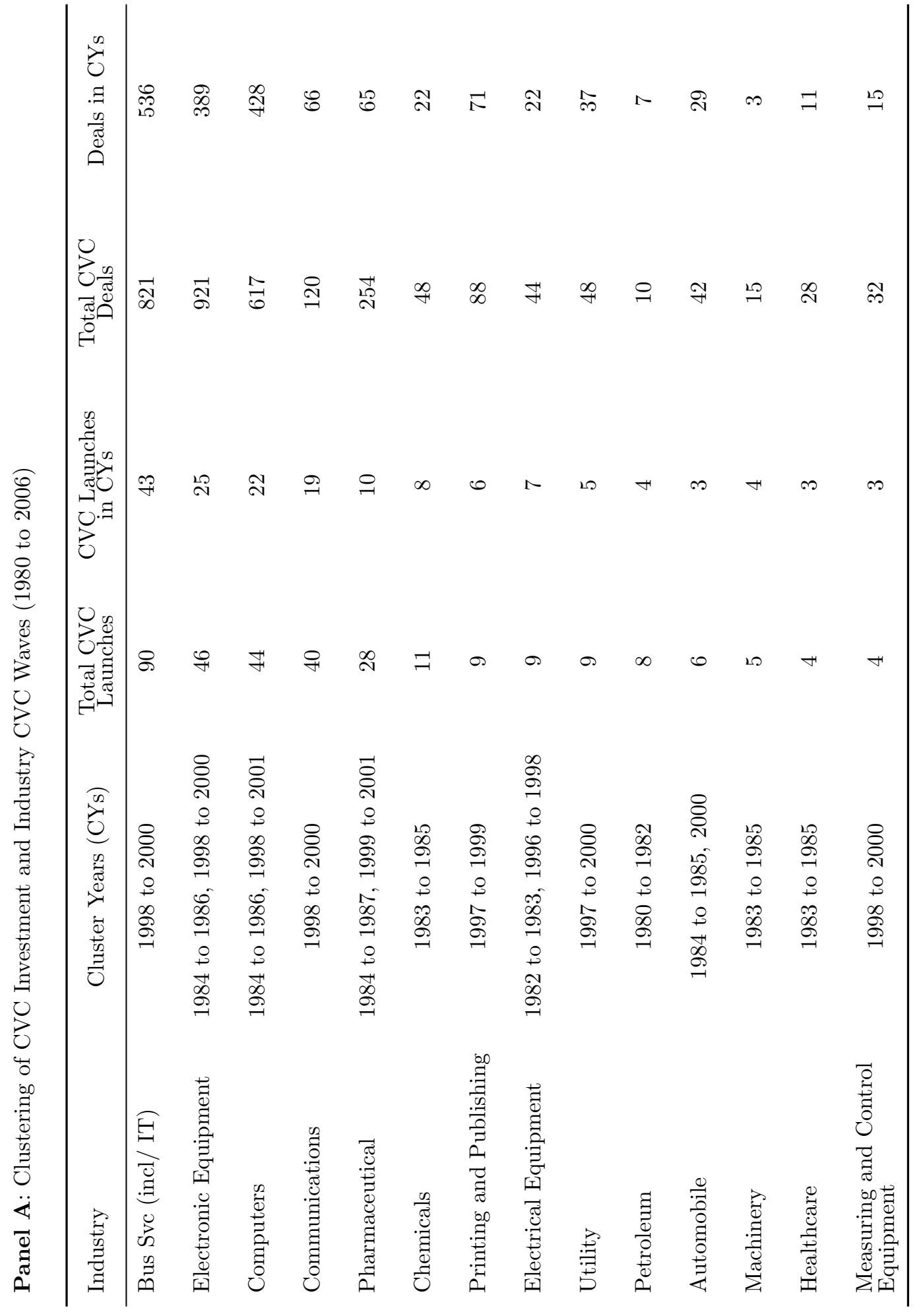




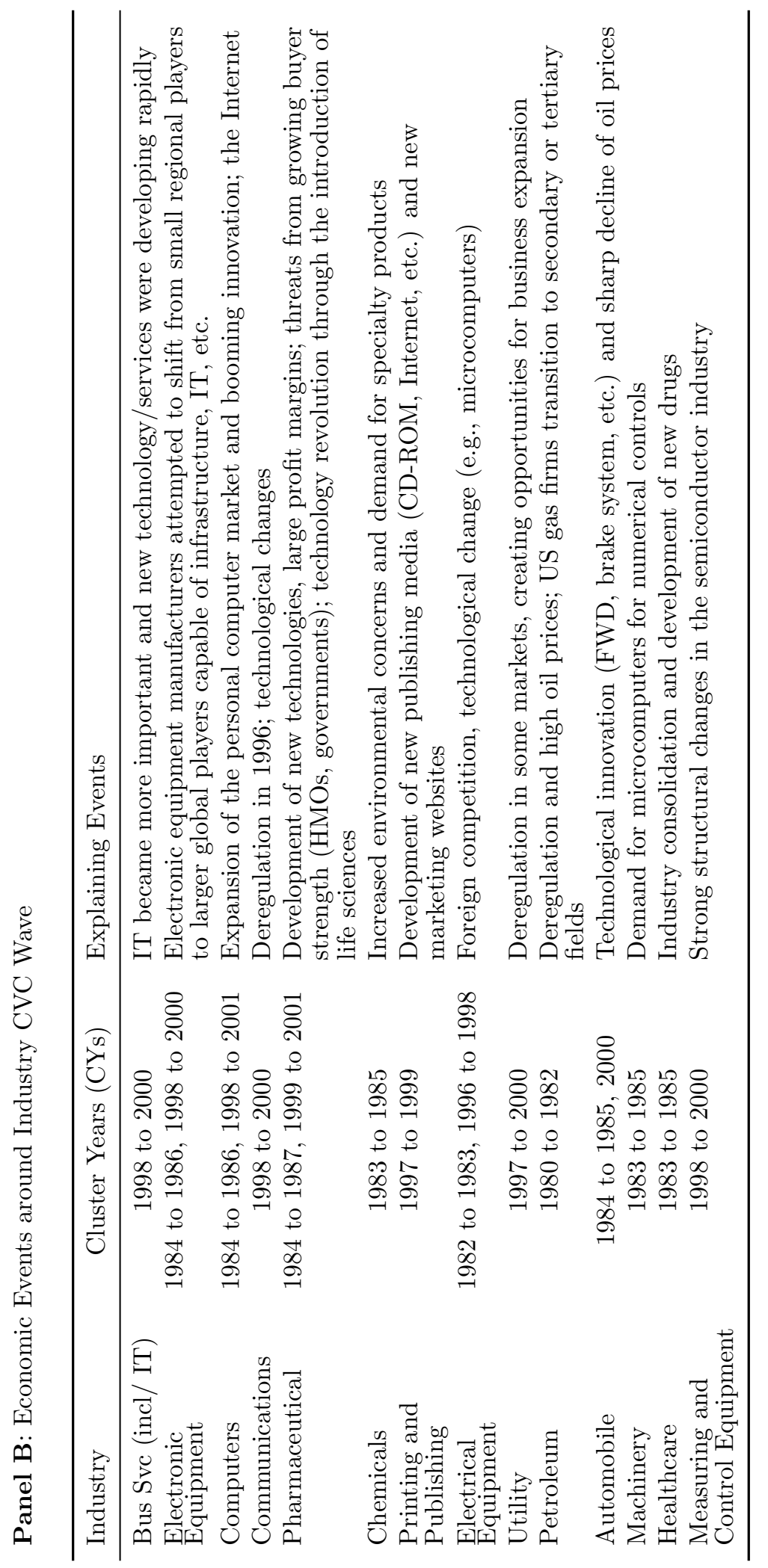


Figure 4.3 suggests that some industry-specific factor motivates firms in the industry to implement Corporate Venture Capital investment simultaneously. Table 4.4 Panel A compiles industry CVC wave periods, jointly defined using the clustering of CVC initiations and investment. I limit each wave period to at most four years. In general, most industries experience at least one wave period and more than $50 \%$ of the CVC investments were made during that short window. For example, printing and publishing firms initiated six CVC units and invested in 71 deals between 1997 and 1999; the total deals made by this industry between 1980 and 2006, however, number just 88. IT firms made most of their CVC investments during the dot-com boom. Pharmaceutical firms have a less clear wave pattern but still had two time windows when they were more active than usual.

\subsection{Additional Economic Forces and Robustness}

Table 4.3 controls the endogeneity problem when establishing the causality between innovation deterioration and the CVC initiation decision. This is consistent with the information acquisition view, which predicts that firms in need of new knowledge are more active in reaching out to the innovative entrepreneurial sector. In this section I discuss additional tests that serve two main purposes - explore the informational motivation further and to study additional economic forces that could affect firms' decision to take the $\mathrm{CVC}$ route.

Technological Uncertainty. I first explore heterogeneous effects of innovation deteriorations on CVC initiations across uncertainty levels that firms face in their informational environment. The working hypothesis is that the impact of innovation deterioration should be stronger when the uncertainty level is higher, that is, when identifying valuable innovation opportunities becomes more difficult and information is therefore more valuable. I estimate an extended model based on the OLS model (4.1) and 2SLS models (4.3) and (4.4). The sample is categorized into two subgroups 
by the median of uncertainty levels of firms' informational environment, indicated by I uncertainty .

The results are reported in Table E.1, which shows that the causal relation between deterioration in innovation and the decision to engage in CVC investment is stronger when there is higher demand to acquire information on new technologies and new markets, favoring the informational rationale behind CVC.

This result cannot be explained by the interpretation that firms make CVC investments before acquiring a new technology, as a way to wait for the uncertainty to resolve. Indeed, CVC investments seldom evolve to acquisition of the portfolio company. Recent studies examine acquisition cases when CVC investors acquire portfolio companies in which they invested (Benson and Ziedonis, 2010; Dimitrova, 2013). In general, the acquisition of portfolio companies is rare -fewer than one-fifth of CVC investors acquired their portfolio companies. CVC units that did conduct such acquisitions acquired fewer than $5 \%$ of their portfolio companies (that is, one out of 20 investments).

Managerial Desperation and Leapfrog Innovation. Early research shows that desperate managers, after experiencing a negative shock, might aggressively seek outside solutions to the deterioration, which typically lead to even worse outcomes (Higgins and Rodriguez, 2006). Therefore, one could reasonably worry that the result simply documents that desperate managers are more likely to conduct CVC investment for leapfrog innovations. I investigate this issue by studying the success rate of the portfolio companies invested by CVCs categorized by the severity of innovation declines at initiation. If the concern is indeed the case, we would expect CVC parents that experienced the largest hit before initiating to have lower performance because they likely made the decision out of desperation. In Table E.2, I find that those CVCs whose parents' performance decline the most actually score a similar, if not higher success rate compared to other CVCs. 
Financial Returns. What is the role of financial condition in firms' decision to operate a CVC? On the one hand, anecdotal cases (e.g., Google, Intel) give us the impression that CVC is an investment channel for cash-rich firms to make equity investments in the startup market. In contrast, the structure and features of CVC investments could lead to the hypothesis that CVC could be poor-man's innovation, that is, declining firms are more financially constrained and cannot conduct internal R\&D or M\&As, which are on average more costly than CVC. In Table E.3, I show that the main result is robust on the subsample of firms whose KZ-index is below the industry median or whose cash-flow ratio is above the industry median (less financially constrained).

More Robustness. To confirm that the results are not driven by the sampling process or specifications, I conduct an array of robustness checks. In the Appendix, I show that: the result is not sensitive to the length used to capture innovation changes ( $\tau=3$ in the paper); the result is robust to removing firms that are large/small, that are from specific industries (such as IT or pharmaceuticals), or that are located in specific locations (in California); and that the result also holds for deteriorations of product market performance such as ROA and growth rate in sales. 


\section{5}

\section{CVC Operations: Select, Acquire, and Integrate Information}

Section 4 presents evidence consistent with the view that the information acquisition motive drives the initiation of the CVC life cycle. To explore the information acquisition view further, this section examines how CVCs select which portfolio companies to acquire valuable information from and identifies the information spillover from those startups to CVC parent firms. Empirically, I construct a comprehensive data set on innovation-related activities in both CVC parents and the entrepreneurial sector. Using this database, I can test the information acquisition view by examining whether CVCs target entrepreneurial companies that could potentially provide higher informational value to the parents, and by tracking the dynamic of incorporating new information into corporate activities within parents.

\subsection{CVC Portfolio Formation}

I start by examining how the selection of portfolio companies reflects the CVC information acquisition rationale. Selecting portfolio companies involves trading off multiple factors that determine the efficiency of information acquisition. The 
first consideration is the technological proximity between the parent firm and a startup. The conceptual idea is that investing in technologically proximate companies facilitates the process of absorbing and integrating information, therefore creating greater informational benefit (Cohen and Levinthal, 1990; Dushnitsky and Lenox, 2005b). The second factor is incremental informational value through investment. Indeed, investing in companies with very similar knowledge sets adds little marginal informational benefit, although it could be efficient for creating synergies (Bena and $\mathrm{Li}, 2014)$. The third determinant is the availability of alternative information acquisition channels. The working hypothesis is that CVC investors should pursue information that would be difficult to acquire without the CVC channel, that is, we should expect CVC investment to concentrate on companies with little informational communication otherwise.

To empirically analyze how CVC parent firms balance these economic forces in selecting portfolio companies, I construct a data set by pairing each $\mathrm{CVC} i$ with each entrepreneurial company $j$ that was ever invested by a VC. I remove cases when the active investment years (between initiation and termination) of CVC firm $i$ and the active financing years of company $j$ (between the first and the last round of $\mathrm{VC}$ financing) do not overlap. I estimate a probability model on this sample to predict the decision of CVC $i$ investing in company $j$, that is,

$$
\begin{aligned}
I_{\left(\text {CVC }_{i} \text { Target }_{j}\right)=\alpha} & +\beta_{1} \times \text { TechProximity }_{i j}+\beta_{2} \times \text { Overlap }_{i j} \\
& +\beta_{3} \times \text { SameC }_{i j}+\gamma \times X_{i, j}+\varepsilon_{i j},
\end{aligned}
$$

where the dependent variable, $I\left(C V C_{i}\right.$-Target $\left.{ }_{j}\right)$, indicates whether CVC $i$ actually invests in company $j$. 


\subsubsection{Measurements}

The key variables of interest in model (5.1) are TechProximity, Overlap, and SameCZ, which capture the informational relation between a CVC parent firm $i$ and an entrepreneurial company $j$, echoing the three potential portfolio determinants outlined above. $^{1}$

The first measure, Technological Proximity (TechProximity), is calculated as the Cosine-similarity between the CVC's and the startup's vectors of patent weights across different technology classes (Jaffe, 1986; Bena and Li, 2014). A higher Technologial Proximity indicates that the pair of firms works in closer areas in the technological space.

The second measure, Knowledge Overlap (Overlap), is calculated as the ratio of-(1) numerator: the cardinality of the set of patents that receive at least one citation from CVC firm $i$ and one citation from entrepreneurial company $j$; and (2) denominator: the cardinality of the set of patents that receive at least one citation from either CVC $i$ or company $j$ (or both). A higher Knowledge Overlap means that the pair of firms shares broader common knowledge in their innovation.

To provide a clean interpretation of the estimation, both Technological Proximity and Knowledge Overlap are measured as of the last year before CVC $i$ and company $j$ both enter the VC-startup community. For example, if firm $i$ initiates the CVC in 1995 but company $j$ obtained its first round of financing in 1998, the measure is constructed using the patent profiles in 1997. The rationale for this criterion is to mitigate the potential interactions between CVCs and startups before investment.

To construct a proxy for the availability of alternative information acquisition channels, I rely on recent studies showing that geographic proximity influences the intensity of knowledge spillover between firms (Jaffe et al., 1993; Peri, 2005). The

1 The Appendix describes the methodology identifying innovation activities of entrepreneurs through merging patent data sets with VentureXpert and defines those variables more formally. 
main variable is a dummy indicating whether CVC firm $i$ and company $j$ are located in the same Commuting Zone (CZ). I use CZ as the geographic delineation because it has been shown that CZ is more relevant for geographic economic activities (Autor, Dorn, and Hanson, 2013; Adelino, Ma, and Robinson, 2016) and innovation spillover (Matray, 2014). Projecting the information acquisition hypothesis on this context,

we should expect that CVCs invest less in companies that are in the same geographic location, from which they could learn through the more inexpensive mechanism of local knowledge spillover.

\subsubsection{Results}

Table 5.1 presents coefficients estimated from model (5.1). In column (1), a positive and significant coefficient means that the Technological Proximity between a CVC and an entrepreneurial company increases the likelihood of CVC deal formation. This result is consistent with the interpretation that CVCs select companies from which they are more capable of absorbing knowledge for their core business.

Column (2) examines the effect of Knowledge Overlap. The negative coefficient means that after conditioning on the technological proximity, CVC parent firms prefer to invest in companies with different knowledge bases. In other words, CVCs select portfolio companies through which they are exposed to more new innovation knowledge. Importantly, this result could potentially distinguish the information acquisition rationale for $\mathrm{CVC}$ with the alternative rationale that $\mathrm{CVC}$ is conducted for product market synergies and asset complementarity. Under non-informational strategic concerns, firms favor targets with both close technological proximity and high knowledge overlap in order to achieve economic synergies (Bena and Li, 2014).

In column (3), I study the effect of alternative information acquisition channels, specifically knowledge spillover, on CVC portfolio selection. The literature on VC, and on investment more broadly, has documented a "home (local) bias" phenomenon- 
Table 5.1: The Selection of CVC Portfolio Companies

This table studies how CVCs strategically select portfolio companies. I construct a cross-sectional data set by pairing each CVC $i$ with each entrepreneurial company $j$ that was ever invested by a Venture Capital investor. I remove cases when the active investment years of CVC firm $i$ (between initiation and termination) and active financing years of company $j$ (between the first and the last round of VC financing) do not overlap. The analysis is performed using the following specification:

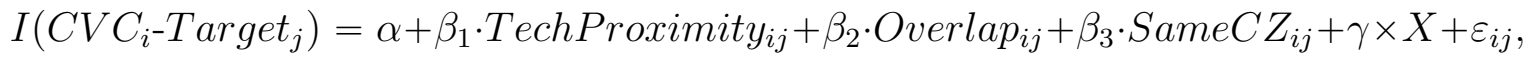

where the dependent variable, $I\left(C V C_{i}\right.$-Target $\left.{ }_{j}\right)$, is equal to one if CVC $i$ actually invests in company $j$, and zero otherwise. Technological Proximity is calculated as the Cosine-similarity between the CVC's and startup's vectors of patent weighting across different technological classes (Jaffe, 1986; Bena and Li, 2014). Knowledge Overlap is calculated as the ratio of the cardinality of the set of patents that receive at least one citation from CVC firm $i$ and one citation from the entrepreneurial company $j$, and the cardinality of the set of patents that receive at least one citation from either CVC $i$ or company $j$ (or both). Geographical distance is measured using a dummy variable if the CVC firm $i$ and company $j$ are located in the same Commuting Zone $(\mathrm{CZ})$, $I($ Same $C Z)$. The Appendix defines those variables more formally. In order to provide a clean interpretation of the estimation, both Technological Similarity and Knowledge Overlap are measured as of the last year before CVC $i$ and company $j$ both enter the VC-startup community, and the goal is to mitigate the potential interaction between them in the VC-startup community. Fixed effects at CVC firm and entrepreneurial company level are included. T-statistics are shown in parentheses and standard errors are clustered by CVC firm. *, **, *** denote statistical significance at the $10 \%, 5 \%$, and $1 \%$ levels, respectively.

\begin{tabular}{lccc}
\hline & $(1)$ & $(2)$ & $(3)$ \\
& \multicolumn{3}{c}{$I\left(C V C_{i}\right.$-Target $\left._{j}\right)$} \\
\cline { 2 - 4 } Technological Closeness & & & \\
Technological Proximity & $0.029^{* *}$ & $0.039^{* *}$ & $0.035^{* *}$ \\
& $(2.020)$ & $(1.969)$ & $(2.358)$ \\
Knowledge Overlap & & $-0.018^{*}$ & $-0.014^{* *}$ \\
& & $(-1.756)$ & $(-2.169)$ \\
Geographical Closeness & & & \\
\hline I(SameCZ) & & & $-0.008^{* * *}$ \\
& & & $(-2.818)$ \\
Observations & & & \\
R-squared & 868,323 & 868,323 & 847,102 \\
CVC FE & 0.129 & 0.129 & 0.130 \\
Portfolio Company FE & Yes & Yes & Yes \\
\hline
\end{tabular}


when investing in companies that are geographically closer, investors can better resolve the information asymmetry problem and conduct more efficient monitoring (Da Rin, Hellmann, and Puri, 2011). In column (3), however, I find that CVCs do not really invest in their "home" companies. The dummy variable indicating that the CVC and the startup are located in the same Commuting Zone negatively affects the probability of investment, which is consistent with the explanation that CVC parent firms can acquire information from startups in the same CZ through local innovation spillover (Matray, 2014), which decreases the marginal benefit of making a CVC investment in them.

Overall, Table 5.1 shows that CVCs strategically select information sources and invest in companies from which they could acquire beneficial information. They invest in companies that work in similar technological areas and possess knowledge new to the parent firm. They are less likely to invest in companies located in the same geographic areas from which they could gain information through inexpensive local knowledge spillover.

\subsection{Internalizing Acquired Information}

The rationale of information acquisition for CVC investment is convincing only if CVC parents can use newly gathered information to improve their operations. Several economic frictions could hinder CVCs from gathering and integrating information from startups, challenging the information acquisition rationale. Hellmann (2002) theoretically shows that entrepreneurs could intentionally avoid CVC investment to protect their innovation. Dushnitsky and Lenox (2005b) and Kim, Gopal, and Hoberg (2013) argue that the absorptive ability (Cohen and Levinthal, 1990) of CVC parent firms imposes a limit on the knowledge transferred through the relationship. Gompers and Lerner (2000) suggest that the efficiency of CVC is constrained by the incentive problem embedded in its organizational and compensation structure. In addition, 
high adjustment costs of R\&D investment (Hall, Griliches, and Hausman, 1986; Lach and Schankerman, 1989) can decrease the speed and intensity of the integration of new knowledge acquired through CVC.

Showing how information is incorporated into corporate decisions can be challenging due to the invisible nature of information. In this subsection, I undertake two empirical settings to study how information acquired through CVC influences the parent firm. First, following the literature that uses patent citations as a measure of knowledge spillover (Gomes-Casseres et al., 2006), I study how CVC parent firms internalize acquired information into organic $R \& D$ by tracking patent citations made to their portfolio companies. I then switch to another setting where I look at the efficiency of corporate decisions in which the acquired information could be crucial.

\subsubsection{Internal Research and Development}

I identify the specific information flow from portfolio companies that is further incorporated into parents' internal innovative activities. Empirically, I follow the economic literature on knowledge spillover (Jaffe and Trajtenberg, 2002), ${ }^{2}$ and estimate whether CVC parent firm $i$ makes new citations to startup company $j$ 's patents or knowledge after the CVC invests in the startup, using the following model:

$$
\begin{aligned}
\text { Cite }_{i j t}=\alpha & +\beta \cdot I(\text { CVCParent }) \times I(\text { Post }) \times I(\text { Portfolio }) \\
& +\Phi[I(\text { CVCParent }), I(\text { Post }), I(\text { Portfolio })]+\varepsilon_{i j t} .
\end{aligned}
$$

To control for observed characteristics of CVC parents that could influence their behaviors in citing entrepreneurial companies, I construct a tighter control group for those firms. I use a propensity score matching method and match each CVC parent firm $i$ that launches its CVC unit with two non-CVC firms from its CVC launch year and 2-digit SIC industry that has the closest propensity score estimated using firm

2 Alcacer and Gittelman (2006) and Gomes-Casseres et al. (2006), among others, discuss the advantages and potential pitfalls in using this approach. 
size (the logarithm of total assets), market-to-book ratio, $\Delta$ Innovation, and patent stock, ${ }^{3}$ similar to the sample construction strategy in Bena and Li (2014). The CVC launching year for a CVC parent firm is also the "pseudo-CVC" year for its matched firms.

Observations are at the $i$ - $j$-t level. The full set of $i-j$ pairs then denotes the potential information flow that could happen between a CVC parent firm (or a matched firm) and a startup, captured by patent citations. I(CVCParent $)$ is a dummy variable indicating whether firm $i$ is a CVC parent or a matched control firm. $I$ (Portfolio) indicates whether company $j$ is in the CVC portfolio of firm $i$. For each $i$ - $j$ pair, two observations are constructed, one for the five-year window before firm $i$ invests in company $j$, and one for the five-year window after the investment. ${ }^{4} I$ (Post) indicates whether the observation is within the five-year post-investment window. The dependent variable, Cite $_{i j t}$, indicates whether firm $i$ makes new citations to company $j$ 's innovation knowledge during the corresponding time period.

The key variable of interest, $I(C V C$ Parent $) \times I($ Post $) \times I($ Portfolio $)$, captures the incremental intensity of integrating a portfolio company's innovation knowledge into organic innovation after a CVC invests in the company. Table 5.2 column (1) shows the regression results. The coefficient of 0.159 , means that the citing probability increases by $15.9 \%$ after establishing the link through CVC investment.

\footnotetext{
3 Patent stock is constructed as the total number of patents applied for by the firm up to year $t-1$.

4 A matched control firm is assumed to have the same investment history as the CVC parent firm to which it is matched to.
} 
Table 5.2: Direct Information Acquisition from Portfolio Companies

This table studies the direct information acquisition of CVC parent firms from their portfolio companies by investigating how investing in an entrepreneurial company affects the CVC parent firm's possibility of innovating based on the entrepreneurial company's innovation. I first identify all the patents applied by a CVC parent firm (or a matched control firm) $i$, and all the patents cited by those patents. I then identify all the patents applied by an entrepreneurial company $j$. These data further allow me to determine whether firm $i$ makes a new citation, which it never cited before, to a patent that is possessed by company $j$. The analysis is performed based on the following framework:

$$
\begin{aligned}
\text { Cite }_{i j t}=\alpha & +\beta \cdot I(C V C \text { Parent }) \times I(\text { Post }) \times I(\text { Portfolio }) \\
& +\Phi[I(C \text { C Parent }), I(\text { Post }), I(\text { Portfolio })]+\varepsilon_{i j t} .
\end{aligned}
$$

The sample is at the $i$ - $j$ - $t$ level. The full set of $i$ - $j$ pairs then denotes the potential information flow that could happen between a CVC parent firm (or a matched firm) and a startup, captured by patent citations. I(CVCParent) is a dummy variable indicating whether firm $i$ is a CVC parent or a matched control firm. I(Portfolio) indicates whether company $j$ is in the CVC portfolio of firm $i$. For each $i-j$ pair, two observations are constructed, one for the five-year window before firm $i$ invests in company $j$, and one for the five-year window after the investment. I(Post) indicates whether the observation is within the five-year post-investment window. The dependent variable, Cite $_{i j t}$, indicates whether firm $i$ makes new citations to company $j$ 's innovation knowledge during the corresponding time period. The key variable of interest, $I(C V C$ Parent $) \times I($ Post $) \times I($ Portfolio $)$, captures the incremental intensity of integrating a portfolio company's innovation knowledge into organic innovation after a CVC invests in the company. Column (1) reports the result. Column (3) performs an analysis similar to that in column (1) except that it estimates the probability that a CVC parent firm cites not only patents owned by the startup but also patents previously cited by the startup. In other words, the potential citation now covers a broader technological area that the startup works in. Columns (2) and (4) separately estimate the intensity of citing knowledge possessed by companies that either exit successfully (acquired or publicly listed) or fail at last. All specifications include fixed effects imposing analysis across firms in the same industry and same year of (pseudo-) launching their CVC programs to absorb time-variant industrial technological trends. T-statistics are shown in parentheses and standard errors are clustered by firm. * $*^{* *}, * * *$ denote statistical significance at the $10 \%, 5 \%$, and $1 \%$ levels, respectively. 


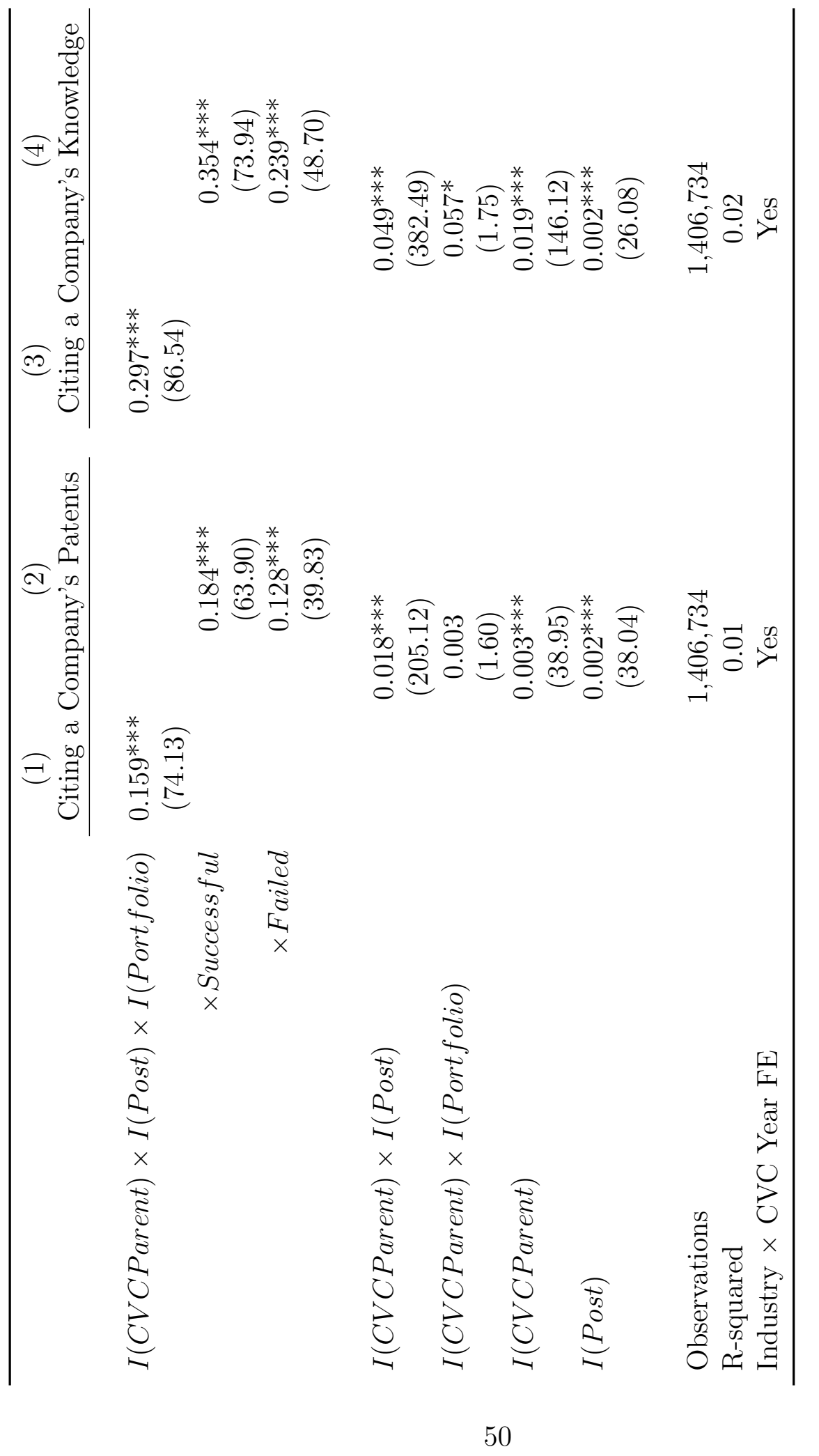


I further explore the depth of information acquisition from portfolio companies. Specifically, in column (3), I perform an analysis similar to that in column (1) except that I look at the probability that a CVC parent firm cites not only patents owned by the startup but also patents previously cited by the startup. In other words, the potential citation now covers the broader technological area that the startup works in. Column (3) extends the message conveyed in column (1) - CVC parent firms not only cite the portfolio company's own patents, but also benefit from the knowledge indirectly carried by portfolio companies, reaching to the broader knowledge behind.

Does information acquisition concentrate only on successful investment? I explore this question by modifying model (5.2) and separately estimate the intensity of citing knowledge possessed by companies that either exit successfully (acquired or publicly listed) or fail at last. The result is reported in columns (2) and (4), and it appears that CVC parents acquire knowledge from both successful and failed ventures.

\subsubsection{Using Information through External Acquisitions}

Here I explore an alternative channel through which firms could benefit from CVCacquired information - acquiring external innovation. Acquiring innovation has become an important component of corporate innovation (Bena and Li, 2014; Seru, 2014), and identifying promising acquisition targets (companies or innovation) requires a valuable information set, such as great understanding of markets and technological trends. Under the information acquisition hypothesis, CVC-acquired information allows parent firms to form more precise expectations of acquisition deals, thereby improving efficiencies when making such decisions. ${ }^{5}$

I first study how efficiently CVC parent firms conduct acquisitions of companies. Following the literature, acquisition efficiency is measured using three-day, five-day,

${ }^{5}$ Those acquisitions are not necessarily limited to their CVC portfolio companies and can reach a broader domain using the general innovation and industry knowledge they learn from CVC experience. 
and seven-day cumulative abnormal returns (CAR) of an acquisition deal centered on the acquisition announcement day. The analysis is performed on a cross section of M\&A deals conducted by CVCs and their matched control firms between five years before and five years after (pseudo-) CVC initiations, and the unit of observation is an acquisition deal. The key variable of interest is the difference-in-differences variable $I(C \text { VCParent })_{i} \times I(\text { Post })_{i, t}$, indicating whether the acquirer $i$ is within five years after launching its CVC division. If firms could conduct more efficient external acquisitions based on the information gathered from CVC investment, one would expect the abnormal announcement returns to be higher for these deals.

Table 5.3: Integration of CVC-Acquired Information through External Acquisitions This table studies the efficiency of acquiring companies or innovation around the start of CVC investment. The analysis is based on the following standard difference-in-differences (DiD) framework:

$y_{i, t}=\alpha_{F E}+\beta \cdot I(C \text { V CParent })_{i} \times I(\text { Post })_{i, t}+\beta^{\prime} \cdot I(\text { CVCParent })_{i}+\beta^{\prime \prime} \cdot I(\text { Post })_{i, t}+\gamma \times X_{i, t}+\varepsilon_{i, t}$.

The sample consists of acquisition deals (Panel A) and patent purchases (Panel B) conducted by CVCs and their matched control firms during five years before CVC initiations and five years after CVC initiations, and the unit of observation is an acquisition deal (Panel A) and a patent purchase (Panel B). The sample consists of CVCs and their propensity score-matched firms. The dependent variables $y_{i, t}$ are cumulative abnormal returns (CARs) for acquisition of companies (Panel A) and annual citation growth for purchases of patents (Panel B). I(CVCParent $)_{i}$ is a dummy variable indicating whether firm $i$ is a CVC parent or a matched control firm. $I(\text { Post })_{i, t}$ indicates whether the firm-year observation is within the $[t+1, t+5]$ window after (pseudo-) CVC initiations. The model includes industry-by-year fixed effects $\alpha_{\text {industry } x t}$. Firm-level control variables include ROA, size (logarithm of total assets), leverage, and $R \& D$ ratio ( $R \& D$ expenditures scaled by total assets). T-statistics are shown in parentheses and standard errors are clustered by firm. ${ }^{*}, * *, * * *$ denote statistical significance at the $10 \%, 5 \%$, and $1 \%$ levels, respectively. 


\begin{tabular}{lccc}
\hline Panel A: Abnormal Returns when Acquiring Companies (in basis points) & \\
& $(1)$ & $(2)$ & $(3)$ \\
& $C A R[-1,+1]$ & $C A R[-2,+2]$ & $C A R[-3,+3]$ \\
\cline { 2 - 4 }$I($ CVCParent $) \times I($ Post $)$ & $65.811^{*}$ & $131.378^{* *}$ & $135.693^{*}$ \\
& $(1.697)$ & $(2.164)$ & $(1.765)$ \\
$I($ CVCParent $)$ & -55.009 & -46.766 & -185.444 \\
& $(-0.575)$ & $(-0.385)$ & $(-1.510)$ \\
I(Post $)$ & 11.615 & 23.546 & 16.984 \\
& $(0.120)$ & $(0.208)$ & $(0.134)$ \\
Observations & & & \\
R-squared & 1,502 & 1,502 & 1,502 \\
Controls & 0.272 & 0.275 & 0.281 \\
Industry $\times$ Year FE & Yes & Yes & Yes \\
\hline
\end{tabular}

\begin{tabular}{lccc}
\hline Panel B: Citation Growth after Purchasing Patents & $(2)$ & $(3)$ \\
& $\Delta$ Citation $[-1,+1]$ & $\Delta$ Citation $[-2,+2]$ & $\Delta$ Citation $[-3,+3]$ \\
\cline { 2 - 4 }$I($ CVCParent $) \times I$ (Post) & $0.200^{* * *}$ & $0.607^{* * *}$ & $1.358^{* * *}$ \\
& $(3.112)$ & $(3.805)$ & $(6.121)$ \\
$I($ CVCParent $)$ & -0.023 & -0.097 & -0.095 \\
& $(-0.177)$ & $(-1.081)$ & $(-1.007)$ \\
$I($ Post $)$ & 0.015 & 0.040 & 0.108 \\
& $(0.375)$ & $(0.395)$ & $(0.764)$ \\
Observations & & & \\
R-squared & 43,874 & 39,167 & 32,254 \\
Controls & 0.045 & 0.093 & 0.082 \\
Industry $\times$ Year FE & Yes & Yes & Yes \\
\hline
\end{tabular}

Table 5.3 Panel A presents the result. Columns (1) to (3) examine three-day, five-day, and seven-day CAR (in basis points, bps), respectively. The positive and significant coefficients across all three columns confirm that firms conduct more successful external acquisitions as they internalize the information acquired through their CVC investment. Quantitatively, compared to their industry peers, acquisitions made by CVC parent firms experience a 65 bps improvement in the three-day abnormal return from one day before the announcement to one day after the announcement, and a greater than 130 bps increase in abnormal return during the $[-3,3]$ window.

To study how CVC-acquired information is capitalized through acquisitions of 
innovation, I compile a detailed data set on firms' acquisition of patents (either "company and patents" or "patents only"). The database on patent transactions is based on USPTO patent assignment files, hosted by Google Patents. This database provides useful information for identifying patent transactions: the assignment date; the participating parties, including the assignee - the "buyer" in a transactionand the assignor - the "seller" in a transaction; and comments on the reason for the assignment. To gather additional information on the original assignee and patent technology classes, I merge the raw assignment data with the USPTO patent databases, and with the HBS inventor database. I then follow a procedure, based on Serrano (2010) and Akcigit, Celik, and Greenwood (2013), in which I separate patent transactions from all patent reassignment records, that is, I remove reassignments associated with cases such as a patent transfer from the employee inventor to the employer firm, or a patent transfer between different subsidiaries of a firm. A more detailed description of the data and methodology is provided in the Appendix.

I perform the analysis on the sample of patent purchases conducted by CVC parent firms and their control firms, and the unit of observation is a patent transaction. ${ }^{6}$ The dependent variable is calculated as the citation growth from the $n$-year $(n=1,2,3)$ period before the patent transaction to the same length after the transaction. ${ }^{7}$ This variable intends to capture whether the purchased patents better fit the buyer than the seller, thereby signaling a more efficient transaction. As in Panel A, the key variable of interest is the difference-in-differences term $I(C \text { VCParent })_{i} \times I(\text { Post })_{i, t}$, indicating whether the patent buyer $i$ is within five years after launching its CVC division. If firms could capitalize the information learned from CVC by conducting more efficient

6 To be clear, some patents are transacted under one "deal," and I necessarily treat each of them as one individual observation.

7 For example, when $n=3, \Delta$ Citation $[-3,+3]$ is calculated as total citations received by the transacted patent from one year to three years after the transaction minus total citations received from three years to one year before the transaction. 
patent purchases, one would expect a positive coefficient to be associated with the difference-in-differences term.

In Panel B of Table 5.3, I report the citation growth around patent transactions. The positive coefficient in column (1), 0.200, means that, after benchmarked by patent transactions conducted by their matched control firms and pre-CVC transactions, patents purchased by CVC parent firms receive on average 0.2 more citations during the first year under the new owner than the last year under the old owner. Column (2) uses a two-year horizon to calculate citation increases, and the economic magnitude increases to 0.607. Column (3) shows an amplified result due to a three-year horizon.

It is worth discussing the economic interpretation behind this spike in citations after CVC firms' patent transactions. In principle, a spike in citations indicates that the underlying patent becomes increasingly visible and popular, plausibly because it better fits the overall innovation profile of the new owner or is commercialized more successfully after the transaction. Specifically in this context, such a particularly strong increase in citations is consistent with the interpretation that CVC parent firms acquire innovation that is in turn better commercialized and made visible to the industry.

\subsection{Human Capital Renewal and Information Acquisition}

Evidence thus far suggests that CVC parent firms devote effort to integrating and using information acquired from the entrepreneurial sector. Identifying, processing, and integrating new information is difficult; how do CVC parents accomplish this task? I identify one important channel that CVC parents actively manage: human capital renewal. Indeed, inventors, usually highly educated scientists and engineers, are key in absorbing, processing, and using information to produce innovation. Recent studies also find that firms actively reallocate innovative human resources to spur innovation and adjust the scope of innovation (Lacetera, Cockburn, and Henderson, 
2004; Bernstein, 2015; Brav, Jiang, Ma, and Tian, 2016). In this section, I explore the role of inventors in facilitating knowledge gathering and use.

I rely on the Harvard Business School patenting database for inventor-level information. ${ }^{8}$ This database includes unique inventor identifiers that are constructed based on a refined disambiguation algorithm employing multiple characteristics (Lai, D'Amour, and Fleming, 2009). After matching inventors to employer firms, I track the employment history and annual patenting activities of each inventor. ${ }^{9}$ Using a criterion similar to that in Bernstein (2015) and Brav et al. (2016), I identify the number of inventors who leave the company and the number of inventors who are newly hired in each year.

8 Available at: http://dvn.iq.harvard.edu/dvn/dv/patent.

${ }^{9}$ One limitation of this analysis is that we detect inventor mobility conditional on new patent filings; the observed mobility is thus associated with inventors who patent more frequently. But at any rate, these people should be those who are economically more important to the firm. See Bernstein (2015) for a detailed discussion of the limitations associated with this database. 


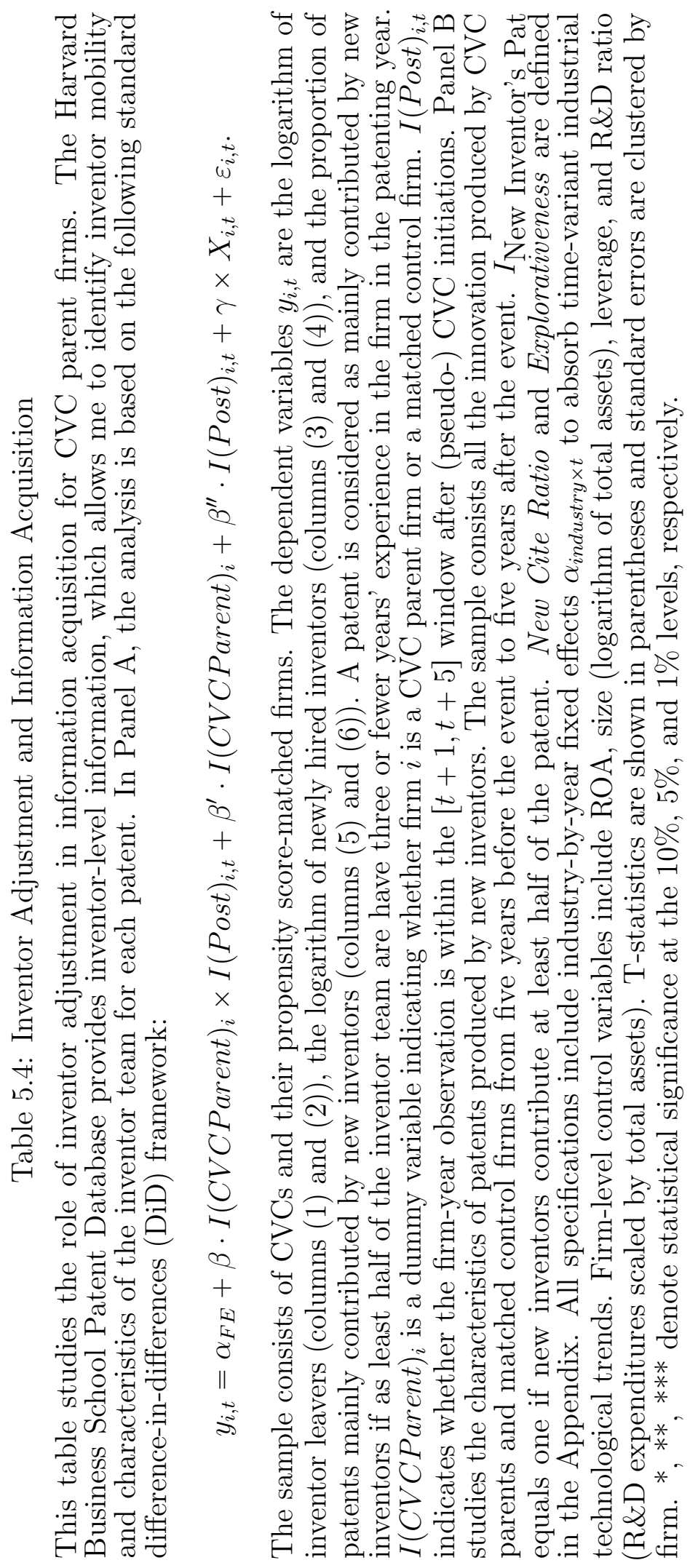




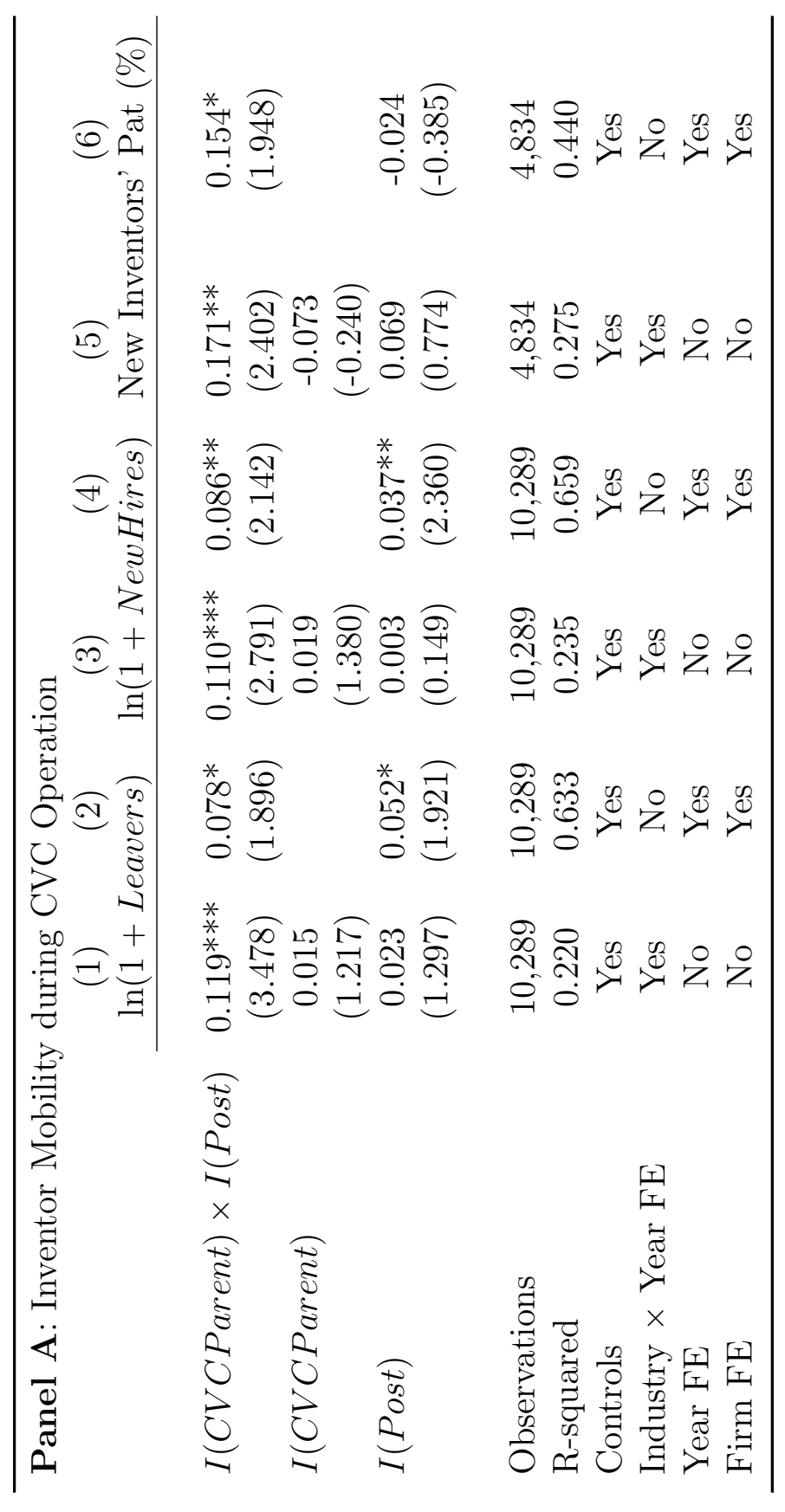




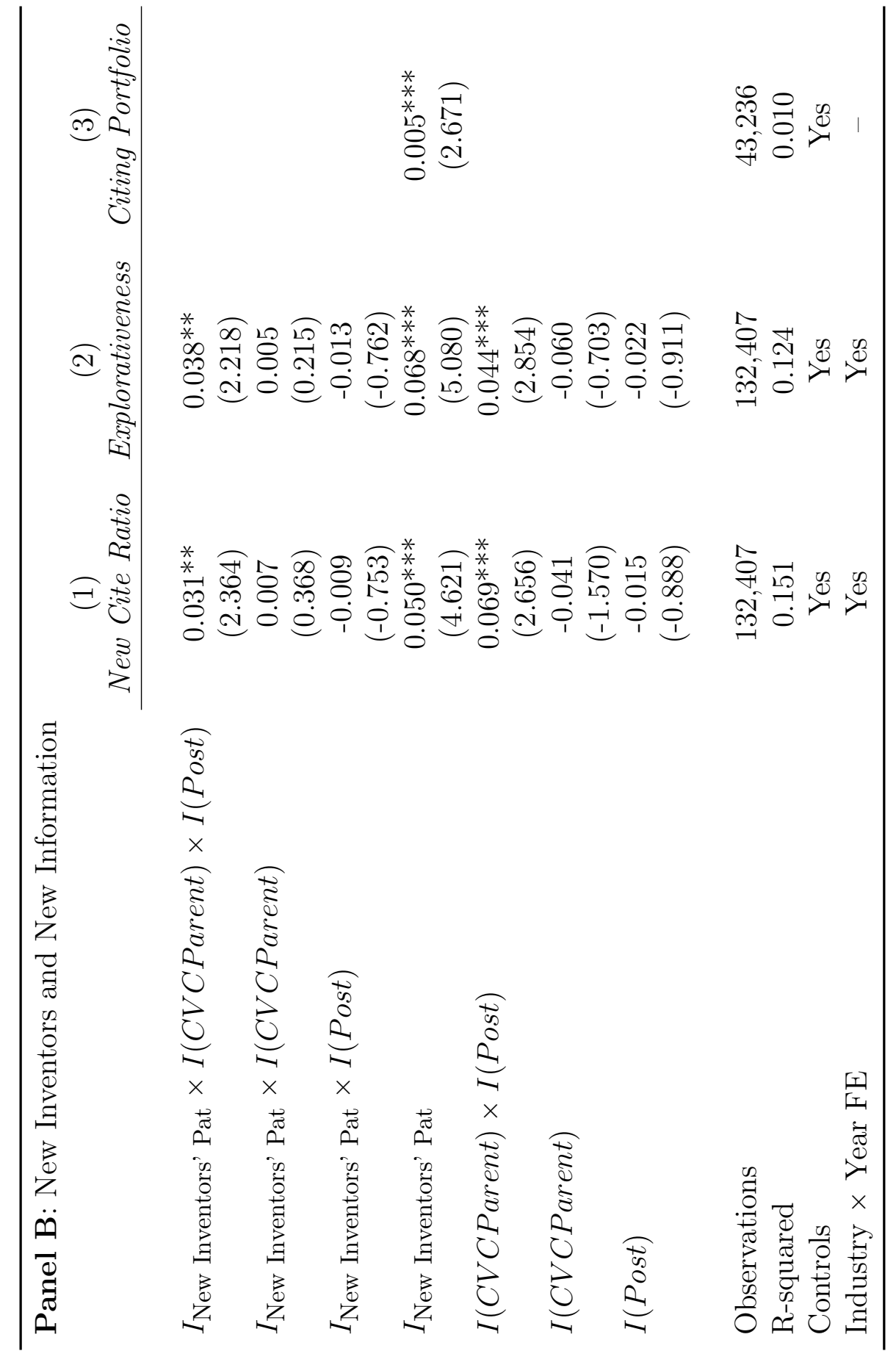


I start by examining the intensity of human resource adjustment around the years of initiating CVC investment. The analysis is performed on the same firm-year panel of CVC firms and their propensity score-matched controls. In Table 5.4 Panel A, I study the number of inventors leaving the firm (columns (1) and (2)) and the number of inventors newly hired by the firm (columns (3) and (4)). The coefficient, 0.119 in column (1), can be interpreted as showing that CVC parent firms have $11.9 \%$ more inventors leaving the firm (leavers) than in the period before CVC investment. The vacancies created by leavers are filled by newly hired inventors; the 0.110 estimated in column (3) means that CVC parents hire about $11 \%$ more new inventors compared to the years before CVC investment, benchmarked by their industry peers.

In columns (5) and (6), I examine the proportion of patents mainly contributed by inventors new to the firm. A patent is considered as "mainly contributed by new inventors" if at least half of the patent's inventor team have three or fewer years of patenting experience in the firm as of the patent application year. The positive coefficient of $17.1 \%$ in column (5) means that CVC parent firms rely more heavily on new inventors when operating a CVC, consistent with the proposition that firms hire new inventors to process new information and produce innovation.

Table 5.4 Panel B presents new inventors' intensity of incorporating new knowledge. The patent-level sample consists of all the patents produced by CVC parent firms and their matched control firms from five years before the event to five years after it. Beyond the standard terms $I(C \text { VCParents })_{i}$ and $I(\text { Post })_{i, t}$, I introduce an indicator

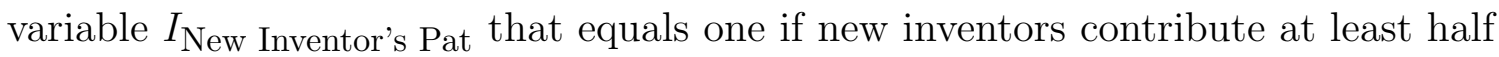
of the patent and zero otherwise. The unconditional effect of $I_{\text {New Inventor's Pat }}$ is positive, meaning that patents produced by firms' new inventors typically incorporate more knowledge new to the firm. Meanwhile, the interaction term $I(C V C$ Parents $) \times$ $I$ (Post) is associated with higher New Cite Ratio and Explorativeness, consistent with Table E.7. A key result in this table is the positive coefficient in front of the 
triple difference $I_{\text {New Inventors' Pat }} \times I(C$ VCParent $) \times I($ Post $)$, which implies that new inventors in CVC parent firms concentrate more heavily on processing and integrating new information and innovation knowledge. In column (3), I focus on the sample of all patents produced by CVC parent firms during the five-year window after CVC initiation (that is, $I(C V C$ Parents $)=I($ Post $)=1)$ and find that newly hired inventors are more likely to use knowledge acquired from CVC portfolio companies in their new innovation. 


\section{6 \\ CVC Terminations: Staying Power and Investment Dynamics}

In a frictionless world, CVC parents would want to keep investing in CVC to acquire information from entrepreneurs. With frictions, however, CVC could become less appealing as the parent firm's internal innovation recovers. For example, a capacityconstrained firm will allocate less resources to information acquisition yet more to innovation production once the internal innovation becomes more premising (Nelson, 1982; Jovanovic and Rob, 1989). In addition, the cannibalization concern (Arrow, 1962) will disincentivize innovative incumbents to search for newer ideas that will replace the existing ones, and this effect could be particularly large, with high adjustment cost and organizational complexity. Overall, as firms assimilate information into their innovation decisions and begin to have an upward innovation trajectory, the benefit of keeping a standalone CVC unit shrinks. In this scenario, CVC investment may fade out as internal innovation recovers and firms devote more resources to this regained innovation path. This section examines this implication of the information acquisition hypothesis by focusing on the termination stage of the CVC life cycle. 
The analysis provides further opportunities to distinguish the important strategic motivation behind $\mathrm{CVC}$ investment. Under alternative $\mathrm{CVC}$ rationales, $\mathrm{CVC}$ remains advantageous in organizing innovation due to its superior ability to obtain asset complementarity (Hellmann, 2002), motivate entrepreneurs (Aghion and Tirole, 1994; Chemmanur, Loutskina, and Tian, 2014), and obtain competitive advantages (Mathews, 2006; Fulghieri and Sevilir, 2009). Even though these studies focus primarily on static trade-offs and do not concern intertemporal dynamics, they implicitly imply that firms might invest persistently in CVCs for long periods of time.

\subsection{The Staying Power of Corporate Venture Capital}

I start by examining the staying power of Corporate Venture Capital. To do so, it is necessary to define the date of terminating each CVC unit, which is not widely disclosed. When this termination date is not available, I define it as the date of the CVC's last investment in a portfolio company. As a result, the staying power analysis could underestimate the duration of CVCs, particularly toward the end of the sample. To mitigate bias, I categorize a CVC unit as "active" if its last investment happened after 2012 (as of March 2015) and VentureXpert codes its investment status as "Actively seeking new investments," and I exclude those active CVCs from the analysis. The duration of a CVC cycle is calculated as the period between the initiation and termination of the division.

Table 6.1 tabulates the duration of CVC divisions. The median duration of a CVC is four years, and a significant portion (46\%) of CVCs actively invest for three years or less, ${ }^{1}$ lending support to the argument that the benefit from CVC investment shrinks as information is assimilated. However, $27 \%$ of firms operate CVCs for a long period (more than 10 years). To understand why this is so, I report the median number of

1 They certainly could interact with their portfolio companies for longer periods of time after terminating incremental investment. 
total and longest consecutive years that a CVC is put into hibernation, defined as a year when no incremental investment was made. When the CVC duration is short, the years between initiation and termination are mostly active. As their duration increases, an increasing proportion of years are under hibernation. When I examine these hibernation periods, I find a pattern of consecutive hibernating years - for example, CVCs with eight-year durations have a median of four years of consecutive hibernation. In other words, these CVCs typically have a lengthy pause in their CVC experience, bridging two shorter active periods of investment. 


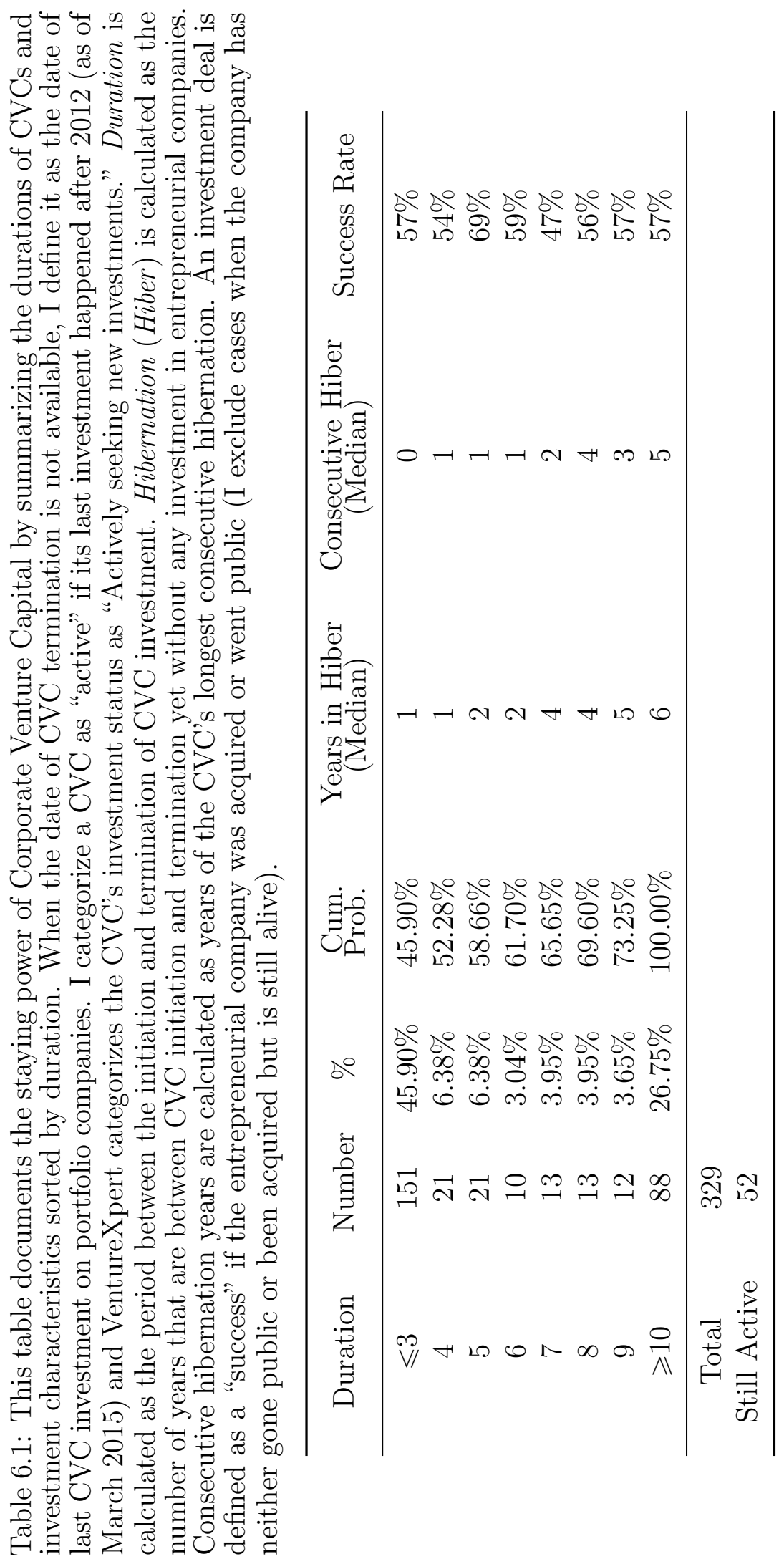


One might conclude that the short average CVC life cycle indicates that some CVC parent firms are incompetent in the VC business and thus terminate their CVC divisions too quickly. To rule out this concern, in the last column of Table 6.1, I calculate the success rate of deals invested by CVCs categorized by CVC durations. An investment deal is defined as a "success" if the entrepreneurial company was acquired or went public (I exclude cases when the company is still alive without a successful exit). Success rates of investments do not correlate with CVC duration, inconsistent with the idea of CVC incompetence.

\subsection{Innovation Improvements and CVC Termination}

What determines the termination and hibernation of CVCs? To echo Table 4.2, which shows that innovation deterioration motivates CVC initiations, I conclude my analysis of the CVC life cycle by examining corporate innovation at termination. Table 6.2 Panel A performs simple statistical tests that compare innovation levels at the initiation and termination of the CVC life cycle. The analysis is performed on all CVCs that can be assigned a termination date (upper panel) and on the subgroup that stayed in business for at least five years. When examining the industry-year adjusted innovation measures, we observe statistically significant improvements at the CVC termination point compared to the initiation stage.

I exploit a hazard model to statistically relate innovation improvements and the decision to terminate a CVC. A CVC parent firm enters the sample in the year of CVC initiation. The key variable of interest is $\Delta$ Innovation, which measures the difference between innovation level in year $t$ and that of the initiation year. The result is shown in columns (1) and (2) of Table 6.2 Panel B. The positive and significant coefficients mean that larger improvements of innovation from the initiation year motivate parent firms to terminate CVC investment.

To capture how innovation improvements affect the decision to put CVC into 
Table 6.2: This table studies the decision to terminate Corporate Venture Capital. Panel A examines average innovation improvement through the CVC life cycle by comparing innovation performance at CVC initiation and CVC termination (definition as in Table 6.1). Innovation performance is measured using innovation quantity and quality, and both are adjusted using the industry (3-digit SIC level) peers in the same year. I also report the $t$-statistics for the differences in means between the two time points. $*, * *, * * *$ denote statistical significance at the $10 \%, 5 \%$, and $1 \%$ levels, respectively. The analysis is performed on all CVCs with a disclosed or defined termination date and the subgroup that lasts for at least five years.

Panel B studies the effect of innovation improvement on CVC termination and investment decisions. The regressions are performed on the panel of CVC sample in their active years. The key variable $\Delta$ Innovation $_{i, t}$ is defined as the difference of innovation between year $t$ and the year of initiation. In columns (1) and (2), the dependent variable is a CVC termination dummy, and the specification is estimated using a Hazard model. In columns (3) and (4), the dependent variable is the annual number of investments in portfolio companies, and the model is estimated using Ordinary Least Squares (OLS). Firm-level control variables include ROA, size (logarithm of total assets), leverage, and $\mathrm{R} \& \mathrm{D}$ ratio ( $\mathrm{R} \& \mathrm{D}$ expenditures scaled by total assets). $*, * *, * * *$ denote statistical significance at the $10 \%, 5 \%$, and $1 \%$ levels, respectively.

Panel A: Innovation at CVC Initiation and Termination

\begin{tabular}{lcccc} 
All & Initiation-Mean & Exit-Mean & Difference & T-Stat \\
\cline { 2 - 5 } Adjusted $\ln ($ NewPatent $)$ & 0.75 & 0.91 & 0.16 & $2.18^{* *}$ \\
Adjusted $\ln ($ Pat.Quality $)$ & -0.03 & 0.23 & 0.26 & $1.90^{*}$ \\
\hline
\end{tabular}

\begin{tabular}{lcccc}
\hline Duration $\geqslant \mathbf{5}$ & Initiation-Mean & Exit-Mean & Difference & T-Stat \\
\cline { 2 - 5 } Adjusted $\ln ($ NewPatent $)$ & 0.79 & 1.03 & 0.24 & $2.43^{* *}$ \\
Adjusted $\ln ($ Pat.Quality $)$ & -0.05 & 0.43 & 0.48 & $2.57^{* *}$ \\
\hline
\end{tabular}

Panel B: Innovation CVC Exit and Investment

(1) Hazard of Termination $0.355^{* * *}$

$$
\begin{aligned}
& \Delta \ln (\text { NewPatent }) \\
& \Delta \ln (\text { Pat.Quality })
\end{aligned}
$$

Controls

Observations

Log-likelihood

R-squared
$(2)$

(3) Number of New CVC Deals

(4) $-2.291^{* * *}$ $0.276^{* * *}$

\begin{tabular}{cccc} 
Yes & Yes & Yes & Yes \\
2,489 & 2,489 & 2,489 & 2,489 \\
-697.86 & -363.88 & & \\
& & 0.127 & 0.128 \\
\hline
\end{tabular}


hibernation, I investigate the intensive margin of CVC investment - the number of portfolio companies a CVC invests in each year and the key variables of interests, $\Delta$ Innovation, are defined as above. Columns (3) and (4) present the results, and the findings are consistent with columns (1) and (2)-innovation improvements are associated with a lower level of CVC activities.

Overall, Table 6.2 matches the finding at the initiation stage, and is consistent with the information acquisition hypothesis, which predicts that when firms regain their upward trajectory in corporate innovation, the marginal informational benefit of CVC shrinks, which in turn leads to the termination or hibernation of the CVC unit. 


\section{Conclusion and Literature Revisited}

How do corporations finance and manage their innovation process in the pursuit of long-term growth? This paper sheds light on this fundamental question by studying an emerging economic phenomenon, Corporate Venture Capital (CVC). Armed with an identification strategy that allows me to isolate firm-specific innovation shocks, I find that firms launch CVC programs following a deterioration in innovation, and their main motivation is to acquire information and innovation knowledge from the entrepreneurial sector. This information acquisition rationale leads me to characterize the life-cycle dynamics of CVC - evolving through the initiation, operation, and termination stages - in which CVC parent firms strategically select information sources (portfolio companies), actively integrate newly acquired information into corporate decisions, and terminate CVCs when the informational benefit diminishes.

Beyond establishing the CVC life cycle and the information acquisition rationale behind these activities, the paper is a stepping stone toward understanding several broad economic questions.

Organizing Innovation. This paper joins the endeavor to understand the architecture of innovation and contributes to this literature by suggesting three areas 
for future work. First, more research should be done to achieve a better understanding of details in CVC operations. Second, the information acquisition motive behind organizing innovation, which I highlight in this paper, has been largely overlooked in the literature (Tirole, 2010) but is worth further exploration. Third, the interaction between CVC investment and alternative organizational forms considered here calls for future studies that could consider the system of organizing innovation as a whole by seriously incorporating the interactions among different organizational structures and a dynamic intertemporal scope.

Information Economics. Information is important in all areas of finance, yet information choices have been hard to study both in asset pricing and in corporate finance, either theoretically or empirically (Van Nieuwerburgh and Veldkamp, 2010). Empirical work on corporate decisions regarding information management is especially limited by the unobservability of related behaviors. By examining the CVC life cycle, this paper obtains several results regarding information acquisition and use that are hard to show under alternative settings. Future work could explore the CVC setting to answer more questions at the intersection of information economics and corporate finance.

Creative Destruction. In broader terms, this paper provides new evidence concerning the co-movement of entrepreneurship, creative destruction, and economic growth. Entrepreneurial companies and incumbent firms differ in their ability to develop radical and disruptive innovation and to capture new investment opportunities (Hall, 1993; Henderson, 1993; Jensen, 1993; Adelino, Ma, and Robinson, 2016; Acemoglu and Cao, 2015), and this difference generates the creative destruction momentum. By highlighting $\mathrm{CVC}$ as an effective incumbent-entrepreneur bridge, this paper essentially suggests that the two seemingly disentangled sectors could be closely intertwined, which in turn affects both micro-level corporate behaviors and the aggregate process of creative destruction. 


\section{Appendix A}

\section{Background Reading on Corporate Venture Capital}

\section{A.1 What Is (not) Corporate Venture Capital?}

Corporate Venture Capital (CVC) is the investment of corporate funds directly in external startup companies (Chesbrough, 2002), usually in the form of minority equity investment (Gompers and Lerner, 2000) made through organized and systematic effort (Ivanov and Xie, 2010). In practice, a CVC parent initiates CVC business by launching a unit (formally or informally), which manages CVC investment for the firm.

In addition to the definition above, it is helpful to describe CVC by explaining what it is not. When a corporation funds an external fund managed by a third party and effectively works as a limited partner, it is usually not considered as a CVC. CVC is also distinctive from strategic alliances or joint ventures in which two or multiple parties reach an agreement to pursue a set of agreed-upon objectives; in contrast, CVC is an investment-based relationship without specific objectives, and the investment amount is significantly smaller. In essence, it is best to think of CVC as a subset of Venture Capital whereby an established firm is systematically investing, 
without using a third-party investment firm, in an external, early-stage startup that it does not own or control.

CVC is typically organized as a normal corporate division rather than a traditional VC fund. First, capital sourced to a CVC is almost $100 \%$ from its corporate parent (either the headquarters or related business units); more than $60 \%$ do not have a fixed amount and fund is allocated on deal-by-deal basis (like capital budgeting). Second, most CVCs have a corporate mission, and more than two-thirds of them report directly to the corporate headquarter. Third, CVC executives are typically compensated through traditional corporate schemes such as salary or bonus, and rarely via carried interests or schemes similar to carried interests.

\section{A.2 Economic Motivation and Operation: Survey Evidence}

In Macmillan et al. (2008), a survey jointly conducted by the National Venture Capital Association, the Wharton School, and the MIT Sloan School, CVC practitioners provide rich evidence that can be seen as supporting the information acquisition hypothesis behind CVC investment. ${ }^{1}$

In response to a question regarding the important strategic aims of CVC investment, $100 \%$ of the respondents agreed on the importance of "CVC provides window on new technology," 54\% considering it extremely important. Ninety-sic percent agreed on CVC's advantages in "providing window on new markets." When asked about the specific use of new information accessed through CVC investment, Corporate Venture Capitalists responded: "seek new directions" (92\%), "develop new products" (90\%), and "supporting existing businesses" (94\%).

To fulfill the role of acquiring technological and market knowledge from entrepreneurial companies, CVCs are organized and operated to bridge their corporate parents with their portfolio startups. On the one hand, CVCs actively interact with

\footnotetext{
${ }^{1}$ I urge interested readers to refer to the original report.
} 
portfolio companies by taking board seats. More than $75 \%$ of CVCs frequently take board seats in their portfolio companies, and two-thirds always take a seat. These board seats are as often non-voting board observers rather than as voting board members. On the other hand, CVCs communicate with business units within their parent firm that are relevant to their CVC portfolio companies - $98 \%$ CVCs involve $\mathrm{R} \& \mathrm{D}$ or business development personnel in their operation, and $64 \%$ intensely do so.

\section{A.3 Acquiring Portfolio Companies}

Information acquisition through CVCs seldom evolves into asset consolidation (i.e., acquisition of the portfolio companies). Recent studies examine acquisition cases when CVC investors acquire portfolio companies in which they invested (Benson and Ziedonis, 2010; Dimitrova, 2013). In general, acquiring portfolio companies is rare-fewer than one-fifth of CVC investors acquired their portfolio companies. CVCs that did conduct such acquisitions acquired fewer than $5 \%$ of their portfolio companies (that is, one out of 20 investments). In another tabulation, acquiring portfolio companies constitute about $16 \%$ of all the acquisitions conducted by those CVC investors.

Interestingly, Benson and Ziedonis (2010) show that acquiring portfolio companies destroys shareholder value, because the market usually reacts negatively to such deals. Dimitrova (2013) shows that CVC parents acquire portfolio companies when their innovation productivity is low and that those acquisitions on average signal poor future innovation prospects. In broader terms, these findings are consistent with the information acquisition rationale proposed in this paper - the main benefit of CVC investment is from acquiring information from not specific assets of, portfolio companies. 


\section{A.4 Macromedia: An Illustrative Case}

As an illustration of Corporate Venture Capital, consider Macromedia Ventures, a CVC unit launched in early 2000 by Macromedia, Inc., a California-based graphics and web development software company. In the late 1990s, the firm experienced a downturn in its traditional area of media-design authoring software. It therefore laid out a blueprint to explore new technologies on the market such as Internet-based tools and services, and the CVC unit was an integral part of the blueprint. Macromedia Ventures was organized as an internal division of Macromedia, Inc., and invested in entrepreneurial companies on behalf of its corporate parent. Within two years of CVC initiation, Macromedia Ventures had invested in nine companies (12 rounds in total), covering Internet-based technologies such as online distribution and mobile solutions. The reason behind the CVC investment, declared by Rob Burgess, then Chairman and CEO of Macromedia, "Macromedia already delivers products that define the cutting edge of the Internet, but it is in our best interest to tap the entrepreneurial innovation going on around us, given the pace of the Internet."

The short period for conducting CVC investment was important for Macromedia, because it enabled the firm to recover from its deteriorated condition and firmly establish itself as a successful web firm. The selected portfolio companies guided and facilitated the redevelopment of Macromedia's product lines and future business models. For instance, Macromedia Ventures invested in Alterego Networks, a developer of enterprise web services that is an innovative extension of Macromedia's technology, and AtomFilms, an innovative online short-film distributer that facilitated Macromedia's extension to online entertainment services. Some other portfolio companies were also successful. 


\section{Appendix B}

\section{Instrument Obsolescence}

This appendix provides more discussions on the instrument Obsolescence, which is used in the paper to shock corporate innovation.

\section{B.1 The Conceptual Idea and Its Roots}

The proposition that knowledge obsolescence affects innovation has its roots in four basic observations.

First, knowledge begets knowledge. Isaac Newton said, "If I have seen further it is by standing on ye sholders of Giants." Indeed, the knowledge stock of an innovative individual or institution determines the quantity and quality of their innovation and knowledge production. This observation has been formalized and discussed in several strands of literature (see Jones (2009) and the papers cited therein).

Second, knowledge ages. Since the 1950s, several disciplines have developed the concept of the obsolescence of knowledge/skills/technology. The most famous result might be, roughly speaking, that half of our knowledge today will be of little value (or even proven wrong) after a certain amount of time (half-life), and this half-life is 
becoming shorter and shorter (Machlup, 1962). In economics, people have studied the effect of obsolescence of knowledge and skills on labor, industrial organization as well as the aggregate growth (Rosen, 1975).

Third, predicting knowledge trends is difficult, if not impossible. Even though mathematicians and bibliometricians have been developing mathematical models to fit the half-life dynamics of the overall knowledge stock, predicting the trend for each specific stock has not been successful. Indeed, it is this "impossibility" that creates the possibility of creative destruction and the fading of generations of firms.

Fourth, knowledge absorption can be difficult and slow. For any individual and institution, knowledge can be identified, absorbed, and managed at a limited rate. Even for firms, which have the option to replace human capital (innovators), the adjustment costs and uncertainty associated with the matching process limits their ability to do so.

Based on these observations, Obsolescence proxies for a shock to the value and usefulness of knowledge possessed by each firm, which in turn affects innovation performance of the firm. Following Newton's storyline, when a firm is already on the shoulder of a standing Giant, the measure captures a shock to the height of the Giant (to make the Giant sit or jump, for example), and this shock exogenously determines how far the firm can see.

\section{B.2 Variable Construction}

The instrument, Obsolescence, attempts to capture an exogenous technological variation that is independent of a firm's recent operations but influences the firm's innovation performance. For each firm $i$ in year $t$, this instrument is constructed in three steps. First, I define firm $i$ 's predetermined knowledge space in year $t-\tau$ as all the patents cited by firm $i$ (but not belonging to $i$ ) up to year $t-\tau$. Then, I calculate the number of citations received by this KnowledgeSpace $_{i, t-\tau}$ in $t-\tau$ 
and in $t$, respectively. Last, Obsolescence ${ }_{i, t}^{\tau}$ is defined as the change between the two, and a more negative Obsolescence means a larger decline of the value of a firm's knowledge:

Obsolescence $_{i, t}^{\tau}=-\left[\ln \left(\right.\right.$ Cit $_{t}\left(\right.$ KnowledgeSpace $\left.\left._{i, t-\tau}\right)\right)-\ln \left(\right.$ Cit $_{t-\tau}\left(\right.$ KnowledgeSpace $\left.\left.\left._{i, t-\tau}\right)\right)\right]$.

Simply put, this instrument first defines the knowledge space of a firm by incorporating detailed information on the firm's innovation profile and citation history ("tree") and then measures the rate of obsolescence using exogenous citation dynamics to this knowledge space.

It is worth discussing the validity of the exclusion restriction for using this instrument in the CVC study. Generally speaking, the validity of this approach rests on the assumption that, controlling for industry-specific technological trends and firm-specific characteristics, the measured obsolescence of a firm's knowledge space predetermined years ago is orthogonal to its current CVC strategy other than through affecting current innovation performance.

- One might worry that a firm's knowledge space might be affected by the type and capability of managers, yet this concern should be allayed by using a predetermined knowledge space formed along the corporate history rather than the concurrent one.

- One might also worry that the firm itself could be the main driver of the technological evolution. This concern is addressed first by excluding patents owned by the firm from its own knowledge space and excluding all citations made by the firm itself in the variable construction. It is further mitigated by a robustness check on a subsample of medium and small firms, which are less likely to endogenize technological evolution. 


\section{B.3 A Simple Illustrative Example Using the Instrument}

To illustrate how the instrumental variable can correct the estimation bias raising from the endogeneity problem, I describe the following simple example. ${ }^{1}$ Assume that a firm's probability of launching a CVC unit is determined by an unconditional probability and a incremental probability determined by $\Delta$ Innovation realized in the near past, formulated as $P_{C V C}+q \cdot \Delta$ Innovation. $P_{C V C}$ stands for the unconditional probability of CVC initiations, and $\Delta$ Innovation is a dummy indicating whether the firm experienced an innovation increase $(\Delta$ Innovation $=1)$ or an innovation deterioration $(\Delta$ Innovation $=-1)$. I make $\Delta$ Innovation a binary dummy to simplify the illustration.

Suppose that the unconditional probability of launching a CVC is heterogeneous and is correlated with $\Delta$ Innovation in some endogenous way (e.g., manager type could be driving both at the same time). Specifically, assume that there are three types of firms based on their ability to innovate: High-type firms are on a upward trajectory innovation $(\Delta$ Innovation $=1$ unconditionally $)$ and have an unconditional probability of launching CVC $P_{C V C}=p_{H}$. Sensitive-type firms are sensitive to technological evolution and will have $\Delta$ Innovation $=1(-1)$ if the technology trend works in favor of (against) them, and these firms have a type-specific CVC probability of $P_{C V C}=p_{M}$. Low-type firms are in a struggling situation ( $\Delta$ Innovation $=-1$ unconditionally) and $P_{C V C}=p_{L}$. For simplicity, assume that the knowledge obsolescence will be either favorable or disruptive to the firm each with probability $50 \%$, and each firm type is with probability $1 / 3$. In the table below, we can summarize the probability of initiating a CVC unit in the six possible cases:

1 This example is based on Bennedsen, Pérez-González, and Wolfenzon (2010) and Bernstein (2015). 
Table B.1: A Simple Illustrative Example Using the Instrument

\begin{tabular}{l|cc}
\hline \multirow{2}{*}{ Firm Type } & \multicolumn{2}{|c}{ Obsolescence } \\
\hline High & Favorable & Disruptive \\
& $\Delta$ Innovation $=1$ & $\Delta$ Innovation $=1$ \\
Sensitive & $p_{H}+q$ & $p_{H}+q$ \\
& $\Delta$ Innovation $=1$ & $\Delta$ Innovation $=-1$ \\
& $p_{M}+q$ & $p_{M}-q$ \\
Low & $\Delta$ Innovation $=-1$ & $\Delta$ Innovation $=-1$ \\
& $p_{L}-q$ & $p_{L}-q$ \\
\hline
\end{tabular}

The OLS estimates essentially compare firms that experience an innovation increase $(\Delta$ Innovation $=1$, the upper left triangle $)$ with the firms that experience an innovation deterioration ( $\Delta$ Innovation $=-1$, the bottom right triangle), and the result reflects both the "treatment effect" and the selection bias (from the heterogeneity of $\left.P_{C V C}\right)$ :

$$
\begin{aligned}
\beta_{O L S} & =\frac{1}{1-(-1)} \times\{E[Y \mid \Delta \text { Innovation }=1]-E[Y \mid \Delta \text { Innovation }=-1]\} \\
& =q+\frac{1}{3} \times\left(p_{H}-p_{L}\right) .
\end{aligned}
$$

The bias term, $(1 / 3) \times\left(p_{H}-p_{L}\right)$, could be either positive or negative based on the assumption on the order of $\left\{p_{H}, p_{M}, p_{L}\right\}$. On the one hand, if we assume that bad governance could be driving both innovation decline and CVC initiation, then $p_{L}>p_{H}$ and $\beta_{O L S}$ is more negative than the true effect $q$. On the other hand, if we assume that forward-looking managers could be driving both innovation improvements and CVC business, then $p_{L}<p_{H}$ and $\beta_{O L S}$ is more positive than $q$. The true size of the bias is hard to ascertain under this framework.

The IV approach uses the exogenous variation in Obsolescence, which affects $\Delta$ Innovation, to help back out the true $q$. The "first-stage" regression captures the 
effect of Obsolescence on $\Delta$ Innovation:

$$
\frac{1}{1-(-1)} \times\{E[\Delta \text { Innovation } \mid \text { Favorable }]-E[\Delta \text { Innovation } \mid \text { Disruptive }]\}=\frac{1}{3} .
$$

The reduced-form estimates the effect of Obsolescence on CVC activities, in the form of:

$$
\frac{1}{1-(-1)} \times\{E[Y \mid \text { Favorable }]-E[Y \mid \text { Disruptive }]\}=\frac{1}{3} q
$$

The IV estimate is the ratio between the reduced-form and the first-stage estimates, that is,

$$
\beta_{I V}=\frac{E[Y \mid \text { Favorable }]-E[Y \mid \text { Disruptive }]}{E[\Delta \text { Innovation } \mid \text { Favorable }]-E[\Delta \text { Innovation } \mid \text { Disruptive }]}=q .
$$

To conclude this example, I wish to highlight two points. First, as shown in the derivation, the IV approach essentially uses only the "Sensitive" group to estimate the true $q$, or, in technical terms, the estimation relies on the "Local Average Treatment Effect (LATE)" based on the "compliers" (the observations that are responsive to the instrument). Second, both $\Delta$ Innovation and Obsolescence take binary values in this example for simplicity. Obviously, those two variables both take continuous value in the data - the example's derivation can be extended to this case by weighting-average the estimates along the support of the instrument. 


\section{Appendix $\mathrm{C}$}

\section{Merging VentureXpert with Patent Databases}

In this section, I describe the process to merge entrepreneurial companies in VentrueXpert database with USPTO patent databases, through matching company names in VentureXpert with assignee names in the USPTO patent database. To minimize potential problems introduced by the minor discrepancy between different versions of the USPTO database, I use both NBER and Harvard Business School (HBS) patent databases to provide patent assignee information. After this step, each company in VentureXpert will have its original name, standardized name and a stem name; similar for USPTO assignees.

\section{C.1 Name Standardization}

I begin by standardizing company names in VentureXpert and assignee names from NBER and HBS patent database, using the name standardization algorithm developed by the NBER Patent Data Project. This algorithm standardizes common company prefixes and suffixes, strips names of punctuation and capitalization; it also isolates a company's stem name (the main body of the company name) excluding these prefixes 
and suffixes.

\section{C.2 The Matching Procedure}

With these standardized and stem company (assignee) names and demographic information provided by both VentureXpert and USPTO, I merge the databases following the matching procedures below:

1. Each standardized VentureXpert company name is matched with standardized names from the NBER data and HBS data.

(a) If an exact match is identified, I consider this as a "successful match." The company is removed from the set of names waiting to be matched on both sides.

(b) Otherwise, next step.

2. Each stem VentreXpert company name is matched with stem names from the NBER data and HBS data.

(a) If an exact match of stem names if identified, and the two companies are located in the same city and state OR the two comapnies are located in the same state and the earliest patenting year in NBER and HBS databases is later than the founding year in VentureXpert, I consider this as a "successful match." The company is removed from the set of names waiting to be matched on both sides.

(b) If an exact match of stem names is identified, but the two companies do not satisfy the location and chronology criterions above, I consider this as a "potential match." The company is moved to a pool of firms waiting for manual checks. 
(c) Otherwise, next step.

3. For the remaining companies, each stem VentureXpert company name is matched with up to 3 close stem names from the USPTO data using a fuzzymatching method based on the Levenshtein edit distance. ${ }^{1}$ The criterion is based on the length of the strings and the Levenshtein distance, and the threshold is determined through a random sampling procedure.

(a) If the fuzzy-matched pair is located in the same city and state OR the two comapnies are located in the same state and the earliest patenting year in NBER and HBS databases is later than the founding year in VentureXpert, I consider this as a "potential match."

(b) Otherwise, the companies are categorized as "failed to match."

4. The "potential matches" set identified in the procedures above are reviewed by hand, incorporating information from both data sources, including full patent abstracts, and company business descriptions.

(a) Pairs confirmed as successful matches through the manual check are moved to the "successful match" set.

1 The Levenshtein edit distance measures the degree of proximity between two strings, and corresponds to the number of substitutions, deletions or insertions needed to transform one string into the other one (and vice versa). 


\section{Appendix D}

\section{Identifying Patent Transactions}

This appendix provides a detailed description of the method used to identify patent transactions. I first introduce the raw dataset on patent assignments and then present the methodology used to identify patent transactions. Specifically, patent assignments other than transfers from an inventor to the firm she works at or from a subsidiary to its corporate parent.

\section{D.1 Data Sources}

I begin with the raw patent assignment database, downloaded from the United States Patent and Trademark Office (USPTO) patent assignment files, hosted by Google Patents. A patent assignment is the transfer of (part of) an owner's property right in a given patent or patents, and any applications for such patents. The patent transfer may occur on its own or as part of a larger asset sale or purchase. These files contain all records of assignments made to U.S. patents from the late 1970s. The original files are then parsed and combined to serve as the starting raw dataset, including all patents assigned from an inventor to the firm, from a firm to an inventor, from one 
inventor (firm) to another inventor (firm).

I make use of the following information for the purpose of identifying patent transactions. First, in regards to patent assignment information, I retrieve information on the assignment date, the participating parties, including the assignee - the "buyer" in a transaction - and the assignor - the "seller" in a transaction, and comments on the reason for the assignment. Some important reasons include assignment of assignor's interest, security agreement, merger, and change of names. Second, in regards to patent information, I retrieve information on patent application and grant dates, identification numbers (patent number and application number), and patent title. I then merge the raw assignment data with the USPTO patent databases so as to gather additional information on the original assignee and patent technology classes. I also combine the dataset with the inventor level data maintained at Harvard Business School (HBS), which allows me to identify the inventor(s) of any given patent. Since I focus on utility patents, I remove entries regarding design patents.

Next, I standardize the names of the assignee and assignor in the raw patent assignment dataset, patent original assignee names reported in the USPTO databases, and inventor names in HBS inventor database. Specifically, I employ the name standardization algorithm developed by the NBER Patent Data Project. This algorithm standardizes common company prefixes and suffixes, strips names of punctuation and capitalization and it also isolates a company's stem name (the main body of the company name), excluding these prefixes and suffixes. I keep only assignment records of which the assignment brief is included under "assignment of assignor's interest" or "Merger," that is, I remove cases when the reason for the assignment is clearly not transactions such as a "change of names." 


\section{D.2 Identifying Patent Transactions}

The central part of the identification of a patent transaction uses several basic principles that predict how patent transactions appear in the data. First, the first assignment in a patent's history is less likely to be a patent transaction. It is more likely to be an original assignment to the inventing firm. Note that this principle is more helpful on patents granted after 1980, when the raw dataset started to be systematically updated. Second, if an assignment record regards only one patent with the brief reason being "assignment of assignor's interest," it is less likely to be a transaction, as it should be rare that two parties transact only one patent in a deal (see Serrano (2010)). Third, if the assignor of an assignment is the inventor of the patent, it is less likely that this assignment is a transaction, but instead more likely to be an employee inventor who assigns the patent to her employer. Fourth, if both the assignor and assignee are corporations, it is likely that this assignment is a transaction, with the exception that the patent is transferred within a large corporation (from a subsidiary to the parent, or between subsidiaries). Based on these principles, the algorithm below is a process in which I remove cases which are unlikely to be patent transactions. The steps I take are:

1. Check if the assignment record date coincides with the original grant date of the patent (the date when the patent was first issued). If it does I label the assignment as a "non-transaction" and it is removed from the data set. Otherwise, I move to step 2.

2. Check whether the patent assignment record contains only one patent, and is the first record for this patent, with assignment of assignor's interest as the assignment reason. If the answer is affirmative I move to Step 3. Otherwise, the record is labeled as a potential transaction and I move to Step 4. 
3. Compare the assignee in the assignment record with the assignee as of the original patent assignment in the USPTO. Similarly, compare the assignor in the assignment record with the inventor names in HBS patent database. If the assignee name coincides, or, the assignor is the patent inventor(s) plus the assignee is a firm, I then categorize the assignment as a "non-transaction" and it is removed from the dataset. This constraint covers cases when either the assignee or assignor have slightly different names across different databases. Otherwise, the record is labeled as a potential transaction and I move to Step 4.

4. Perform the analysis described in step 3 on the "potential transactions" with one minor change: when comparing the assignee in the assignment record with the assignee as of the original patent assignment in USPTO, and when comparing the assignor in the assignment record with the inventor names in HBS patent database, I allow for spelling errors captured by Levenshtein edit distance less or equal to $10 \%$ of the average length of the two strings under comparison, and I denote these name as roughly equal to each other. Then, if the assignee name roughly coincides, or the assignor is roughly the patent inventor(s) plus the assignee is a firm, then assignment is categorized as a "non-transaction" and is removed from the data set. Otherwise, the record is kept as a "potential transaction" and I move to Step 5.

5. Compare the standardized names and stem names of the assignee and assignor of records in the "potential transactions." If the names coincide, this is consistent with an internal transfer and the record is labeled as a "non-transaction." If the names do not coincide the record is labeled as a "transaction." 


\section{Appendix E}

\section{Supplementary Discussions and Results}

\section{E.1 Additional Analysis on the CVC Initiation Stage}

The result that innovation deteriorations motivate CVC initiations raises a number of questions regarding the mechanisms behind it, which challenge the information acquisition interpretation.

One might worry that the result simply documents that desperate managers are more likely to conduct CVC investment to test their luck without carefully evaluating their abilities and potential benefits from investing in CVC. I investigate this issue by studying the success rate of the portfolio companies invested by CVCs categorized by the severity of innovation declines at initiation. If the concern is correct, we would expect CVC parents that experienced the largest hit before initiating to have lower performance as they mostly make the decision under desperation. In Table E.2, I find that those CVCs whose parents' performance decline the most actually score a similar, if not higher success rate compared to other CVCs.

One might also worry that deteriorating firms choose to launch CVC units as a constrained optimal - that is - declining firms are more financially constrained and 
cannot conduct internal R\&D or M\&As, which are on average more costly than CVC. In Table E.3, I show that the main result is robust on the subsample of firms whose KZ-index is below industry median or cash flow ratio above industry median (less financially constrained).

In order to confirm the result is not driven by the sampling process or specifications, I conduct a vast of robustness checks. In Table E.4, I show that the result is not sensitive to the length used to capture innovation changes ( $\tau=3$ in the paper); in Table E.5, I show that the result is robust to removing firms that are large/small, that are from specific industries (such as IT or pharmaceuticals), or that are located in specific locations (in California). In Table E.6 I show that the result holds for deteriorations of product market performance, that is, ROA and growth rate in sales.

\section{E.2 Internal Innovation during CVC}

To set the stage, I first examine how CVC investment influences internal innovation. Under the information acquisition hypothesis, parent firms should be able to harvest the informational benefit, particularly through improvements in information-sensitive activities such as innovation; moreover, newly gathered information should be reflected in those activities.

I assess this idea by characterizing the innovation dynamic of CVC parents around their CVC investment across several dimensions. The first set of measurements is simply innovation quantity and quality as employed in Section 4. The second set of variables is New Cite Ratio and Explorativeness, which measure the proportion of new knowledge used in innovation. New knowledge is identified using patent citations referring to patents that never previously cited by the firm. Specifically, I first define firm $i$ 's existing knowledge in year $t$ as all patents that are owned by $i$ or that were cited by firm $i$ 's patents filed up to $t$; other patents are considered new knowledge to the firm. New Cite Ratio of a patent is calculated as the ratio between citations 
made to new knowledge and the total number of citations made by the patent. Based on this measure, a patent is flagged as Explorative if at least $80 \%$ of its citations are based on new knowledge (New Cite Ratio $\geqslant 80 \%$ ). I transform these patent-level measures to firm-year level by averaging across all patents produced by firm $i$ in year $t .{ }^{1}$ Higher New Cite Ratio and Explorativeness suggest an innovation scheme focusing on exploring new ideas using new knowledge.

To construct a proper control group for CVC parents, I use a propensity score matching method and match each CVC parent firm that launches its CVC unit in year $t$ with two non-CVC firms from the same year $t$ and 2-digit SIC industry that have the closest propensity score estimated using firm size (the logarithm of total assets), market-to-book ratio, $\Delta$ Innovation, and patent stock, ${ }^{2}$ similar to the sample construction strategy in Bena and Li (2014). The CVC launching year for a CVC parent firm is also the "pseudo-CVC" year for its matched firms, and I include firm data beginning five years before the (pseudo-) event year through five years after the event.

I characterize corporate innovation dynamics around CVC investment under a standard difference-in-differences (DiD) framework:

$$
\begin{aligned}
y_{i, t}=\alpha_{F E} & +\beta \cdot I(\text { CVCParent })_{i} \times I(\text { Post })_{i, t} \\
& +\beta^{\prime} \cdot I(C \text { V CParent })_{i}+\beta^{\prime \prime} \cdot I(\text { Post })_{i, t}+\gamma \times X_{i, t}+\varepsilon_{i, t},
\end{aligned}
$$

where dependent variables $y_{i, t}$ are innovation quantity, quality, new cite ratio, and explorativeness. $I(C V C \text { Parent })_{i}$ is a dummy variable indicating whether firm $i$ is a CVC parent or a matched control firm. I(Post $)_{i, t}$ indicates whether the firm-year observation is within the $[t+1, t+5]$ window after (pseudo-) CVC initiations. The

${ }^{1}$ This measure is motivated by theoretical work on motivating innovation (e.g., Manso (2011)), and recently implemented in empirical studies (Almeida, Hsu, and Li, 2013; Custódio, Ferreira, and Matos, 2013; Brav, Jiang, Ma, and Tian, 2016).

${ }^{2}$ Patent stock is constructed as the total number of patents applied for by the firm up to year $t-1$. 
model includes industry-by-year fixed-effects $\alpha_{\text {industry } \times t}$ to absorb industry-specific technological trends. ${ }^{3}$ The coefficient of interest $\beta$ measures the incremental changes in innovation benchmarked by those of the matched firms.

Table E.7 reports the results. Columns (1) to (4) study the dynamics of patent quantity and quality. The $\beta$-coefficients associated with the difference-in-differences term are positive and significant across all columns, meaning that CVC parent firms' innovation performance improves following CVC investment. The coefficients should be interpreted in semi-elasticity terms. Following CVC investment, parent firms' innovation quantity increase is $23.9 \%$ larger than the matched firms (column (1)), and these new innovations collect on average $21.7 \%$ more lifetime citations (column (3)) compared to the level before CVC investment.

Columns (5) and (6) study the ratio of new knowledge used in innovation. After CVC initiations, firms conduct innovation that involves more intense use of knowledge that they have not used before - the estimate of 0.097 in column (5) can be interpreted as a $9.7 \%$ increase in using new information (that is, one out of ten citations). Similarly, in columns $(7)$ and $(8)$, the proportion of explorative patents that are mainly $(\geqslant 80 \%)$ produced based on new knowledge increases by around $4 \%{ }^{4}$

\footnotetext{
3 The result is robust to controlling for firm fixed effects and year fixed effects.

${ }^{4}$ Some might worry that this result merely means that CVC parent firms start to diversify and thus innovate in areas that they had not explored before. In unreported results, I find that the increase in using new information concentrates on technological areas closer to the firm's core expertise, which is inconsistent with the "diversification" story.
} 
Table E.1: Innovation Deterioration and CVC Initiation-The Role of Uncertainty

This table documents the causal relation between innovation deterioration and CVC initiations across firms with heterogeneous informational environment. The analysis is performed using extended specifications based on Table 4.2 and Table 4.3:

$$
\begin{aligned}
I(C V C)_{i, t}=\alpha_{\text {industry } \times t} & +\beta \times \Delta \text { Innovation }_{i, t-1} \\
& +\beta^{\prime} \times \Delta \text { Innovation }_{i, t-1} \times I_{\text {uncertainty }, i t} \\
& +\gamma^{\prime} \times I_{\text {uncertainty } i t}+\gamma \times X_{i, t-1}+\varepsilon_{i, t} .
\end{aligned}
$$

The panel sample is described in Table 4.1. Observations are categorized into two subgroups by the median of uncertainty level of the firm's informational environment, indicated by $I_{\text {uncertainty }}$, which is measured using the average dispersion of patent quality in a technology class weighted by the technological distribution of the firm's portfolio over technology classes. When estimating using 2SLS, I instrument $\Delta$ Innovation $_{i, t-1}$ with Obsolescence, and the interaction term is instrumented by the interaction of Obsolescence with $I_{\text {uncertainty } i t}$.

Columns (1) and (4) report the first-stage regression, which regresses the three-year change in innovation quantity (the natural logarithm of the number of new patents in each firm-year plus one) and innovation quality (the natural logarithm of average citations per new patent in each firm-year plus one) on the three-year knowledge obsolescence as defined in (4.2) in the paper. Columns (2) and (5) report the OLS regression results, where $I(C V C)_{i, t}$ is equal to one if firm $i$ launches a Corporate Venture Capital unit in year $t$, and zero otherwise. Columns (3) and (6) report the second-stage regression. Firm-level controls $X_{i, t-1}$ include the ROA, size (logarithm of total assets), leverage, and $R \& D$ ratio ( $R \& D$ expenditures scaled by total assets). Industry-by-year dummies are included in the specification to absorb industry-specific time trends in CVC activities and innovation. T-statistics are shown in parentheses and standard errors are clustered by firm. *, **, *** denote statistical significance at the $10 \%, 5 \%$, and $1 \%$ levels, respectively. 


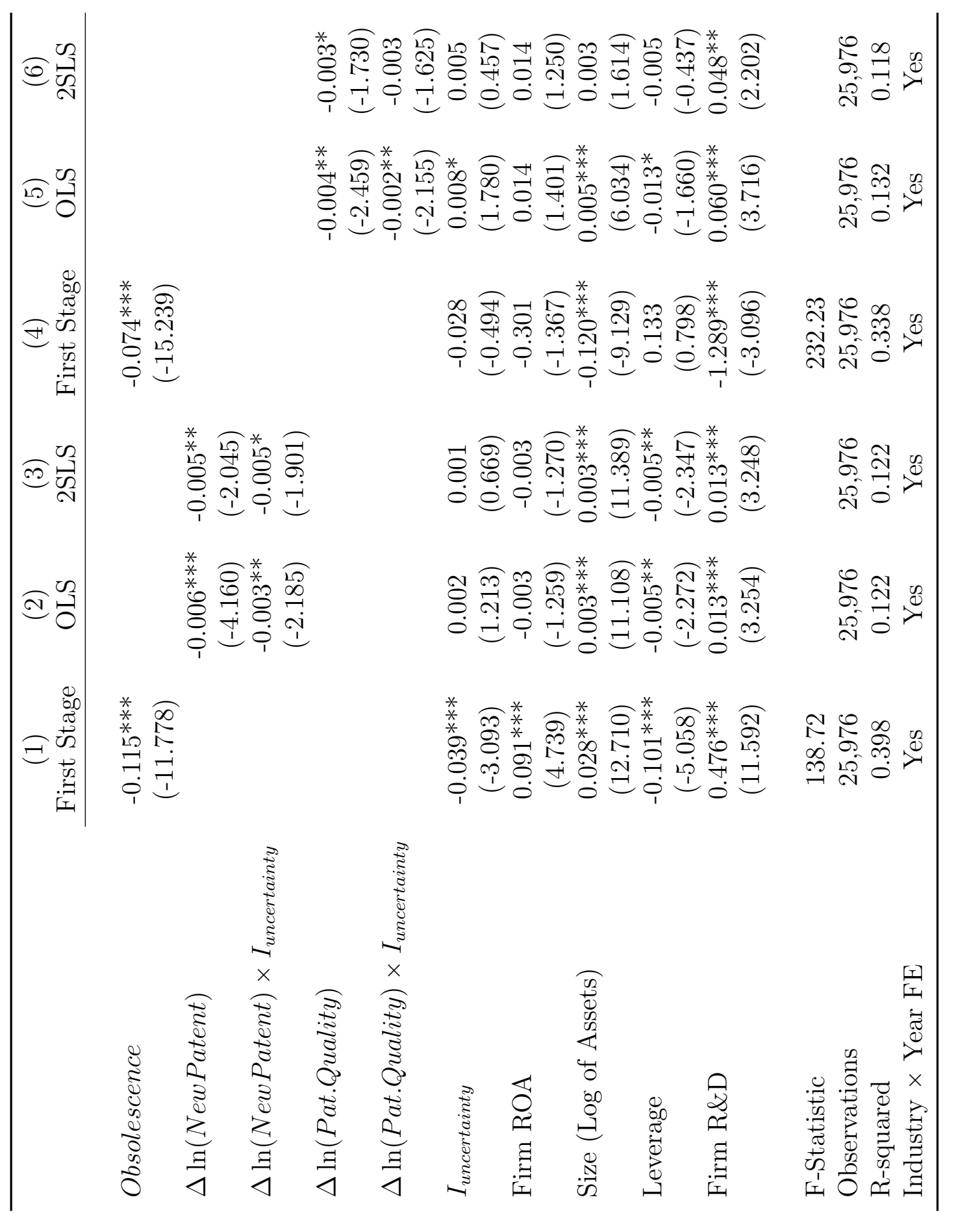


Table E.2: This table investigates the success rate of portfolio companies supported by CVCs, as of Mar 2015. CVCs are categorized into low, medium, and high by the severity of their innovation deterioration at initiation - the low category consists of the CVCs whose parents experience the most severe innovation deterioration before initiating their CVC divisions. CVCs are categorized by $\Delta \ln ($ NewPatent $)$ in Panel A and $\Delta \ln ($ Pat.Quality) in Panel B. The table reports rates of going public, being acquired, and being liquidated of portfolio companies backed by CVCs in each category. The CVC sample is as described in Table I in the paper.

\begin{tabular}{cccc}
\hline \multicolumn{4}{c}{ Panel A: CVCs Categorized by $\Delta \ln ($ NewPatent $)$} \\
\hline \multirow{2}{*}{ IPO } & Low & Medium & High \\
\cline { 2 - 4 } Acquisition & $13.57 \%$ & $15.18 \%$ & $13.53 \%$ \\
Liquidation & $87.54 \%$ & $36.97 \%$ & $35.17 \%$ \\
\hline \multirow{2}{*}{ Panel B: CVCs Categorized by $\Delta \ln ($ Pat.Quality $)$} \\
\hline
\end{tabular}


Table E.3: This table documents the relation between innovation deterioration and the initiation of Corporate Venture Capital on subsamples of financially unconstrained firms. The analysis is performed using the following specification: $I(C V C)_{i, t}=$ $\alpha_{\text {industry } \times t}+\beta \times \Delta$ Innovation $_{i, t-1}+\gamma \times X_{i, t-1}+\varepsilon_{i, t}$, The original panel sample is described in Table III in the paper. In columns (1) and (2), the sample is restricted to firms of which the KZ-index is below industry medians (less financially constrained); in columns (3) and (4), the sample is restricted to firms of which the cash flow over asset ratio is above industry median. $I(C V C)_{i, t}$ is equal to one if firm $i$ launches a Corporate Venture Capital unit in year $t$, and zero otherwise. $\Delta$ Innovation $_{i, t-1}$ is the innovation change over the past three years (i.e., the innovation change from $t-4$ to $t-1$ ). Innovation is measured using innovation quantity (the natural logarithm of the number of new patents in each firm-year plus one), shown in columns (1) and (3) and innovation quality (the natural logarithm of average citations per new patent in each firm-year plus one), shown in columns (2) and (4). The model is estimated using Two-stage Least Squares, and $\Delta$ Innovation is instrumented using knowledge Obsolescence. Firm-level controls $X_{i, t-1}$ include ROA, size (logarithm of total assets), leverage, and $R \& D$ ratio (R\&D expenditures scaled by total assets). Industry-by-year dummies are included in the model to absorb industry-specific time trends in CVC activities and innovation. T-statistics are shown in parentheses and standard errors are clustered by firm. * **, *** denote statistical significance at the $10 \%, 5 \%$, and $1 \%$ levels, respectively.

\begin{tabular}{lcccc}
\hline & $(1)$ & $(2)$ & $(3)$ & $(4)$ \\
& Low KZ Index & High Cash Flow Ratio \\
\cline { 2 - 5 }$\Delta \ln ($ NewPatent $)$ & $-0.006^{* * *}$ & & $-0.005^{* * *}$ & \\
& $(-3.119)$ & & $(-2.903)$ & \\
$\Delta \ln ($ Pat.Quality $)$ & & $-0.002^{*}$ & & $-0.003^{* *}$ \\
& & $(-1.692)$ & & $(-2.394)$ \\
Firm ROA & $-0.004^{* *}$ & 0.001 & -0.001 & 0.005 \\
Size (Log of Assets) & $0.003^{* * *}$ & $0.003^{* * *}$ & $0.002^{* * *}$ & $0.003^{* * *}$ \\
& $(7.426)$ & $(7.980)$ & $(7.583)$ & $(5.541)$ \\
Leverage & $-0.003^{* *}$ & $-0.014^{* * *}$ & -0.000 & $-0.006^{* *}$ \\
& $(-2.226)$ & $(-2.946)$ & $(-0.011)$ & $(-2.220)$ \\
Firm R\&D & 0.002 & $0.010^{* * *}$ & 0.001 & $0.018^{* * *}$ \\
& $(0.804)$ & $(3.764)$ & $(0.439)$ & $(4.471)$ \\
Observations & & & & \\
Pseudo R-squared & 17,043 & 17,043 & 14,982 & 14,982 \\
Industry $\times$ Year FE & 0.323 & 0.381 & 0.404 & 0.351 \\
\hline
\end{tabular}


Table E.4: This table documents the relation between innovation deterioration and the initiation of Corporate Venture Capital. The analysis is performed using the following specification: $I(C V C)_{i, t}=\alpha_{\text {industry } \times t}+\beta \times \Delta$ Innovation $_{i, t-1}+\gamma \times X_{i, t-1}+\varepsilon_{i, t}$, The panel sample is described in Table III in the paper. $I(C V C)_{i, t}$ is equal to one if firm $i$ launches a Corporate Venture Capital unit in year $t$, and zero otherwise. $\Delta$ Innovation $_{i, t-1}$ is the innovation change over the past four years (that is, the innovation change from $t-5$ to $t-1$ ) in columns (1) and (2), and over the past two years (that is, the innovation change from $t-3$ to $t-1$ ) in columns (3) and (4). Innovation is measured using innovation quantity (the natural logarithm of the number of new patents in each firm-year plus one), shown in columns (1) and (3) and innovation quality (the natural logarithm of average citations per new patent in each firm-year plus one), shown in columns (2) and (4). The model is estimated using Twostage Least Squares, and $\Delta$ Innovation is instrumented using knowledge Obsolescence during the same period as in $\Delta$ Innovation. Firm-level controls $X_{i, t-1}$ include ROA, size (logarithm of total assets), leverage, and $R \& D$ ratio ( $R \& D$ expenditures scaled by total assets). Industry-by-year dummies are included in the model to absorb industry-specific time trends in CVC activities and innovation. T-statistics are shown in parentheses and standard errors are clustered by firm. ${ }^{*}, * *, * * *$ denote statistical significance at the $10 \%, 5 \%$, and $1 \%$ levels, respectively.

\begin{tabular}{lcccc}
\hline & $(1)$ & $(2)$ & $(3)$ & $(4)$ \\
& $4-Y e a r \Delta$ Innovation & 2-Year $\Delta$ Innovation \\
\cline { 2 - 5 }$\Delta \ln ($ NewPatent $)$ & $-0.006^{* * *}$ & & $-0.005^{*}$ & \\
& $(-3.058)$ & & $(-1.727)$ & \\
$\Delta \ln ($ Pat.Quality $)$ & & $-0.003^{*}$ & & $-0.004^{* * *}$ \\
& & $(-1.827)$ & & $(-4.532)$ \\
Firm ROA & -0.003 & -0.002 & -0.003 & $-0.003^{*}$ \\
& $(-1.315)$ & $(-1.485)$ & $(-1.500)$ & $(-1.747)$ \\
Size (Log of Assets) & $0.003^{* * *}$ & $0.003^{* * *}$ & $0.003^{* * *}$ & $0.003^{* * *}$ \\
& $(11.486)$ & $(11.442)$ & $(11.300)$ & $(11.042)$ \\
Leverage & $-0.005^{* *}$ & $-0.003^{* *}$ & $-0.005^{* *}$ & $-0.004^{* *}$ \\
& $(-2.449)$ & $(-2.089)$ & $(-2.307)$ & $(-2.251)$ \\
Firm R\&D & $0.014^{* * *}$ & $0.011^{* * *}$ & $0.014^{* * *}$ & $0.012^{* * *}$ \\
& $(3.521)$ & $(3.258)$ & $(3.128)$ & $(3.123)$ \\
Observations & 25,976 & 25,976 & 25,976 & 25,976 \\
Pseudo R-squared & 0.124 & 0.121 & 0.120 & 0.117 \\
Industry $\times$ Year FE & Yes & Yes & Yes & Yes \\
\hline
\end{tabular}




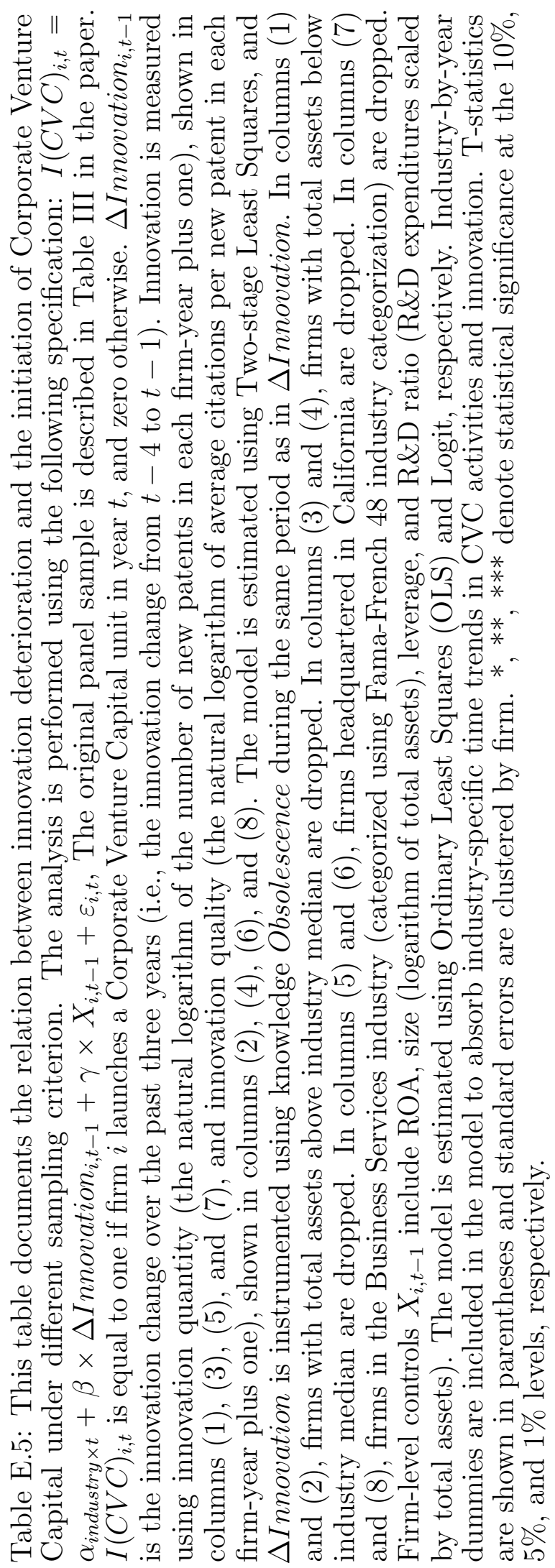




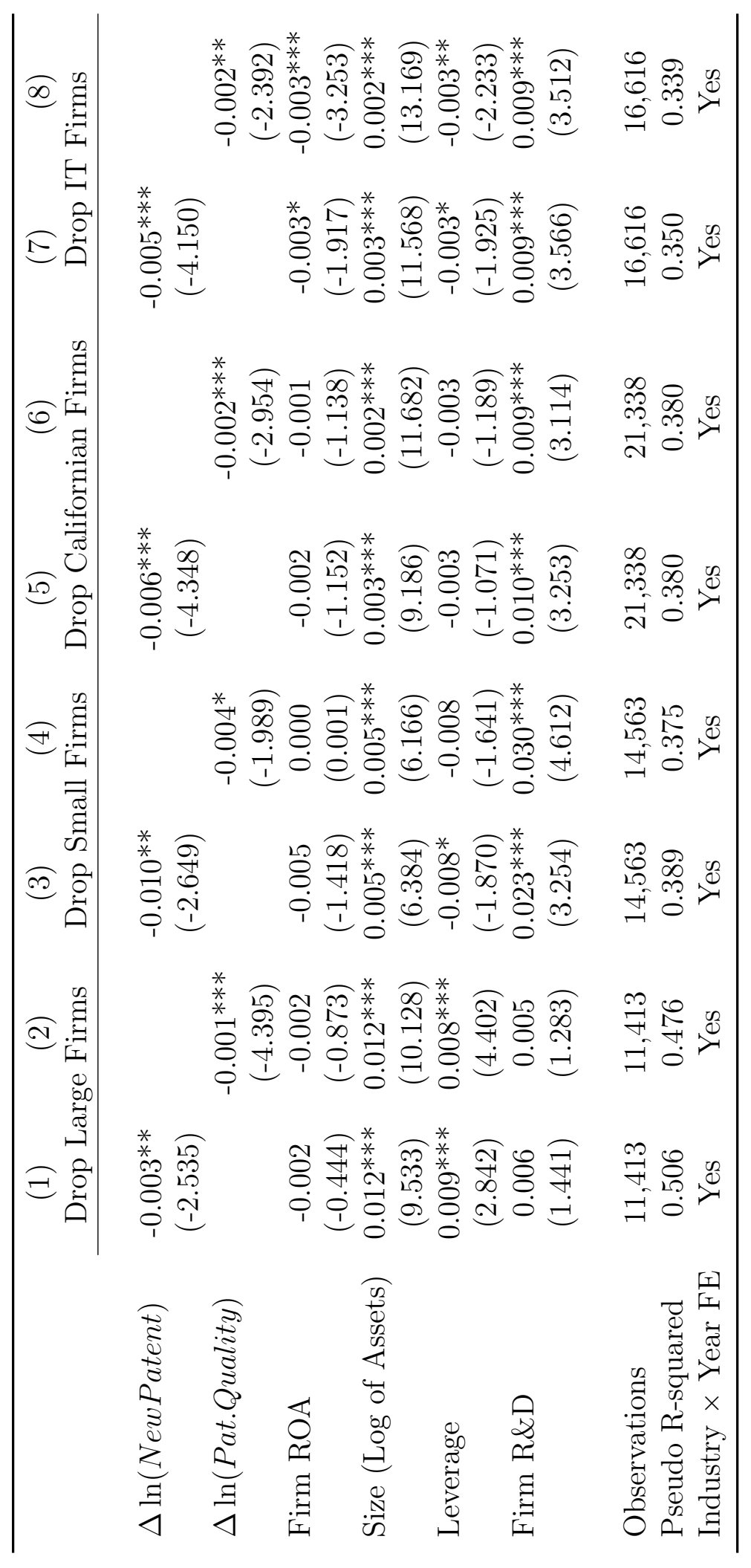


Table E.6: This table documents the relation between product market performance changes and the initiation of Corporate Venture Capital. The analysis is performed using the following specification: $I(C V C)_{i, t}=\alpha_{\text {industry } \times t}+\beta \times \Delta$ Performance $_{i, t-1}+$ $\gamma \times X_{i, t-1}+\varepsilon_{i, t}$, The panel sample is described in Table III in the paper. $I(C V C)_{i, t}$ is equal to one if firm $i$ launches a Corporate Venture Capital unit in year $t$, and zero otherwise. $\Delta$ Performance fort $_{i}$ is the product market performance change over the past three years (i.e., the performance change from $t-4$ to $t-1$ ). Product market performance is measured using Return-on-Assets (ROA), shown in column (1) and sales growth, shown in column (2). Firm-level controls $X_{i, t-1}$ include ROA, size (logarithm of total assets), leverage, and $R \& D$ ratio ( $R \& D$ expenditures scaled by total assets). The model is estimated using Ordinary Least Squares (OLS). Industryby-year dummies are included in the model to absorb industry-specific time trends in CVC activities and innovation. T-statistics are shown in parentheses and standard errors are clustered by firm. * **, *** denote statistical significance at the $10 \%, 5 \%$, and $1 \%$ levels, respectively.

\begin{tabular}{lcc}
\hline & $(1)$ & $(2)$ \\
& OLS & OLS \\
\cline { 2 - 3 }$\Delta$ ROA & $-0.006^{* *}$ & \\
& $(-2.160)$ & \\
$\Delta$ SalesGrowth & & $-0.002^{* * *}$ \\
Firm ROA & & $(-2.706)$ \\
& $-0.005^{* *}$ & -0.001 \\
Size (Log of Assets) & $0.003^{* * *}$ & $(-0.624)$ \\
& $(10.683)$ & $(10.333)$ \\
Leverage & $-0.004^{* *}$ & $-0.006^{* * *}$ \\
& $(-1.989)$ & $(-2.581)$ \\
Firm R\&D & $0.015^{* * *}$ & $0.022^{* * *}$ \\
& $(3.446)$ & $(4.413)$ \\
& & \\
Observations & 25,976 & 25,976 \\
R-squared & 0.101 & 0.107 \\
Industry $\times$ Year FE & Yes & Yes \\
\hline
\end{tabular}




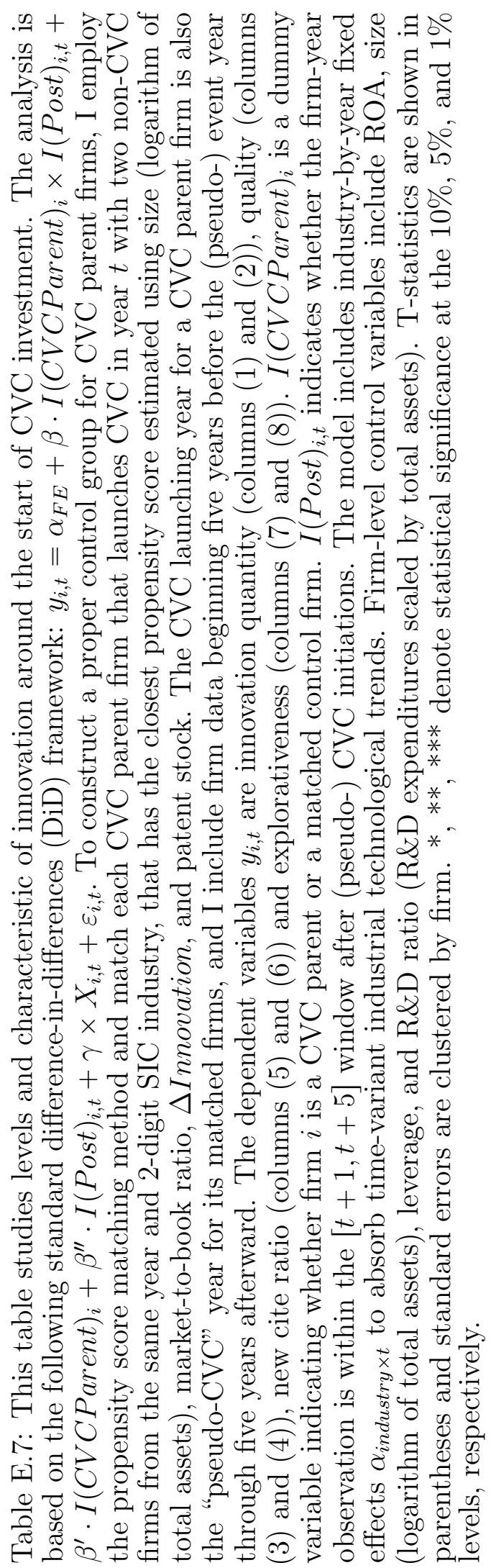




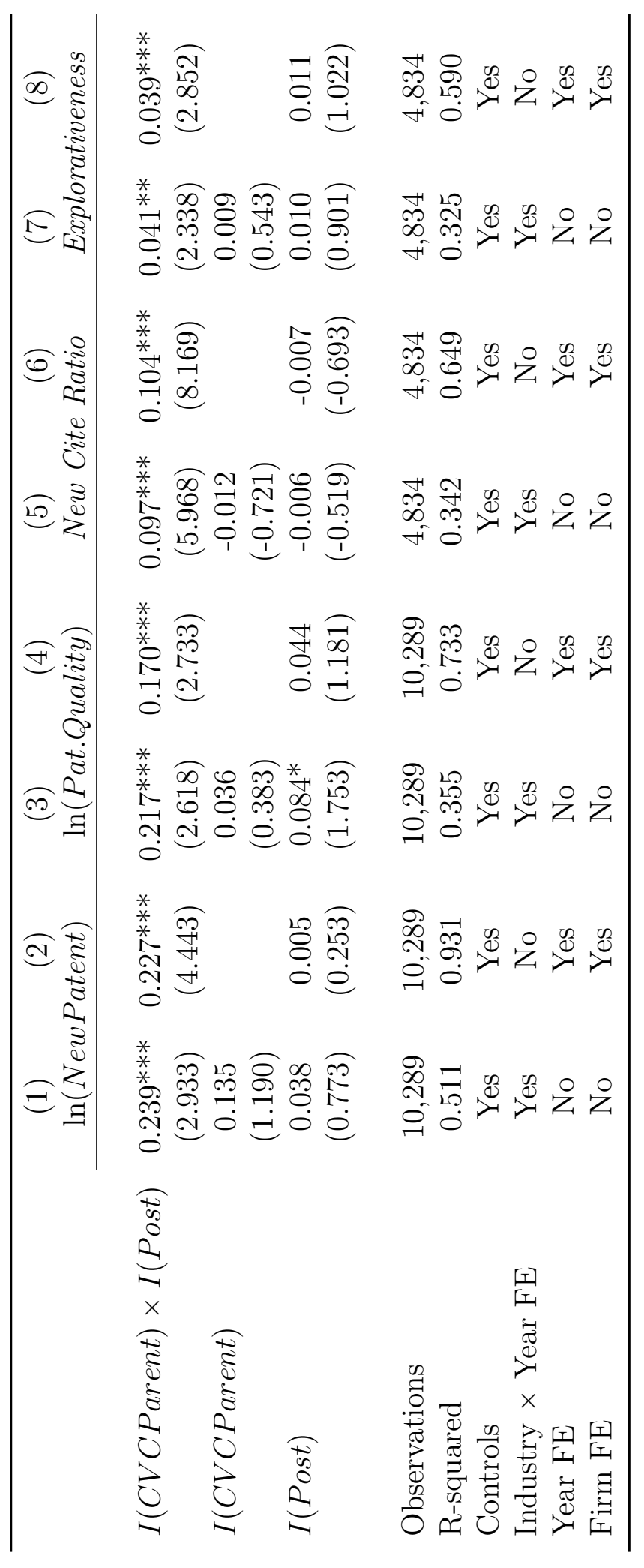




\section{Bibliography}

Acemoglu, Daron, Ufuk Akcigit, Nicholas Bloom, and William R. Kerr, 2013, Innovation, reallocation and growth .

Acemoglu, Daron, and Dan Cao, 2015, Innovation by entrants and incumbents, Journal of Economic Theory 157, 255-294.

Acs, Zoltan J., and David B. Audretsch, 1988, Innovation in large and small firms: an empirical analysis, American Economic Review 678-690.

Adelino, Manuel, Song Ma, and David T. Robinson, 2016, Firm age, investment opportunities, and job creation, Journal of Finance Forthcoming.

Aghion, Philippe, Ufuk Akcigit, and Peter Howitt, 2014, What do we learn from schumpeterian growth theory?, in Handbook of Economic Growth, volume 2, 515563 (Elsevier).

Aghion, Philippe, and Jean Tirole, 1994, The management of innovation, Quarterly Journal of Economics 109, 1185-1209.

Akcigit, Ufuk, Murat Alp Celik, and Jeremy Greenwood, 2013, Buy, keep or sell: Economic growth and the market for ideas .

Alcacer, Juan, and Michelle Gittelman, 2006, Patent citations as a measure of knowledge flows: The influence of examiner citations, Review of Economics and Statistics 88, 774-779.

Allen, Jeffrey W, and Gordon M Phillips, 2000, Corporate equity ownership, strategic alliances, and product market relationships, Journal of Finance 55, 2791-2815.

Almeida, Heitor, Po-Hsuan Hsu, and Dongmei Li, 2013, Less is more: Financial constraints and innovative efficiency .

Arrow, Kenneth, 1962, Economic welfare and the allocation of resources for invention, in The rate and direction of inventive activity: Economic and social factors, 609-626 (Princeton University Press: Princeton, NJ). 
Autor, David H, David Dorn, and Gordon H. Hanson, 2013, The china syndrome: Local labor market effects of import competition in the united states, American Economic Review 103, 2121-2168.

Basu, Sandip, Corey Phelps, and Suresh Kotha, 2011, Towards understanding who makes corporate venture capital investments and why, Journal of Business Venturing 26, 153-171.

Bena, Jan, and Kai Li, 2014, Corporate innovations and mergers and acquisitions, Journal of Finance 69, 1923-1960.

Bennedsen, Morten, Francisco Pérez-González, and Daniel Wolfenzon, 2010, The governance of family firms, Corporate governance: A synthesis of theory, research, and practice $371-390$.

Benson, David, and Rosemarie H. Ziedonis, 2010, Corporate venture capital and the returns to acquiring portfolio companies, Journal of Financial Economics 98, 478-499.

Bernstein, Shai, 2015, Does going public affect innovation?, Journal of Finance 70, 1365-1403.

Bernstein, Shai, Xavier Giroud, and Richard R. Townsend, 2014, The impact of venture capital monitoring: Evidence from a natural experiment, Rock Center for Corporate Governance at Stanford University Working Paper .

Bloom, Nicholas, 2009, The impact of uncertainty shocks, Econometrica 77, 623-685.

Bloom, Nicholas, Max Floetotto, Nir Jaimovich, Itay Saporta-Eksten, and Stephen J Terry, 2012, Really uncertain business cycles, Technical report, National Bureau of Economic Research, Inc.

Bloom, Nicholas, Mark Schankerman, and John Van Reenen, 2013, Identifying technology spillovers and product market rivalry, Econometrica 81, 1347-1393.

Bond, Philip, Alex Edmans, and Itay Goldstein, 2012, The real effects of financial markets, Annual Review of Financial Economics 4, 339-60.

Bottazzi, Laura, Marco Da Rin, and Thomas Hellmann, 2004, The changing face of the european venture capital industry: Facts and analysis, Journal of Private Equity 7, 26-53.

Brav, Alon, Wei Jiang, Song Ma, and Xuan Tian, 2016, How does hedge fund activism reshape corporate innovation, Available at SSRN 2409404.

Brown, James R, Steven M Fazzari, and Bruce C Petersen, 2009, Financing innovation and growth: Cash flow, external equity, and the 1990s r\&d boom, Journal of Finance $64,151-185$. 
Ceccagnoli, Marco, Matthew J Higgins, and Hyunsung D Kang, 2015, Corporate venture capital as a real option in the markets for technology .

Chemmanur, Thomas J., and Paolo Fulghieri, 2014, Entrepreneurial finance and innovation: An introduction and agenda for future research, Review of Financial Studies 27, 1-19.

Chemmanur, Thomas J, Elena Loutskina, and Xuan Tian, 2014, Corporate venture capital, value creation, and innovation, Review of Financial Studies 27, 2434-2473.

Chen, Qi, Itay Goldstein, and Wei Jiang, 2007, Price informativeness and investment sensitivity to stock price, Review of Financial Studies 20, 619-650.

Chesbrough, Henry W, 2002, Making sense of corporate venture capital, Harvard Business Review 80, 90-99.

Cohen, Wesley M., and Daniel A. Levinthal, 1990, Absorptive capacity: a new perspective on learning and innovation, Administrative science quarterly 128-152.

Custódio, Cláudia, Miguel A Ferreira, and Pedro Matos, 2013, Do general managerial skills spur innovation? .

Da Rin, Marco, Thomas F Hellmann, and Manju Puri, 2011, A survey of venture capital research .

Dimitrova, Lora, 2013, Strategic acquisitions by corporate venture capital investors .

Dosi, Giovanni, 1988, Sources, procedures, and microeconomic effects of innovation, Journal of Economic Literature 1120-1171.

Dow, James, and Gary Gorton, 1997, Stock market efficiency and economic efficiency: Is there a connection?, Journal of Finance 52, 1087-1129.

Dushnitsky, Gary, 2006, Corporate venture capital: past evidence and future directions (Oxford University Press: Oxford, UK).

Dushnitsky, Gary, and Michael J. Lenox, 2005a, When do firms undertake r\&d by investing in new ventures?, Strategic Management Journal 26, 947-965.

Dushnitsky, Gary, and Michael J. Lenox, 2005b, When do incumbents learn from entrepreneurial ventures?: Corporate venture capital and investing firm innovation rates, Research Policy 34, 615-639.

Dushnitsky, Gary, and Michael J. Lenox, 2006, When does corporate venture capital investment create firm value?, Journal of Business Venturing 21, 753-772. 
Fee, C Edward, Charles J. Hadlock, and Shawn Thomas, 2006, Corporate equity ownership and the governance of product market relationships, Journal of Finance 61, 1217-1251.

Fleming, Lee, and Olav Sorenson, 2004, Science as a map in technological search, Strategic Management Journal 25, 909-928.

Frydman, Carola, and Dimitris Papanikolaou, 2015, In search of ideas: Technological innovation and executive pay inequality .

Fulghieri, Paolo, and Merih Sevilir, 2009, Organization and financing of innovation, and the choice between corporate and independent venture capital, Journal of Financial and Quantitative Analysis 44, 1291.

Gomes-Casseres, Benjamin, John Hagedoorn, and Adam B. Jaffe, 2006, Do alliances promote knowledge flows?, Journal of Financial Economics 80, 5-33.

Gompers, Paul, and Josh Lerner, 2000, The determinants of corporate venture capital success: Organizational structure, incentives, and complementarities, 17-54 (University of Chicago Press).

Gompers, Paul A., 2002, Corporations and the financing of innovation: the corporate venturing experience, Economic Review-Federal Reserve Bank of Atlanta 87, 1-18.

Gonzalez-Uribe, Juanita, 2013, Venture Capital and Innovation, Ph.D. thesis, Columbia University.

Hackbarth, Dirk, Richmond Mathews, and David Robinson, 2014, Capital structure, product market dynamics, and the boundaries of the firm, Management Science 60, 2971-2993.

Hall, Bronwyn H, 1993, The stock market's valuation of r\&d investment during the 1980's, American Economic Review 259-264.

Hall, Bronwyn H., Zvi Griliches, and Jerry A. Hausman, 1986, Patents and r\&d: Is there a lag?, International Economic Review 265-283.

Hall, Bronwyn H., Adam B. Jaffe, and Manuel Trajtenberg, 2001, The nber patent citation data file: Lessons, insights and methodological tools .

Hall, Bronwyn H, and Josh Lerner, 2010, The financing of r\&d and innovation, Handbook of the Economics of Innovation 1, 609-639.

Harford, Jarrad, 2005, What drives merger waves?, Journal of Financial Economics $77,529-560$.

Hellmann, Thomas, 1998, Some thoughts on the theory of corporate venture investing, Corporate Governance Today, Columbia Law School 37-43. 
Hellmann, Thomas, 2002, A theory of strategic venture investing, Journal of Financial Economics 64, 285-314.

Hellmann, Thomas, Laura Lindsey, and Manju Puri, 2008, Building relationships early: Banks in venture capital, Review of Financial Studies 21, 513-541.

Henderson, James, and Benoit Leleux, 2002, Corporate venture capital: effecting resource combinations and transfers, Babson Entrepreneurial Review 2, 31-46.

Henderson, Rebecca, 1993, Underinvestment and incompetence as responses to radical innovation: Evidence from the photolithographic alignment equipment industry, RAND Journal of Economics 248-270.

Higgins, Matthew J, and Daniel Rodriguez, 2006, The outsourcing of r\&d through acquisitions in the pharmaceutical industry, Journal of Financial Economics 80, $351-383$.

Igami, Mitsuru, 2014, Estimating the innovator's dilemma: Structural analysis of creative destruction in the hard disk drive industry, Available at SSRN 1733174.

Ivanov, Vladimir I, and Fei Xie, 2010, Corporate venture capital, Venture CapitalInvestment Strategies, Structures and Policies, New Jersey, NJ .

Jaffe, Adam B., 1986, Technological opportunity and spillovers of r \& d: Evidence from firms' patents, profits, and market value, American Economic Review 984-1001.

Jaffe, Adam B., and Manuel Trajtenberg, 2002, Patents, citations, and innovations: A window on the knowledge economy (MIT Press: Cambridge, MA).

Jaffe, Adam B., Manuel Trajtenberg, and Rebecca Henderson, 1993, Geographic localization of knowledge spillovers as evidenced by patent citations, Quarterly Journal of Economics 577-598.

Jensen, Michael C., 1993, The modern industrial revolution, exit, and the failure of internal control systems, Journal of Finance 48, 831-880.

Jones, Benjamin F, 2009, The burden of knowledge and the death of the renaissance man: is innovation getting harder?, Review of Economic Studies 76, 283-317.

Jovanovic, Boyan, and Rafael Rob, 1989, The growth and diffusion of knowledge, Review of Economic Studies 56, 569-582.

Jurado, Kyle, Sydney C Ludvigson, and Serena Ng, 2013, Measuring uncertainty, New York University, mimeo .

Kim, Keongtae, Anandasivam Gopal, and Gerard Hoberg, 2013, Product market competition and corporate venture capital investment in the it industry: An empirical analysis, Available at SSRN 2259967. 
Klette, Tor Jakob, and Samuel Kortum, 2002, Innovating firms and aggregate innovation .

Kortum, Samuel, and Josh Lerner, 2000, Assessing the contribution of venture capital to innovation, RAND Journal of Economics 674-692.

Kortum, Samuel S, 1997, Research, patenting, and technological change, Econometrica 1389-1419.

Lacetera, Nicola, Iain M Cockburn, and Rebecca Henderson, 2004, Do firms change capabilities by hiring new people? a study of the adoption of science-based drug discovery, Advances in strategic management 21, 133-160.

Lach, Saul, and Mark Schankerman, 1989, Dynamics of $\mathrm{r} \& \mathrm{~d}$ and investment in the scientific sector, Journal of Political Economy 880-904.

Lai, Ronald, Alexander D'Amour, and Lee Fleming, 2009, The careers and coauthorship networks of us patent-holders since 1975 .

Lerner, Josh, 2012, The architecture of innovation: The economics of creative organizations (Harvard Business Press).

Machlup, Fritz, 1962, The production and distribution of knowledge in the United States, volume 278 (Princeton university press).

Macmillan, Ian, E Roberts, V Livada, and A Wang, 2008, Corporate venture capital (cvc) seeking innovation and strategic growth. recent patterns in cvc mission, structure, and investment, NIST GCR 08-96.

Manso, Gustavo, 2011, Motivating innovation, Journal of Finance 66, 1823-1860.

Mathews, Richmond D., 2006, Strategic alliances, equity stakes, and entry deterrence, Journal of Financial Economics 80, 35-79.

Matray, Adrien, 2014, Essays in Empirical Corporate Finance, Ph.D. thesis, Jouy-en Josas, HEC.

Maula, Markku VJ, 2007, 15 corporate venture capital as a strategic tool for corporations, Handbook of research on venture capital 371.

Maula, Markku VJ, et al., 2001, Corporate venture capital and the value-added for technology-based new firms (Helsinki University of Technology).

Mitchell, Mark L., and Harold J. Mulherin, 1996, The impact of industry shocks on takeover and restructuring activity, Journal of Financial Economics 41, 193-229.

Nelson, Richard R, 1982, The role of knowledge in r\&d efficiency, Quarterly Journal of Economics 453-470. 
Nelson, Richard R, and Sidney G Winter, 1982, An evolutionary theory of economic change (Harvard University Press: Cambridge, MA).

Peri, Giovanni, 2005, Determinants of knowledge flows and their effect on innovation, Review of Economics and Statistics 87, 308-322.

Rhodes-Kropf, Matthew, David T. Robinson, and S. Viswanathan, 2005, Valuation waves and merger activity: The empirical evidence, Journal of Financial Economics 77, 561-603.

Robinson, David T., 2008, Strategic alliances and the boundaries of the firm, Review of Financial Studies 21, 649-681.

Rosen, Sherwin, 1975, Measuring the obsolescence of knowledge, in Education, income, and human behavior, 199-232 (NBER).

Scherer, Frederic M., 1965, Firm size, market structure, opportunity, and the output of patented inventions, American Economic Review 1097-1125.

Schumpeter, Joseph Alois, 1942, Socialism, capitalism and democracy (Harper and Brothers).

Serrano, Carlos J., 2010, The dynamics of the transfer and renewal of patents, RAND Journal of Economics 41, 686-708.

Seru, Amit, 2014, Firm boundaries matter: Evidence from conglomerates and r\&d activity, Journal of Financial Economics 111, 381-405.

Siegel, Robin, Eric Siegel, and Ian C. MacMillan, 1988, Corporate venture capitalists: Autonomy, obstacles, and performance, Journal of Business Venturing 3, 233-247.

Stock, James H, and Motohiro Yogo, 2005, Testing for weak instruments in linear iv regression, Identification and Inference for Econometric Models: Essays in Honor of Thomas Rothenberg 80.

Sunder, Jayanthi, Shyam V. Sunder, and Jingjing Zhang, 2014, Ceo sensation seeking and corporate innovation, Available at SSRN 2474909.

Tirole, Jean, 2010, The theory of corporate finance (Princeton University Press: Princeton, NJ).

Van Nieuwerburgh, Stijn, and Laura Veldkamp, 2010, Information acquisition and under-diversification, Review of Economic Studies 77, 779-805.

Wadhwa, Anu, Corey Phelps, and Suresh Kotha, 2015, Corporate venture capital portfolios and firm innovation, Journal of Business Venturing, Forthcoming . 
Yang, Ming, 2013, Optimality of debt under flexible information acquisition, Available at SSRN 2103971.

Zingales, Luigi, 2000, In search of new foundations, Journal of Finance 55, 1623-1653. 


\section{Biography}

Song $\mathrm{Ma}$ is a $\mathrm{PhD}$ candidate in Business Administration (Finance) from Duke University's Fuqua School of Business, in Durham, North Carolina. His research interests lie in empirical corporate finance and entrepreneurial finance.

He was born in Shandong, China, on May 13, 1987. Before attending Duke, he obtained his Bachelor of Art in Economics from Zhejiang University, China, in June 2010. He was awarded the National Scholarship during his undergraduate studies and graduated with highest honors from Chu Kochen Honors College.

During his doctoral studies, he received Duke Graduate School Fellowship from 2011 to 2016. He was awarded the 2016 AQR Top Finance Graduate Award, the 2015 PhD Outstanding Paper Award in Honor of Stuart I. Greenbaum, and several best paper awards from academic conferences. His research has been presented at numerous university workshops and academic conferences, including National Bureau of Economic Research (NBER) meetings, American Finance Association (AFA) meetings, Econometric Society meetings, and the Financial Intermediation Research Society (FIRS) Conference.

Song Ma is joining Yale School of Management in New Haven, Connecticut, as an Assistant Professor of Finance in July 2016. 